
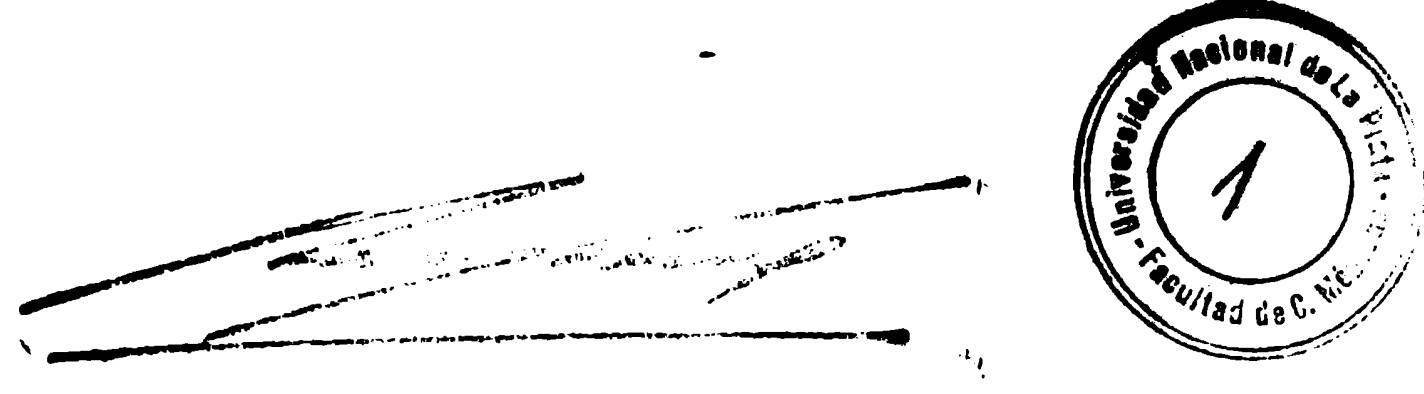

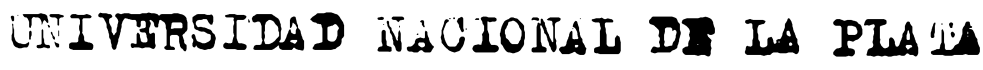

FACULTAD DF CIFNCIAS HDICAS

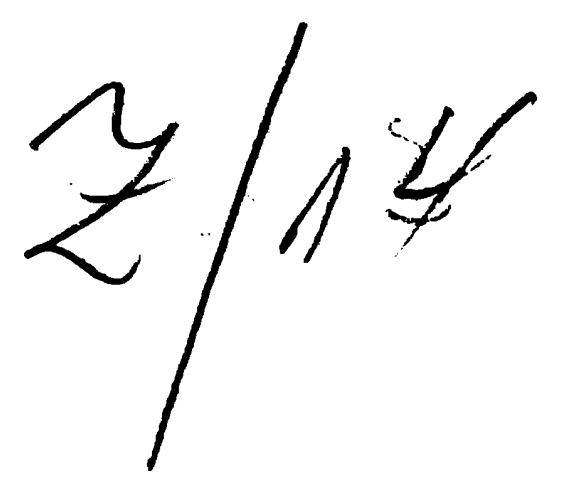

IUCHA LEDICO SOCIAI

OCHTRA IAS CARDIOPA IIAS REULALIUAS

To sis de

àoctorado

$d_{\theta}$

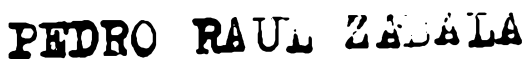




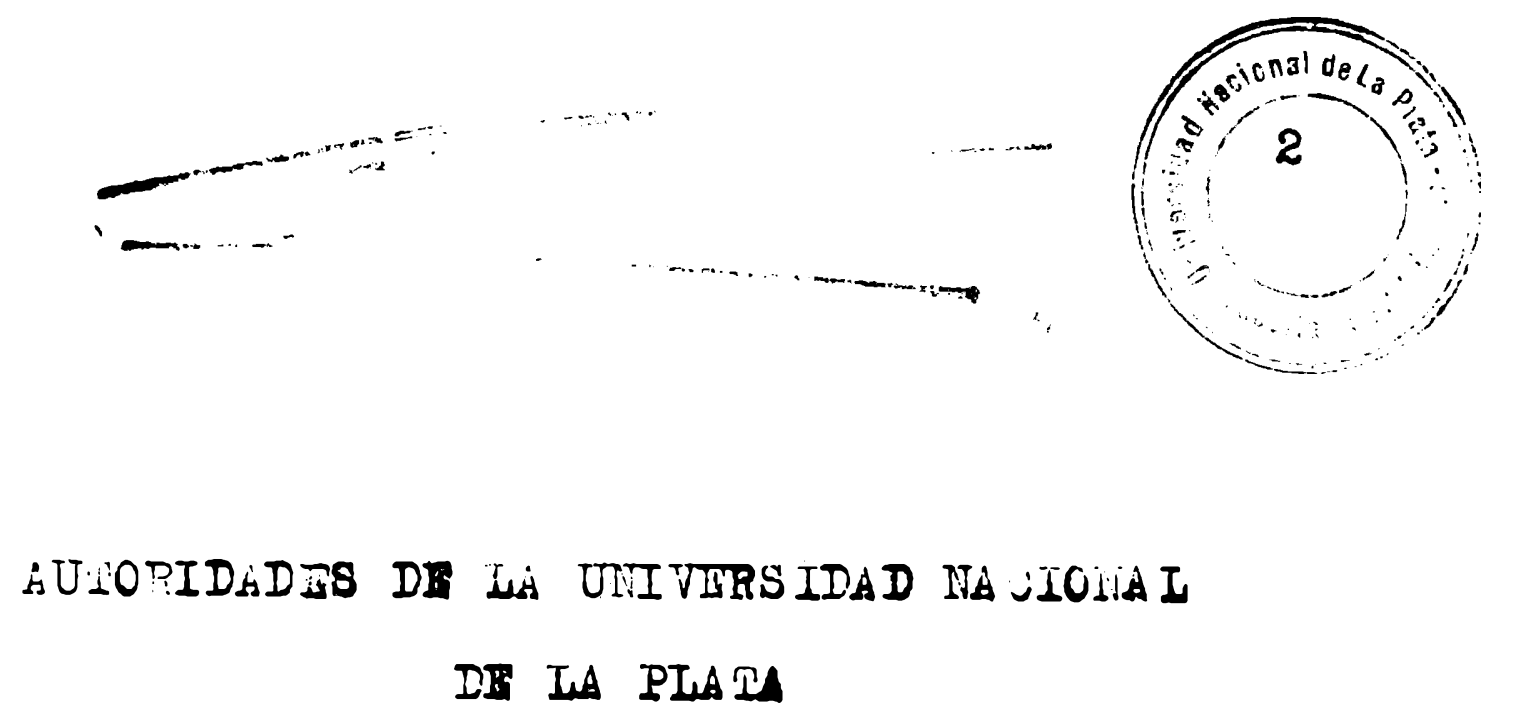

Interventor

Dr. Carlos I. Rivas

Secreterio dè la Intervención

7f. Victor M. Arroyo

Prosecretaxio Gonoral de Ie Univorsidad

sr. Inrique I. Ro gsi

Guarde Sellos

Dr. Faus tino J. Legón 

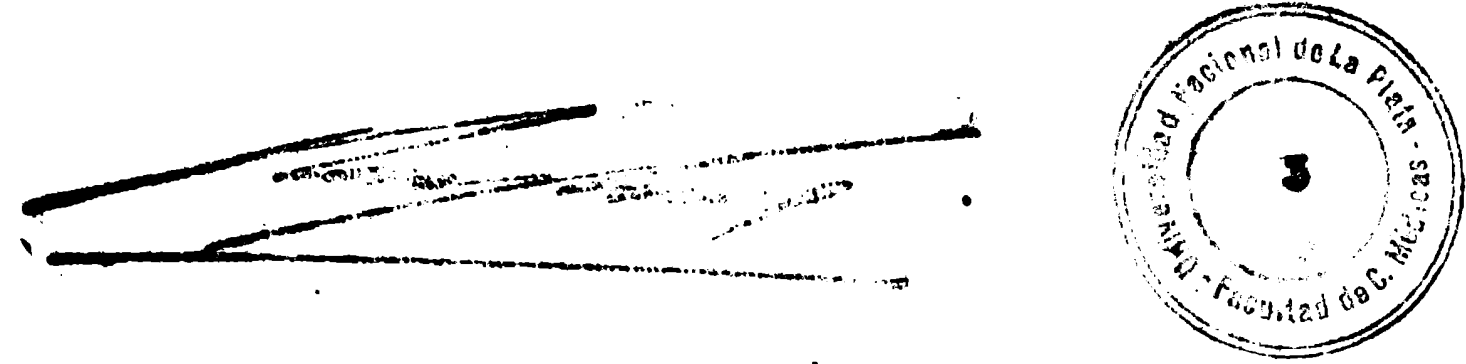

TRIVHAST DAD HACTOKAI DI IA PIATM

MATSTAD DT CDHCIAS MEDICAS

GUTORIDADYS DE LA HAUUTIAD

DE UIR_CIAS WETHCIS

Delogado Interventor

Dx. Vicente H. Cicarđo

Secretario

Dr. Hector J. Basso

Prosecretario

SI. Refael G. Rose 

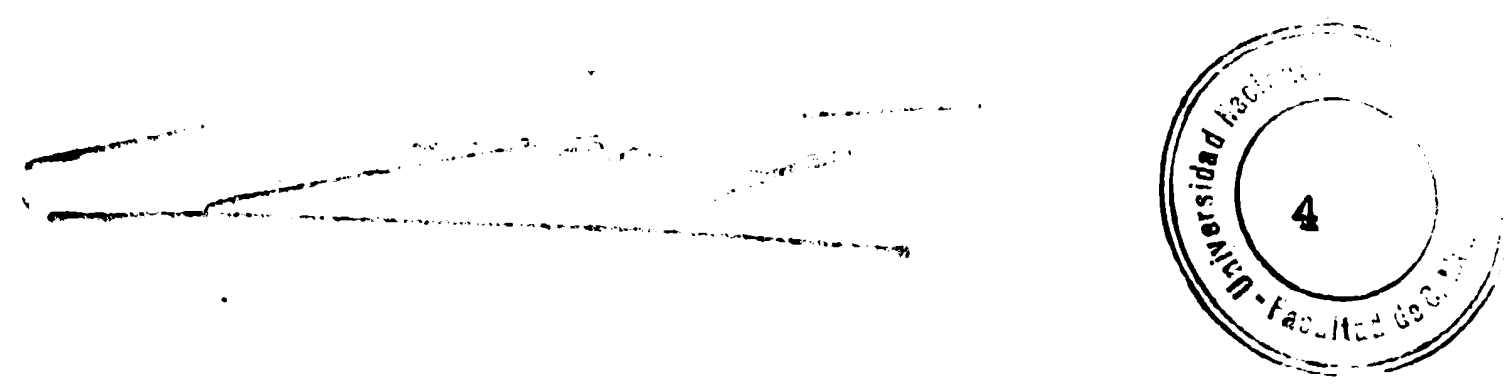

UNIVBRS DDAD NACIONAI DI IA PIA TA

FACULTAD DI CIEICIAS WEDICAS

E*ofesores Eonorarios

Ir. A:egnino Arturo

"Ropirilla Varlos

" Greco Nicolás V.

"Soto liario I.

Propesores ritulares

Dr. Argüello Diego in. - Clínica Oftalkiológica

" Beldassarre Mrique C. - F. F. J. Terepéutice

" Bianchi anarés T. - A. y F. Patolóricas

" Caciro José A. - Patoloria quirúxeica

" Eanestri Inocencio ${ }^{*}$. - Luedicina operatoria

"Carratalá Rogelio - Toxicologio

" Carreño Carlos V. - Higiene héeica y Proventiva

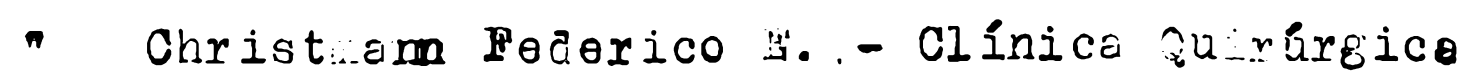

" Cicarae Vicente Ii. - FIsica Eiológica

" D'Oriaio Francisco R. - P. J Cl. de lo Tuborculosis

- Irrecart Podro I. - Ul, Otorrinolaringológlco

" Floriani corlos - Parasi tologla

- Gascón 1 lborto - Fisiologia

- Gandolfo Herrora Boborto - Clínica Ginocolófica

- Girári Volentín C. - Ortopodio y Irauliatologlo

" Gonzblez Herpán D. - O1, de Inf. Infocoiosos J P.T.

" Irigojen Iuis - mb.. Hiatolog1a Normal

- Lambra fonulo R. - Anatomí Deacriptiva

- Li onnet Julio H. - Lnatomí Topografica

- Lambre Rómulo R. - Inatomí Doscriptiva 


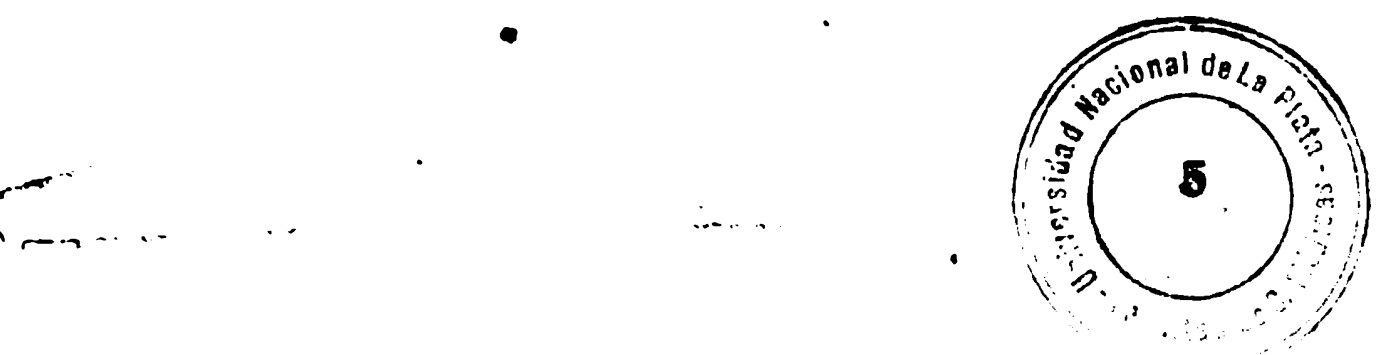

Dr. Loudat Osvalá - Cl. Pgiquítrica

" Luciol urespo Pidel A. - Sentolocia y Cl. Propodoutico

"Leingo So to Alberto B. - Microbiologia

" i.artinez Diego J.J. - Patologla inádicalla.

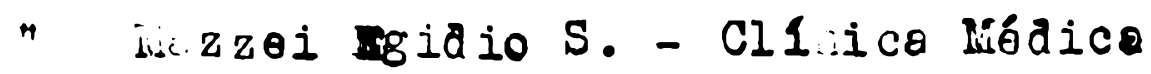

" Lontenegro Antonio - Cl. Genitourologica

" i.onteveráa Victorio - Cl. Obstátrica M. y Potológ.

" Obiflio Julio R. - Liedicina Iacal y I. Lédica

" Othaz Frnes to I. - Ul. Derratosifilográfica

- Pivas Carlos I. - Ul. Quirúxgica Ia.

"Rossi Rodolfo - Ullínica liédica

"Sepich Lurcel ino J. - Ul. Neurológica

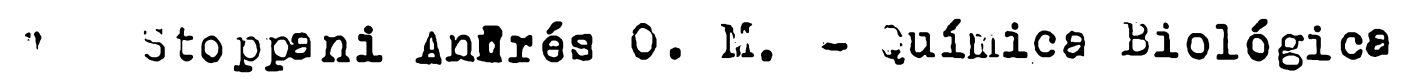

". Uslenghi Jo:6 I. - Radiologéa y Hisioterapia

Profesores Iitulares Interinos

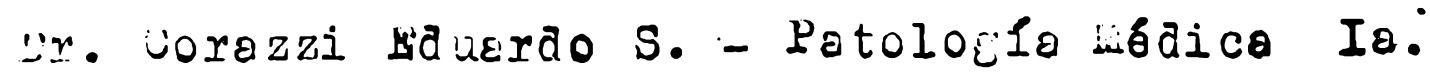

"Cervini fascuaz R. - Cl. Pediátrica y Pusicultura

Profosores Adjun tog

Dr. Acuilar Giraldes Delio - U. Pediátrica y Puericultura

"Acevodo. Benigno S. - Química Biológica

" anariou Luciano Ki. - Cl. Llááica

" Bach Víctor A.B. - C1. quirúrgica

" Carri Fnrigue I. - Parasitologlá

" Caselli saurá G. - Cl. Podiatrice y Puericultura

n Ciafarao Roborto - Cl. Psi diátrica

n Choscotta Néstor A. - Anatomle Descriftiva

n Dragonettiarturo R. - Hieieno NGaico y Proventive

" Dussout 1 lejana ro - Nodicina Operatoria

" Gaxcía Olivera higuel ä. - Medicino Legal y D. Médica 


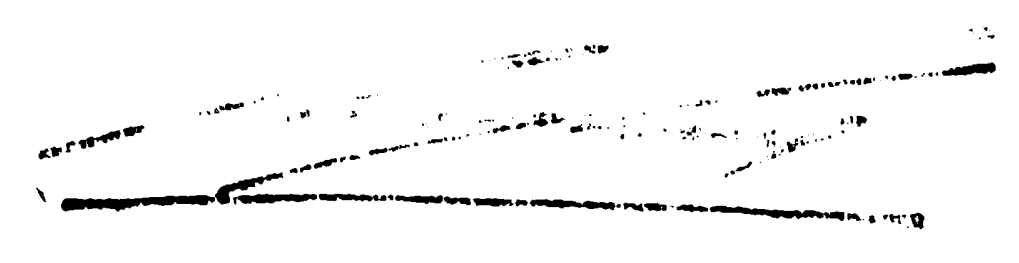

Dr. Girotto Rodolto - Clinica Genitourológice

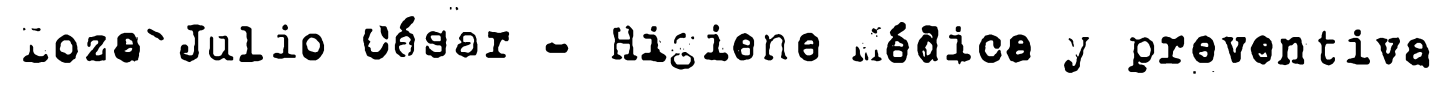
¿ozano rejerico シ̈. - Úlínica liédica íacif Victorio - Racioiogía j Higioterapia

" iverrete Daniel H. - P. y Ul. de la Tuberculosio Fereire Roberto H'. - Vínica Oftelliológica Prini sbel - Clínica otorrinolarincológica Puera Juan - Patolofila íáaica Taj Lor Gorostiega Diogo J.J. - Cl. Obstétrica Corres bianuel lú. הel C. - Clínica Oostétrica Votto Enriquo A. - Patoljela Quirturgica.

- Del lingi José - Pat. J Ul. de la "Luerculosia

" Lieilij Ilís - P. de la Tuberculosis

r Dal Iáco Héctor - Ortopeàia y írauriatológ

* Jastillo Odena Ieiauro - Ortop. j Irau. atologla

" Guixá Háctor I. - Cl. Ginec ológica

" Fernender Audicio Julio L. - Ul. Ginecológice

" Eriasco rlevio - Ul. Podítrica y Puericultura

" Lorano Bra di José Fi. - Ul. Pediátrica y Puericultura

: baila tiario R. - Cl. iledica

" Mianguel imaricio - Ul. ivedico

" "zabludovich Saloción - vl. Nadioa

n De Lene rogelio-H1giene y H. Sociel

" Ingratta bicardo N. - vl. Odostétrica N. y P.

" LOgercio Juan - Petolugli Lédicy Gerlbot to xomán u. - P. Múdioe

" Tezquez Podro C. - P. Medico

"Calzetto Rál V. - Semiologlo y Cl. Propodótica 
Dr. Tau Rinión - Somiolog la y Cl. Propodoütica

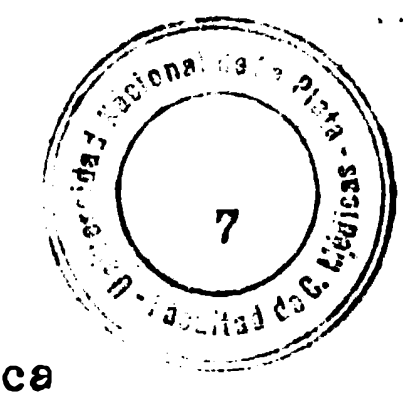

"Vanizi amundo - Somiologia y Ul. Propodoutica

" Tolose sauunao - Ulínico Otorrinolar neolósioa

" Vatuserich Jose - Ul. Otorrinolaringológico

" zatti Iorwinio I. - Ul. Anf. Infoociosas i P.T

" Troparno Antonio - licrobiologia

" Warini Luis C. - Wicrobiolog1a

" Fcheve Dionisio - Gúrica Biologico

n Conti Alciäes I. - Ul. Derratosifilográfica

" Bigatti alberto - Cl. Deriatosifilográfice

n Giflio Iruia C. de-Cl. Oftalmológice

" Correa Bustog Horacio - Cl. Oftalmológice

n kicbolini Raul m. - Cl. Quirúrgica

" Trinca Saul F. - Cl. Zuirúrgice

n Castodo César - C1. Neurölógica

" Curcio Francisco I. - Cl. Nourotógico

" Gotusso Gaillermo 0. - Cl. Neurolbgice

" Priero Herierto F. - Emb. O His tologia Normal

- Wertiner Joaquin D. A. - Semiologia y C $C_{1}$ Propedéutica

- Polizza Amleto - Liodicina Operatoria

n Beglietto Iuid A. - Medicino Operatoria

- Costillo Oano Iriaro - Ortopeaia y Trauliatologia

n Del Iogo Hetor - Oxtopedia y Traumatología

- Pernara dudicio Jalio C. - Cl. Ginecologia

- Faveiro Bodolfo - Perologla Quirurgica

n Sanohor Hector J. - P. Quirurgia

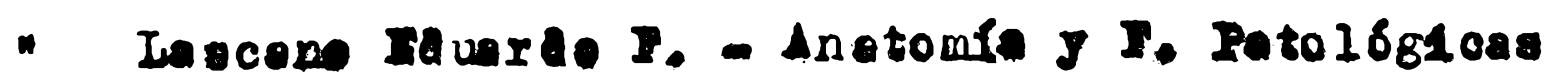



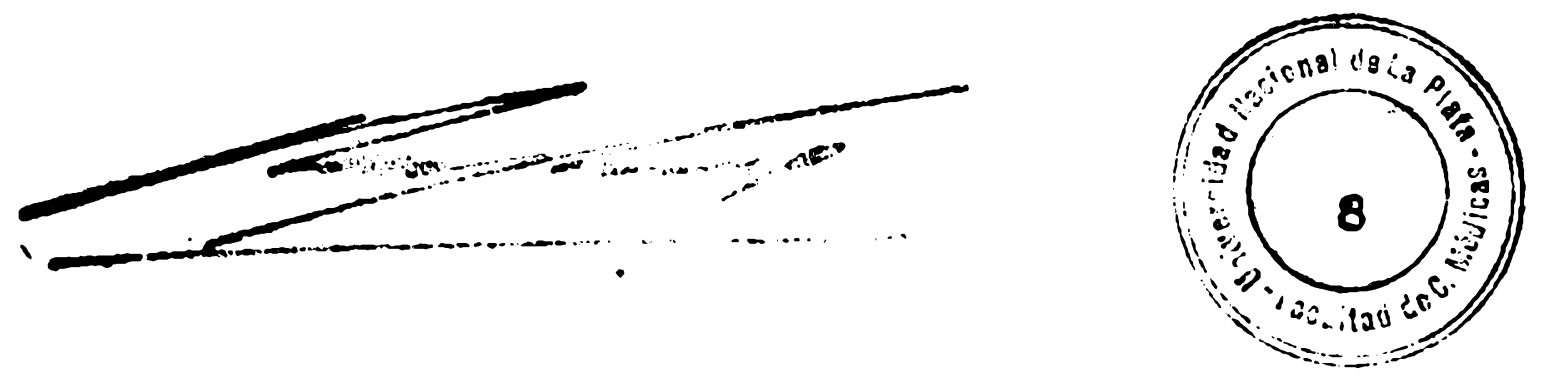

$\triangle$ MIS PADRE

A IIIS HiRMANO

A M PROMITID 

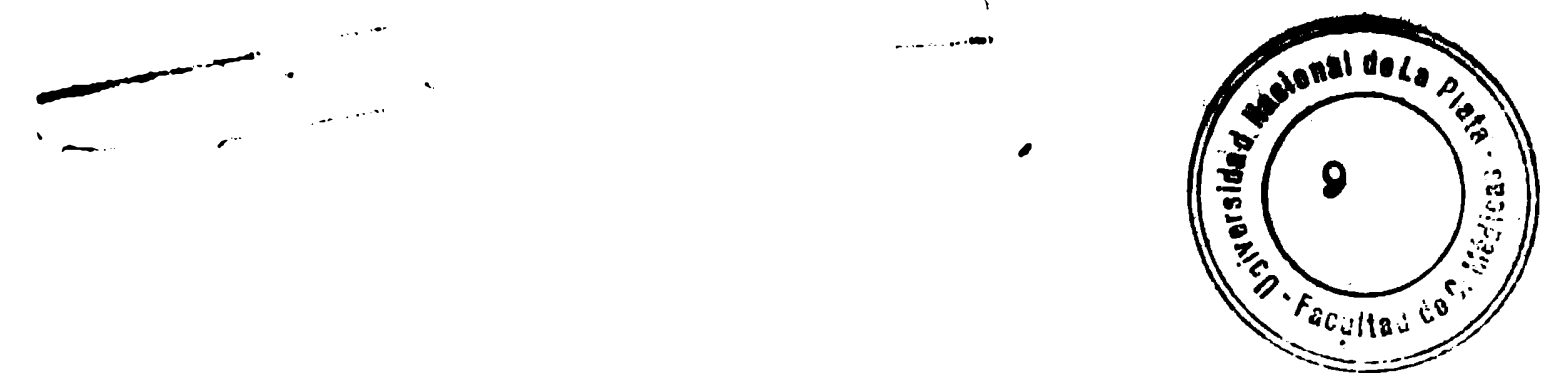

AI Ix. PIDIA L HACIEU CRESPO

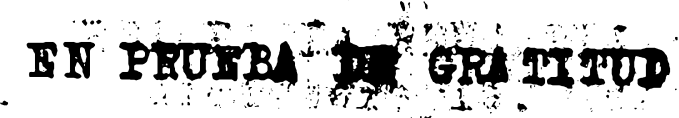



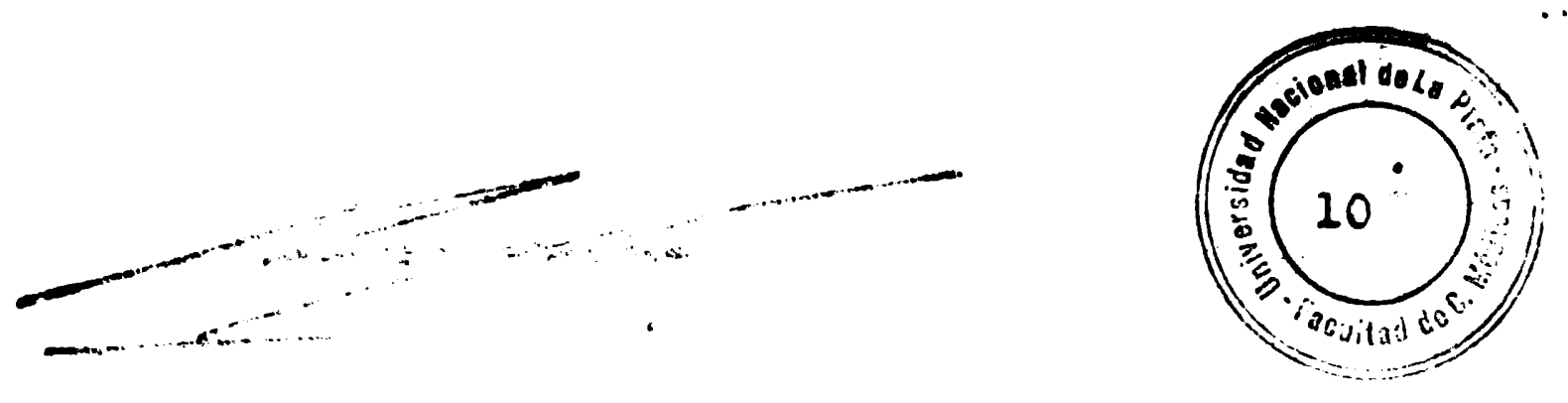

- CONHIDERGOIONES GRNERALBS.

- UAUSAS DE CARDIOPAIIAS. Porcentajes.

- FREUTICIAS DF IAS AFBCCIONES CARDIACAS POR EDAD.

- SONDICION RCONOLICA. Su Importancia.

- IA FIEBRT REULiatica. Dofinición

- BRSVIS CONSIDARACIONES SOBH: Sintónatologia - Saxo Raza - Canstitución - Contagio Influencia do las ostacionos J clima.

- MORBIIIDAV: Frecuencio por edad. Cuadros ostadisticos.

- RERTAIIDA D

- PROFIIAXIS DF IA CARDIOPATIA REULUATCA: Clinoterapia. Quimiotorapia. Infeccionos focaIos:

- IUCHA SOCIAI CONTRA ITA F IRBRE REULIATICA. Antecodentes vistoricod.

- ORGANIZACION DE ICA IUCHA HN EI MYTRANJARO.

- ORgaNIZACION DI IA IUCHA INN NUESTRO PAIS.

- vONCIUSIONHS.

- BIBIIOGRAPIA. 


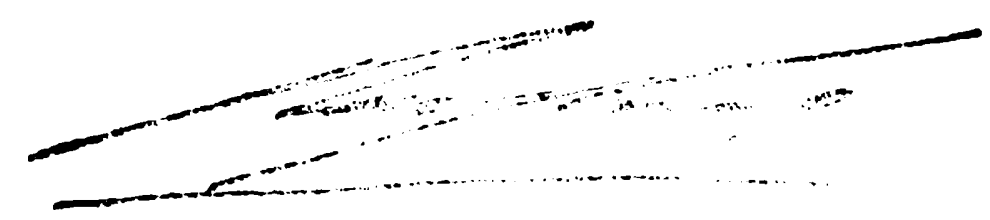

LUCHE LIDIUU-BOCIAI UONIRA LAS CARDIOPATIAS

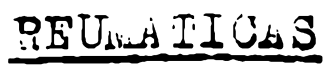

\section{Soncicoreciones genoralos}

Ir frecuencia creciente de las afecciones cardiovascularesen estos últimos años, os un iacho concreto ue constatan les estadíticas de topos los pelíses civi-

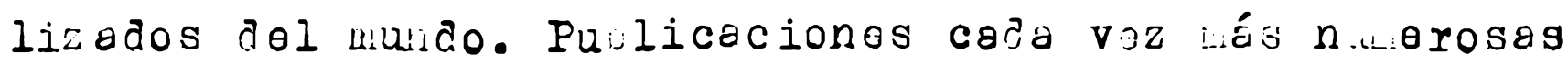
Sostacan la gravodad de esto problelu, haciondo notar

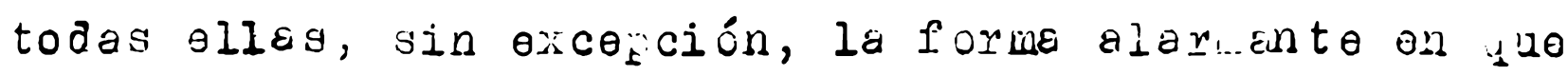
han crecido log ínaicos de morbinortalidad. Lo osterístice woderna liovede al terreno de los probrewas liéricosocialos por los noxteabericanos, he peruitido a los in-

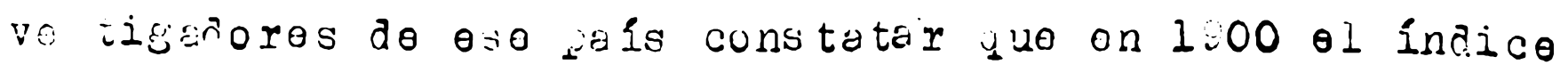
de Lortalidad por cardiopatícis era 132 por cadu 100.vic babitantes y desdo 1920 las cifras jrogreson en la oi suiente forma:

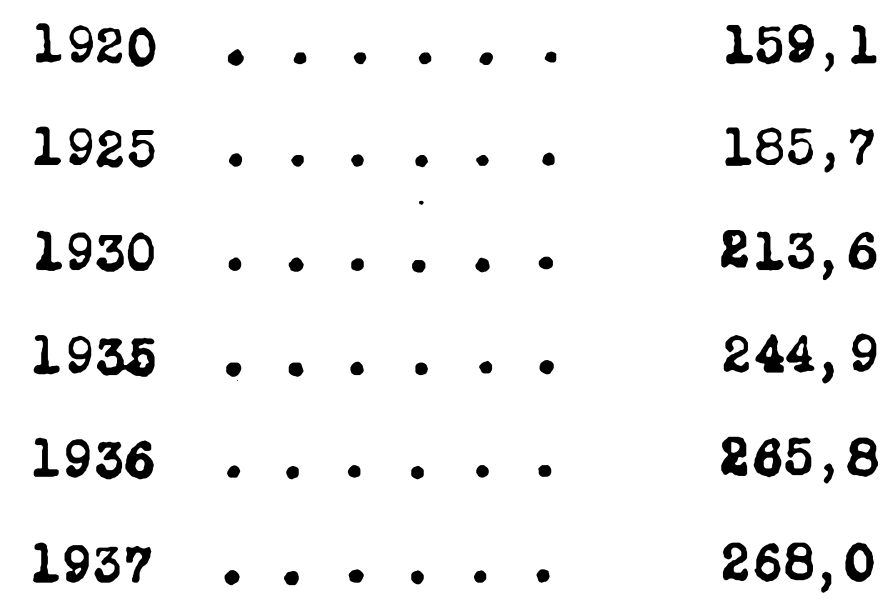



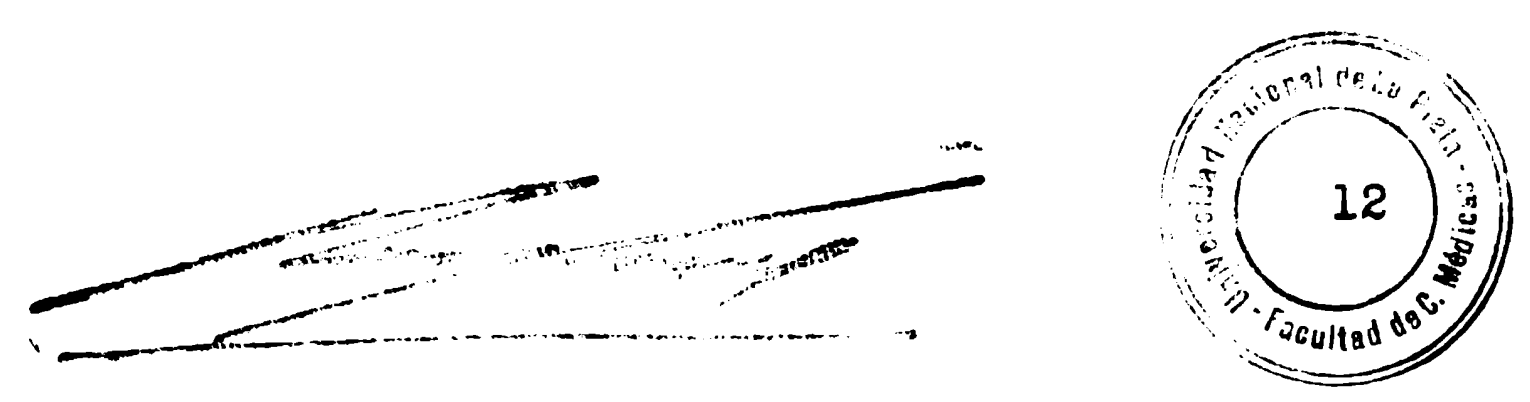

Istas ostadisticas publicadas por 18 Vit. Stat. Spec. Rep. U. S. no 29 - 1938, no onstante las objeciones que puedan merecer, destacan quo ol aumento do $1 a$ mortalided por las enfermedades dol corazón: os real. Roangel, del Departalento Nacionol do Selud dol Bragil, en ostacistices por él confeccionados, compruob que on Río de Janeiro ha habido an aumento on la mortaliaed por afoccionos cardiovesculares, as del índico 56 en 1928 por cada 100.000 habitanteg; so 11 oga a 82 en 1938. Th nuestro país, según estadisticas del Dopartamento Nacional de Higiene, on 1921, nuestro Indice por cada 100.000 habitentos ora de 194, y on 1935 do 213 para todo ol pals y de 267 para Buenos Aire. Dice Stone: "Lo opinión de clínicos capacitados og coincidonto on soñar r que las enfermodades del corazón son mucho wás comunes ahore que 30 anos antes, $y$, dosde el punto de visto de 18 selud pública, no og exagerado decir, quo el problano más importanto a lo modiolno moderne, 08 ol de las muerter por cardiopetian". In ouanto a la morbilided por oardiopetiar, on ano de 108 primeror trabejog pablicedoo antro nogotros por el Dx. Berlorer, belaloba que on un ortadio sobro 5.600 internados on 180 galas XVI $y$ XVII a Hoopital Centenario a Rogario (catedro de clinico

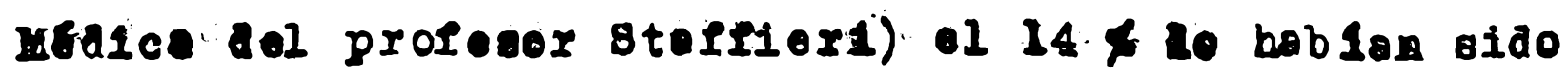
por caralopatias. 


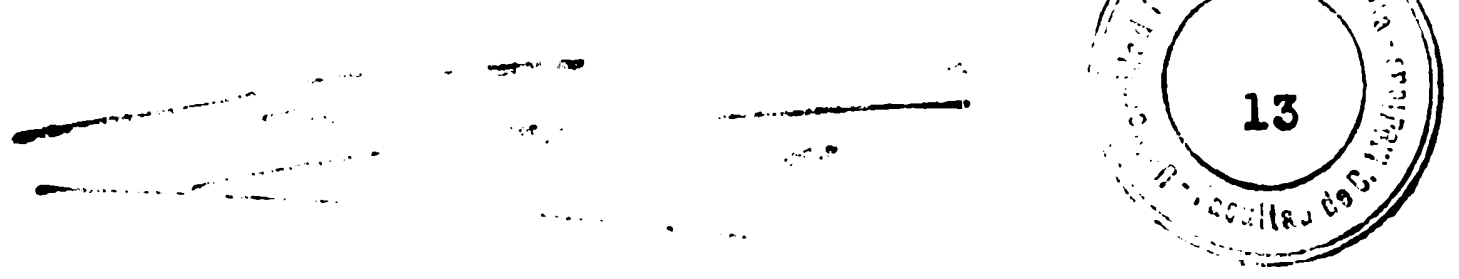

CAUSAS DE UARDIOPATIAS. PORCENTA JRB

Io importaneio respective do los distintos fectores cousantes de las cerdiopetíg, ha porico ser wiojor Vélorade on estos últiuos tros docenios gracias el proeroo to nuestros conociliontos. Ia es ecielizáión on este r. cfecciones cardiovascularos, la creación re centros, inositales y dispensarios para cardecos, han periuitido conter con datos wucho wás procisos.

Dejando de lajo las varianter goográficas, raciales clibatéricas, y los factores econó..icos sociales, puede ostablecorso iue clatro factores son los responsables del 80 沼 de las afocciones cardacas: fiebre reumatica, hi pertensión exterial, sifilis y artrioesclerosis.

La caráiop tías congénitas, la caraiotirotoxicosis, el corazón pullonar y la endocarditis infecciose, couprende el resto. Bl problema social, le lucha médico social contra las caraiopatís, debe encararso teniendo en cuenta, on primer terwino, aquellos cuatro gícinà fectores que determinan la in:-enga neyoria de las afocciones car ¿द́cas.

Veakor la erecuencia respectiva según las estedisticar publicadas en nuestro pala pox Cossio y lampana sobre 4.000 objervaciones; 2.500 de lo clientela hospitalo ria y 1.500 de lo clientela privade: 


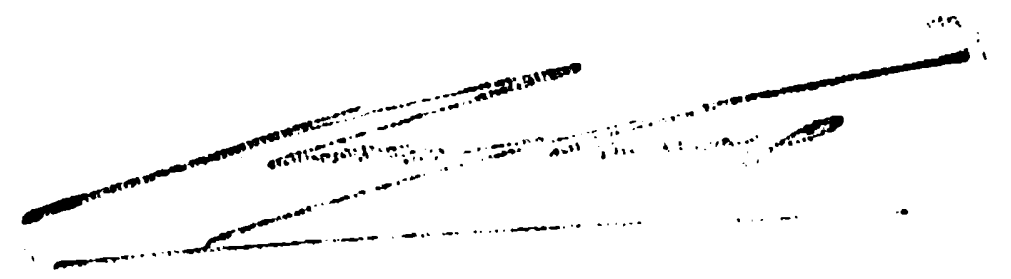

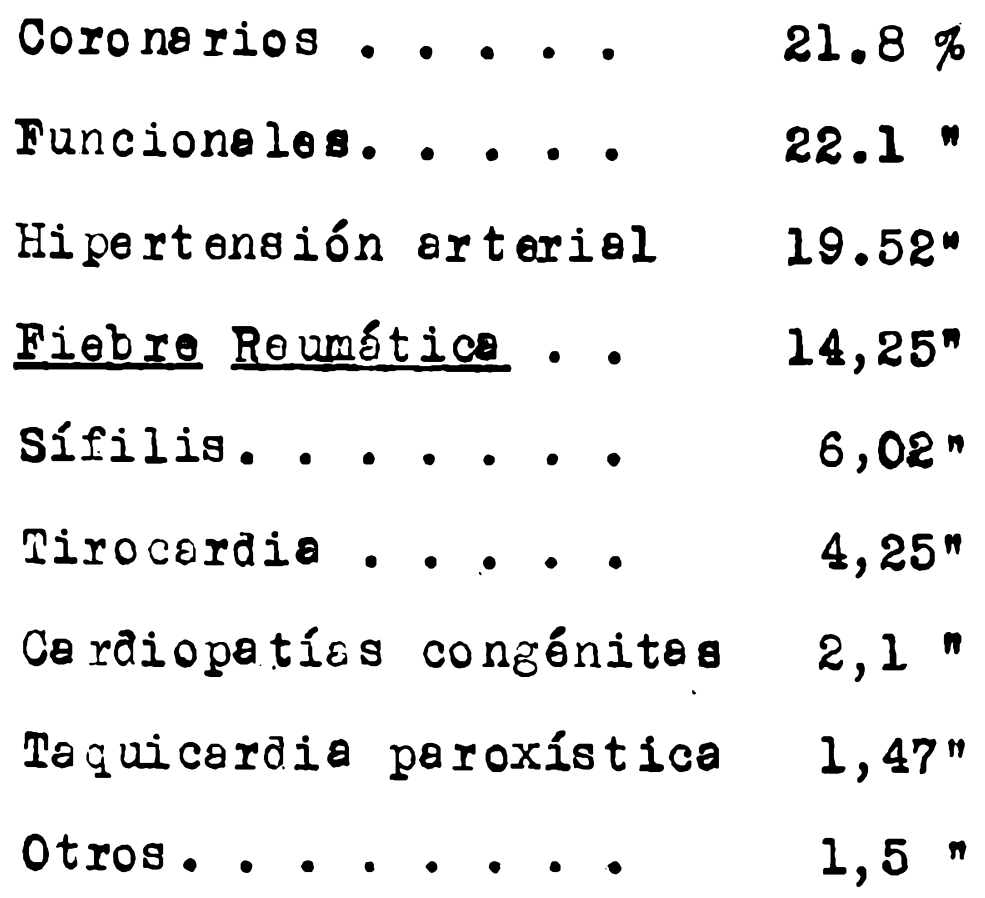

Cowo vemos, la fiebre reumétice ocupa aquí el cuerto lugar en orden de frecuencia. Il profosor steffieri y colaboradores dan sobre un total de 3.000 enfermos, 1.86 de lé práctica hospitelaria y 1.200 de la préctica priváda:

Hiportengión arterial . . 25,8\%

Puncionalos... . . . 24,3"

Coronarios. . . . . 18,9 "

F. Roungtice - . . - . 12,7 "

Sifilio . . . . . . . 5,4n

Cardiopatias congénitas . . 1,6

Tirocaraia. . . . . . 2,4 "

Taquicarair paroxlstica . . 1,0 "

maceraitis infocciose . 0,56 "

Otro8......... 6,8 . 

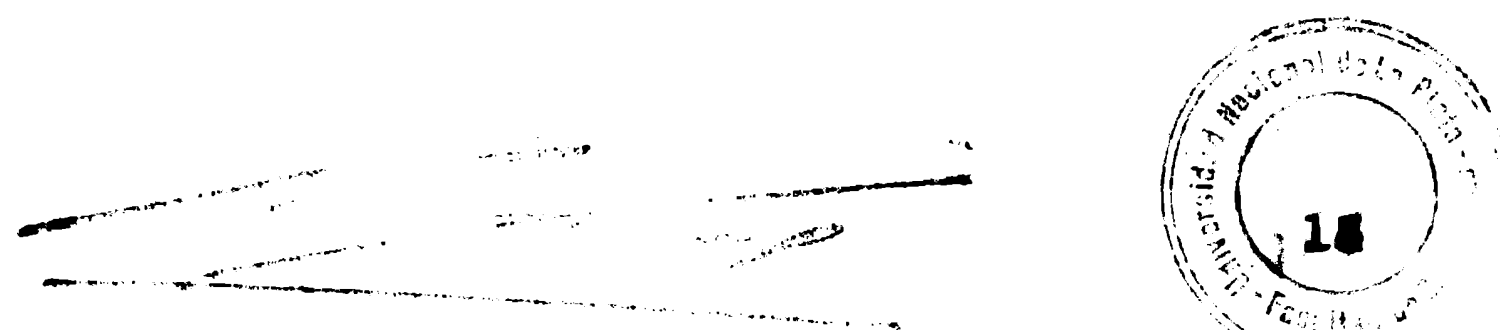

Aquí tambín, la Fiobro Roumbitice ooupa ol 48 in ger on ordon do erecuencia, oon of $72,7 \%$. 

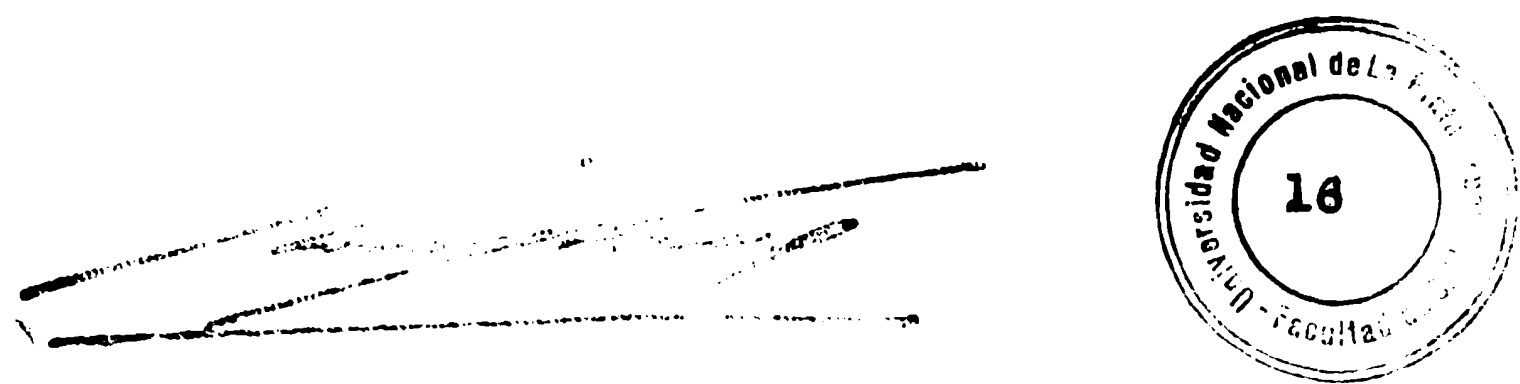

\section{FRTCUFCIA DE IES BHECULONDS UARDIA JAS}

\section{POR EDAD}

Según el deconio de la vida que se considero, vo ríun noté. Ieliente los féctores casantes ảo las cotíio Fatias, tanto en su neturaleza cono on la magnitud dol peliuro. Resumiendo las ostadística do Cabot, de Willins, de Lierocitb y de Porte, se puede establecer quo le Iro cuencia mayor de las cordiopatias corresponde al 49, 5 y $6 \cong$ decenio de la vide. Cossio, Campana dan los sieuiontes datos:

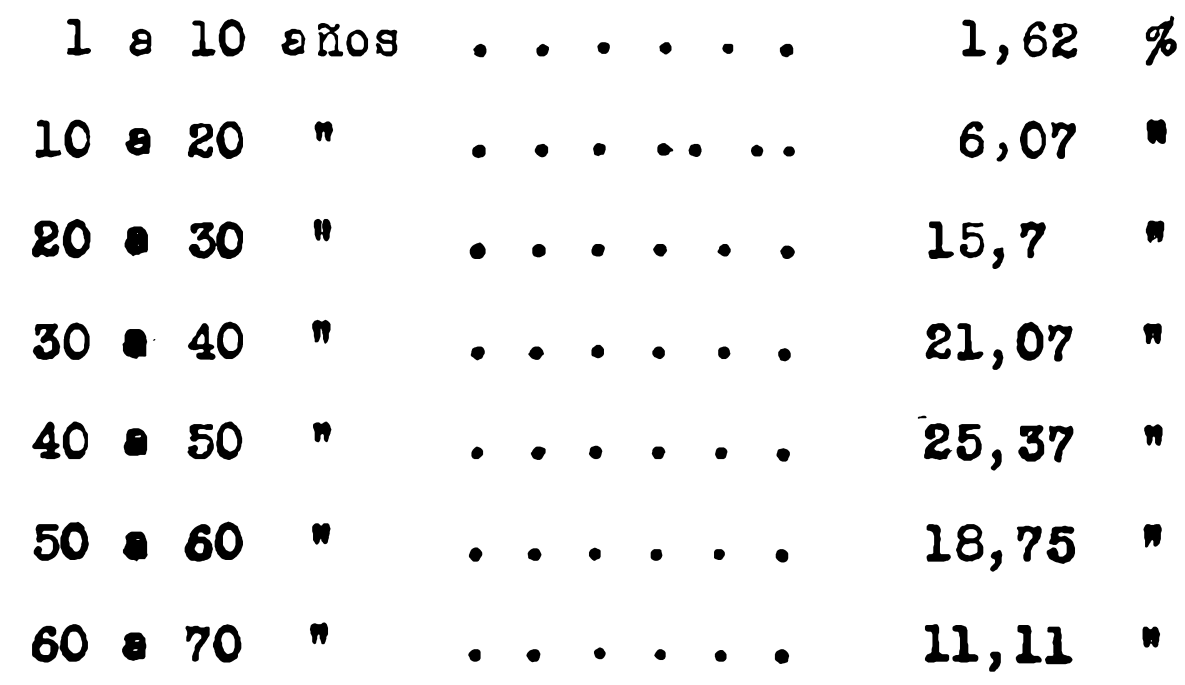

Hosta la 3a. decada do la vide prodominon las car diopatlas reamáticas, luogo las congenitas, sobre todo on 10 primere ácoda.

In lo 40. afceda se observe, según Cossio, $20 s$ roumbicos, coronertos - hipartensos, y on segundo término log tirotóxicos y alfillticos. 


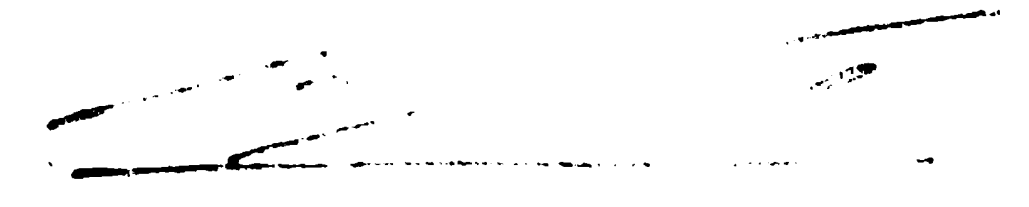

In 10 50. afcade: coronar108, niportenoos, sirillticos y rouméticos. In lo 6a. décade: coronariog, hiportonsos, rouméticos, sifiliticos, corazón pulmonax, caraion tirotoricosis. In lo 70. J domé coronarios, hipertengión artorial, sitilis $g$ corazón pulmonar. 

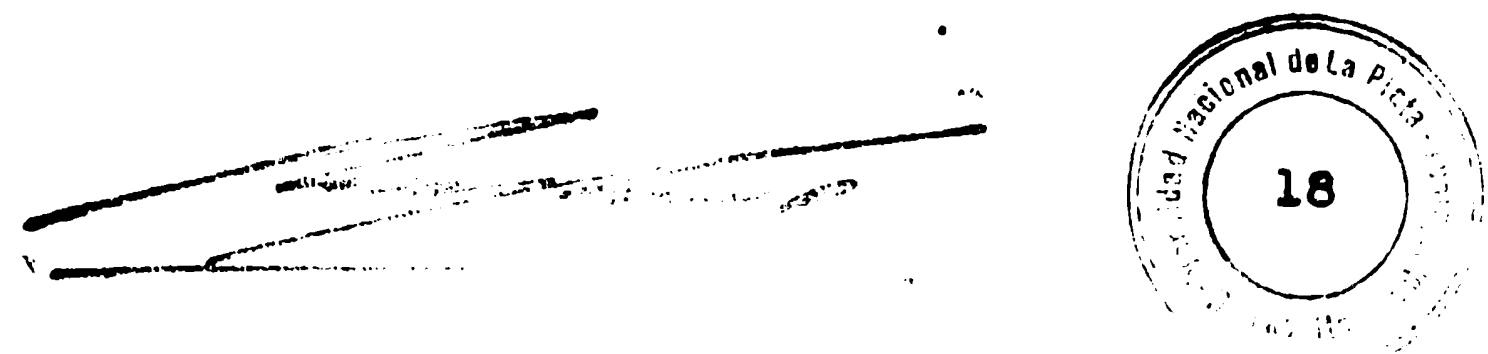

CONDLULON RUNOHIUA. Su inportancia.

Dico Aríoz alfaro: "Los ceráácos ricos tienen una vida large y relatovanente trenquila. Los pobros caon Fronto y reiteradomento on la insuficiencia caralace, on esistolia, su vida os corta y dolorosa."

Si sajemos que una de las conaiciones más ikportantes, por no decir la principal, os la reculación de la actividea física, podra valorarse en toda su extensión el oistéculo que significa para su tratamiento racional y ericez, las imperiosas necesidades matejiales del cerdíaco pobre, precisado a tener que realizar trabajos que están fuera de la úrita de sus posibilidades fícicas y runcinalos. Bs agi jus el reposo, considerado el primer y Lés iuportante medicamento del cardíaco, o la activicad física liscreta que tento favorece a estos enfermog, no go cuisplen, trayena o como lófica consecuajcia una aceleración de la evolución wortal de los mismos. Io prafesión que realizan los caralacos que se internan ep los servicios bosiztelarius, en el 80 \% de los casos eatá contraindicada para su onfermedad, lo que sugiero lo nocosidad imperiose de evitur el reintegro a sus ocupociones habituales aque llos enfermos, cha hen logrado con el tratamiento adecua do restablecer el oquilibrio cardiocirculatorio. So imprescindible la reancectondol caralaco on estos casos, en establecimientos dedicados ospocialmento a to 1 fin. 


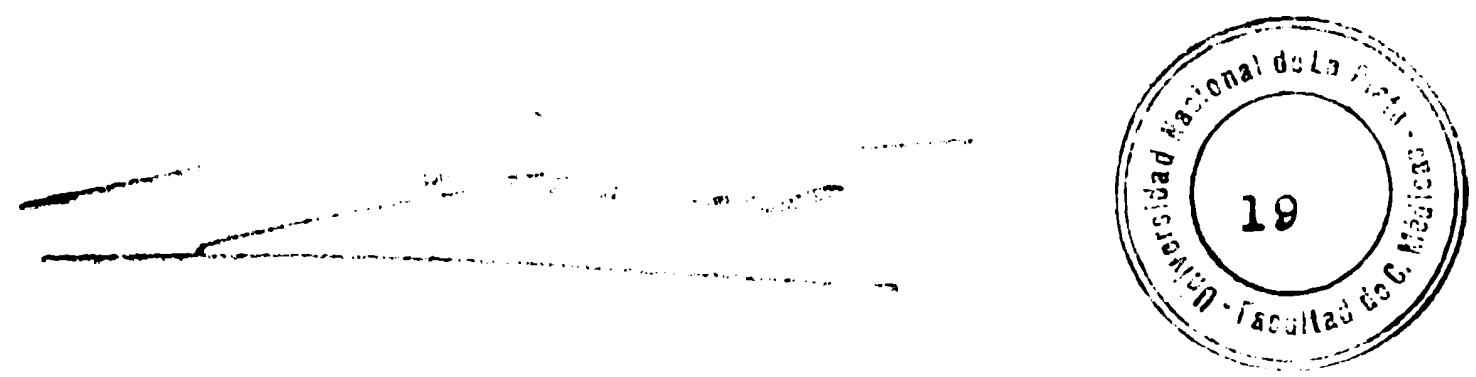

Ias condicionas de trabajo, la nala vivionda:

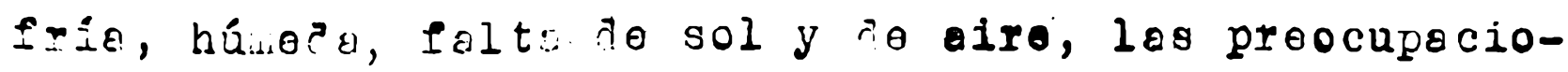
nos propicis ce uno situación oconómica deplorable y 1 a alinentoción ingrocuado, son otros tentor factoreg quo incicen porerosariente sobre el cardíco pobro, para prom cipitarlo on la insuficiencia coralaca irroversiblo quo a trovés de una invaliąoz ruás o kenos brove terminará con su vida. In ta to Unidos el cuidado y tratamionto da

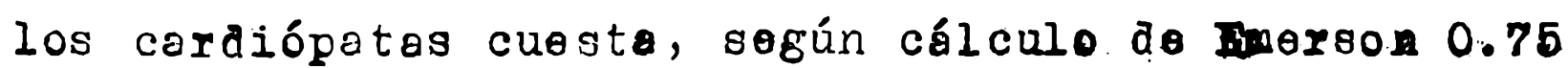
do doliar por babitanto y por año. Ias caraiopatía, son puer, une seria carga para el Fatado, sobro todo si se considera le mayor erecuencia de las mismes en la edaa do la vida on quo el inaividuo ha alcanzado ol máxino de capecidad y.rospongabilidad, osto es, de los 30 a 10850 anos y por lo que demanda la asiatencia mádica do las mismos y lo póráä que representar ooma valox humano,por invalidez total a parcial, pormanente o tranaitorio. Intro nosotros, Sussini y Cossio, teniendo on cuenta que en nuestro país mueren 25.000 persones por cardiopatias por ax́o y que el 40 \% de las jubilaciones que so otorgan on el peis. ae devon a afoceiones cardioresculeren, estiman que la carge que representen para la coloctividad acionde a 100 millones de pesos por ago. I ogregen: "pare formarae uno idoe concrete de las porr aida económice por invelidez que originon log onforkodader del coraser on ol pois, booto sozalar quo en lo ca-

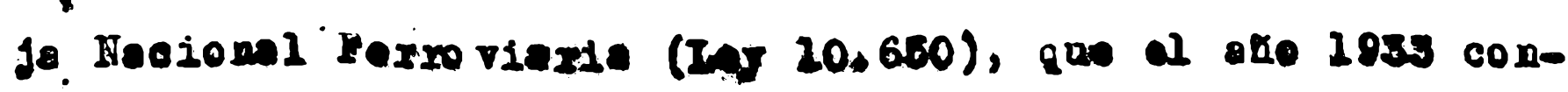




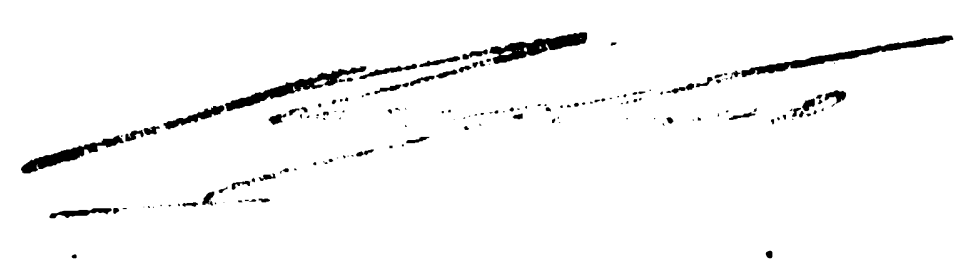

taba con 138.216 ofiliados, hasta ose facha nats conce तido 11.608 jubilaciones y pensiones civiles (Iey 4.349;, la yue el año 1935 contaba con 153.589 afiliados y ye hasto ol ano 1936 so habian concodido 3.662 jubilacio nes extraordinarias por onfermodad, lo cual significa un desembolso wensual de 508.157 pesos. Como las onferwedacios cardiovasculares han sido la cauga de esas juiliecionos extraoriinarias por enfermodad, on la proporción aol 38,33\% ol 42,39 \%, se tiono que ostas han notivodo ol pego de 2.235 .514 pesos anuales en concepto de jub1laciones extraorainarios".

So haco nocesario pues, trater do modificar ostar - errea abordando ol problema sogún las directivar que inpone la modicina moderno y sobre la base de una protec cín oconómiga ofoctive por perte del Irtado, quien mo atan to una logislación adecuada podrá arbitrar los modios para poder ponar un diguo los ostragos do las coraiopot180. 


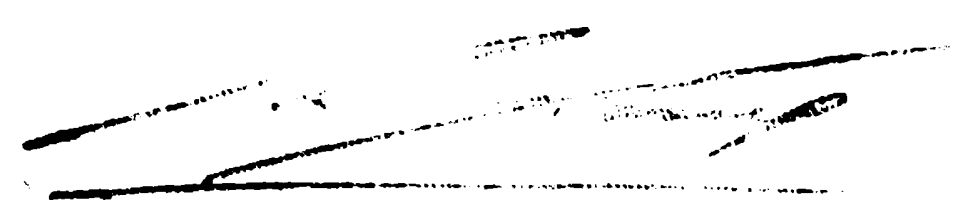

$21 ;$

\section{IA FIFB BT RRUMATICA}

Dofinición.- Eo fiobro roumbtica, reumotismo poliarticular agudo, reumetismo caraioarticular o enformodad do Bouillond, os una poliartritis infocoiosa y ospecifica que ataca sobre todo la segunda infancia y ol adal to jovon, determinendo tumefacción y dolor articular de $\operatorname{sen} \theta-$ ra ofíliera y móvil, pero losionando frocuentemente ol corazb, determinando lesiones graves y definitivas. To deja inmunidad, sino que por el contrarlo, vuelve a log sujetos wốs sensiblos a sus ataques, siondo casi la ro-

gla que hagan recidivas articulares ó carálacos, lo qu lo da significación de enferciedad crónica matizada con opisodios aeudos y ruidosos. Cada reagudización lasiona más ol corazón. Il rejmatismo cardíco ropreseŕte una invasión proliforante y oxudativa de las válvalas, ondo cardio, miocardio, tojidos do conducción y pericardio, que suele conotituir la benifostacion principal de lo onformedad. 


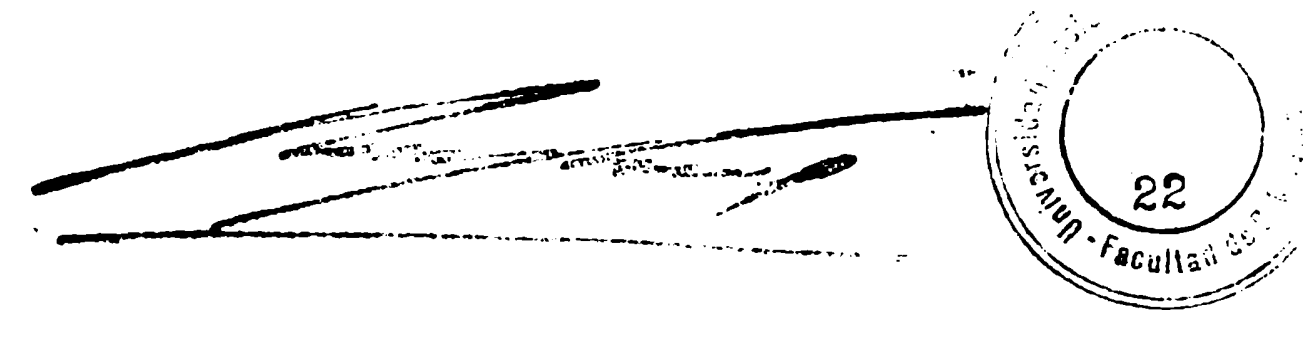

\section{BRIVPS COISIDEPACIONIS SOBRT}

Sintonatologia. Il cuadro clínico es proteiforme: angina, fiebre, tumefacción y dolor arti cular, que suele ser muy intenso, pero que desaperece on pocos dís bajo la influencia del salicileto o espontánoewente. Se aculupana de palicer, astenia, ta cocitosis $g$ eritrosedimentación acelerada.

otras veces simpleriente dolores vagos en les articulaciones o en los wísculos que son interpretados cuenco se trate de nixos, como "dolores cel creciniente" por los

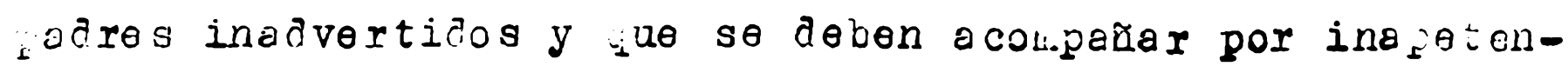
cia, decaimiento, fal te de deseos ie jucrar, etc. Todos los autores están acordes en destacar estas formes frustres de la fiebre reumática, pues solo en el 50 al $75 \%$ de los casos, puede descubrirse historia de reumatismo on la anannesis de estos enfermos.

Las cardiopetias de origen reumbtico contribujen con un gran porcentajo a engrosar el número do los carafocos adultos, cuando ban conseguido salvar de lo muerto duronte el perído do la infancia g adolescencio.

Sexe. - Do la lectura de los cuadros estadsticos corres pondientes o encrestes realizados en hospitalos de la Capitel Federe1, por 20s Dres. Wacere, Rachell1 y Cogto Berteni, so podrlo doductr un ligero prodominio de los varones sobre 


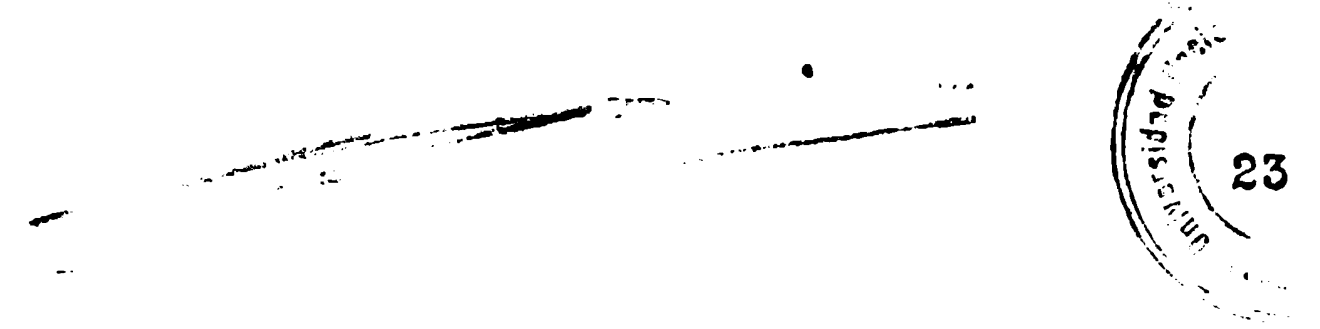

las nifas afectada de roumatismo poliarticular. Asl sobre un total de 847, figuran 444 verones is 403 mujeres.

In cuanto a los 1 de mostraban afectado su corazón, entre varones y majeres suman 477, de los cuales 264 eren varones y 213 mujeres.

In otras estedisticas, como de White y Jones, sobre 956 enfermos, 525 eran de sexo remen1no y 431 de sexo mesculino, por 10 y ue debomos acoptar que esta onfermo dad ataca ambos sexos por igaal.

Paz8. -

Asch, on el Chilaren's Hospital Philadelphia on donje se internan aproximadanente ol mismo nkworo do nidos blancos g negmos, encuentra que los reurbticos eran 83 \% Mlancos y 17 \% negros. A su vez Sutton on el Bellovue Hospital de Naeva York encuentro un porcenteje similax lo que confirmaría la conviccion genoral do que lo raza negra perece tener una registencio espocial contra le Iiebre reunática.

\section{Constitucion.}

Desde Bouillaua, se beble de preaisposicion, pues ál croía on le exigtencia de un terreno artritico. Duque, Fordo y Ioper Morales, ereen que lo entermedad revuetica con machloime. Irecuencie oo instalo on individuos de constitución anormal, consdarando los ostados ao infontilismo como $100 \mathrm{mb}$ propicior y luego, on orden do Irecuencia 


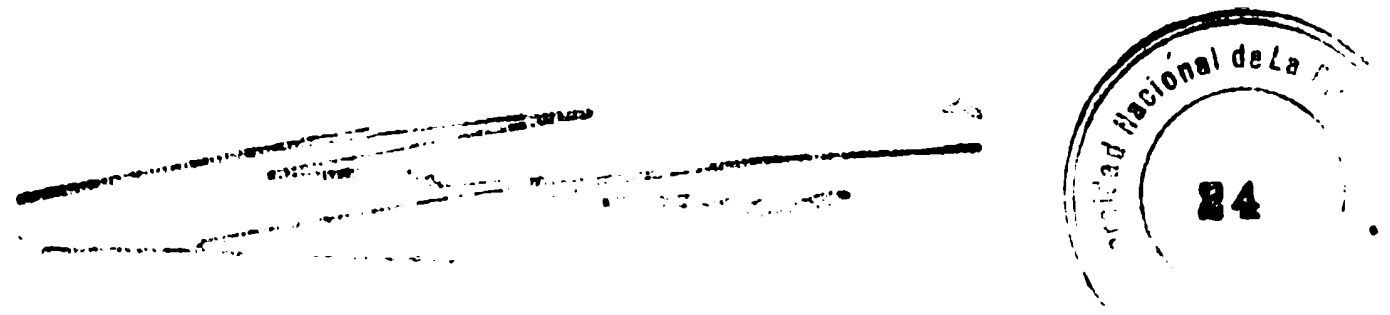

los ostados estónicos, plenicos o intersexuglos. Wo interesante destacer que los tipos que se defiencien menos son 109 asténicos a hipoplésicos, quo por utra parto sun los tipos constitucional or mós aroctadoo.

\section{vontasie.}

Ia mayoría de los autores consultados aceptan la contagiosidad de la fiebre reunática. Durante la querre del 14, Grenet, hizo observaciones harto convincentes. Seleccionó este autor casos indiscutibles de fiebre rewética, rechazando todas aquellas observaciones dudoses. vins. totó en un territorio limitado, cinco focos opidémicos aistintos, la independencia relativa de estos focos el desplezalien to de la epidemia con el äesplazamien to de una unidad contaminada y la inwunided de un regimiento indem no que releva a un regimiento atacedo y que ocupa sus antiguos cuartelos. Is to íltimo probaría para ol autor ze la contaminación no se hace por el suelo o la hoiltación, cino por el contacto de bombre a bombro. Acepta el carácter eplármico $g$ contegioso del reumatismo, cuyo porlodo do incubacion ostimo entro $8 \mathrm{~g} 21$ alas, saponiondo yue of contagio ae hace por lo faringe (amigdalitis) a otros puntos del tabo digertivo $g$ de sus anexos. Is contogiosidad sorla relotivamente deb1l, lo que explica que pese mug amenudo inodrertila y no oe monifiesto con evi dancia oino on condicioner un poco especieles. Luchos autores acopton ootos hechos y a su vez han pablicado obserrecioner concordenter (Bezangen g Foill, Ioncerrapx, hara- 


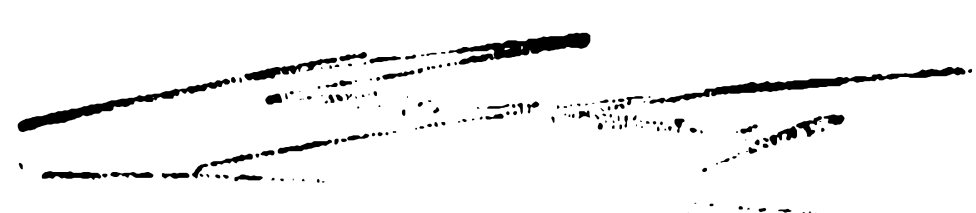

28

Ión, Talawon, (uhouel, Faulkner, etc.)

Fntro nositros, Cooto Lertani, jeretervido, y Lolfino, Recalde Cuestas, etc., aduiten lo contaciosidac cel $r e$ uat isto sobre todo para aquellas fortias que so acupeián de amigdalitis $y$ on la faz aguda de las miskas. Es en base a estos antecedentes, que todo reumático cordiovascular debe ser considerado corno contagioso para los Le conviven con él g por lo tanto en la medida de lo poGivie se debe intentar disminuir los peligros del contacio evitando conveniencias estrechas, los contectos innecestrios y directos, desinfectando periódicamente las fáces ael enfermo y extirpando las amigdalas si se juzge estên al teradas on el cowento oportuno y haciendo sistemáticoLente lo wedicación salicilada aún on los períodog de reposo, de la enferraded.

\section{Influencie de les est}

In América, la fiebre reumatica es Lés frecuente durante la primevera y verano, lo nismo que en Francia. In cambio en Inglaterra la estación liés favorablo para la oclosión de la fiebra roulática os el invierno. In cuento al climo osté demostrado que desempoxa un iruportante real papol sobre lo genosis, frecuencio y rocidiva dil mel. Il roumotismo caraloarticular os mus poco frocuente on los pelses tropicaloa; en cambio so le observe on los polsoe frlog g húnedoa, esje cielmente on aquellas regionas donde oxiste gxan variacion meteorológica 


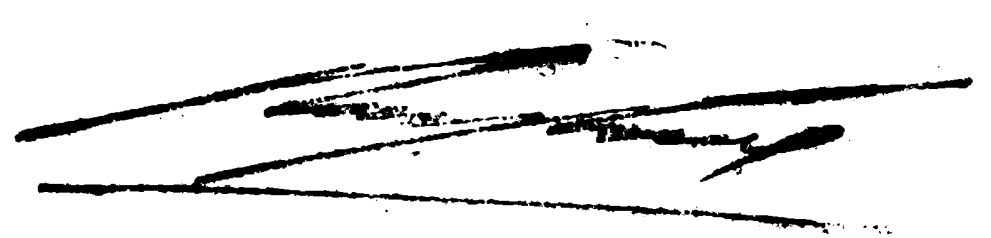

Interrienen con froenencie on el primer optoodio roumátice. ol onfriamiento g las mojaduras; sionto factoros prodispononte la misoria, lo vida urbana, el bocinomiente on riviendas mal ventilades g húmodos, la folta de orrigo otc. Factores estos que puedon combatirso internande a esta claso do nifos, o do lo contrario, hociendo Intervenir el Servicio social, que dobo conter deade luego con todos las eletontos indispensables y aplicarlos con la amplitus necesarie pare conjurar los factorea negatiros mencionedos que pesan on lo ovolución de la enfermedad. 


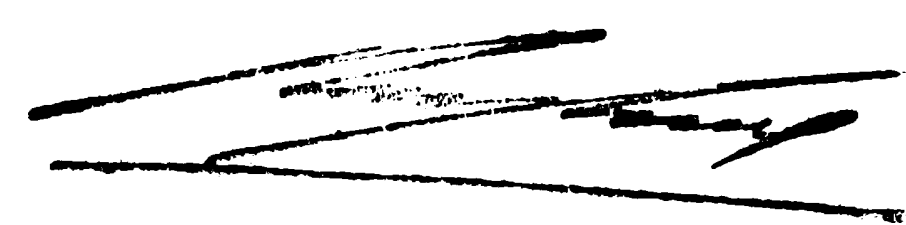

\section{IFEPILIDAD. Freouencia por oded}

Io Liebre reumátice puedo objervarsoo en todas las odados de la vida, poro es a partir ¿a los cinco años que la curva de frecuercia crece on todas las estadis ticas has ta los doce allos, para luego cescender hasta los quince y nás on forma progresiva. Los doctore liacera, Ruchelil y Costa Bortani entre nosotros, en trabajos sucosivos realizados desdo ol año 1935 en adelante, hen puesto en evidencia lo cifra alarmante de nixos coraioreumáticos existentes on el poís, planteando bajo su aspecto social, ol grave problema del reumotismo infantil por las cardiopatias que origina. In uno, encuesta realizada por ostos autores on el axo 1938 sobre concurrencia de nitos roujaticos con o sin cardiopatipa a los Hospitalos de la Capital Foderal llageron a la conclugión que sobre 1.100 nixos con enfernoded reurática otendidos on 26 Hospitales del wunicipio, 649 acusaban Iranca caraiopatias, o sea yue ol 58,5 oran caraiópatan. In un último trabajo similar del ano 1942, sobro il bospitalog del Munigipio, anoton 847 n1Loa con onformoded roumbtice de los cuales 477 son caxdispatar erancoa, valo deciri, ol 57,8 sto

Iated cifrae, como os frcil comprender eatín mus lojoe de replejax on un todo la realidad del probleme que trotenos, pues han quedado exolufaos do esto registro

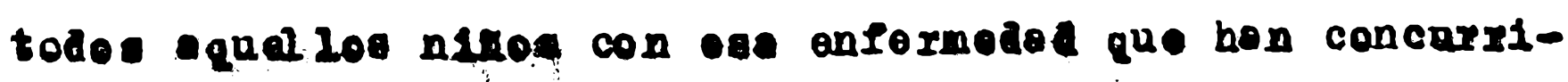




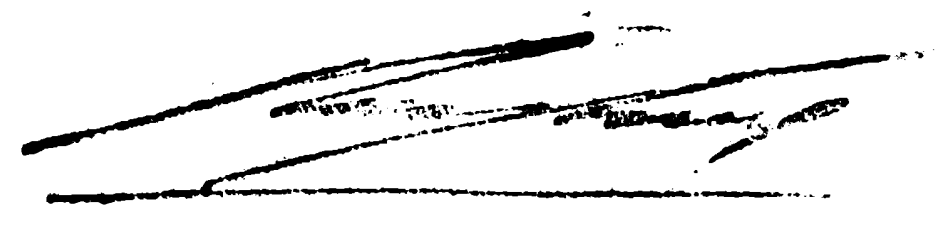

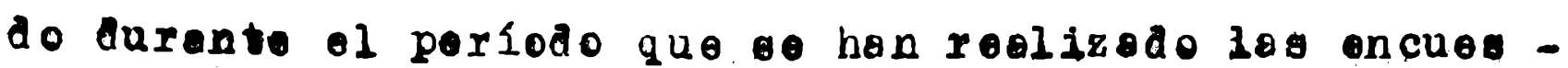
tas, las innumerables sociedades do Sooorros lífuos, los que han esistidos a los Hospitales do las colect1 videder g lo gran mosa de onfermos atendido on 108 cono sultoriog particularea.

In ol cunaxo que ajunto a continnocion ostin aion tribulaco los onfermos por oded g por soxa, tento rounticos como ceralacoa. In ol conjunto do los nifos roumbticos sin coraiopetio, oxis to un ligero prodoninio do las majexes sobre 108 varones: 180 para 188 primeray $J$ 180 para 109 oggundor. In cambio, on los nigos con car diopotilas los varones son ligoramente mág numorosos que los mujeres: 264 para los pxinoros y 213 para 198 gogunaas. Vomos tambión on el' cuadro, quo ol roumatismo de

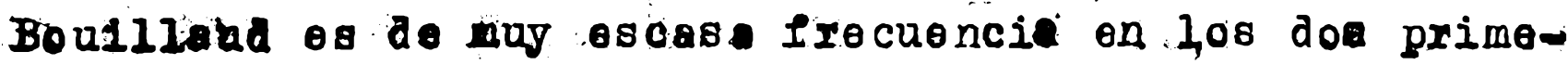

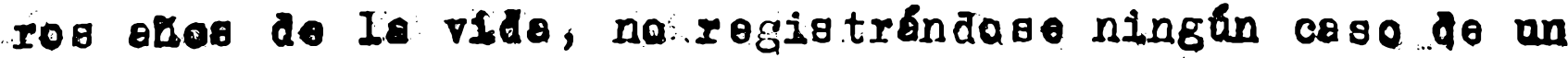
so do odad, poro si, cubtra caralacos, la iug hoqo ouponer qo ogtoa nillos han tenido una cardiopatlo oongent te arocialo con un proceso doloroso ogguramento no linputobla

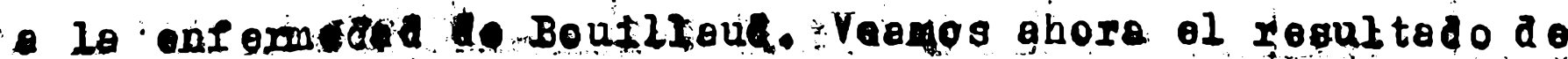
Io encuesta realizade por 108 Dros. Moere, macholl1 J Coota Berton: 


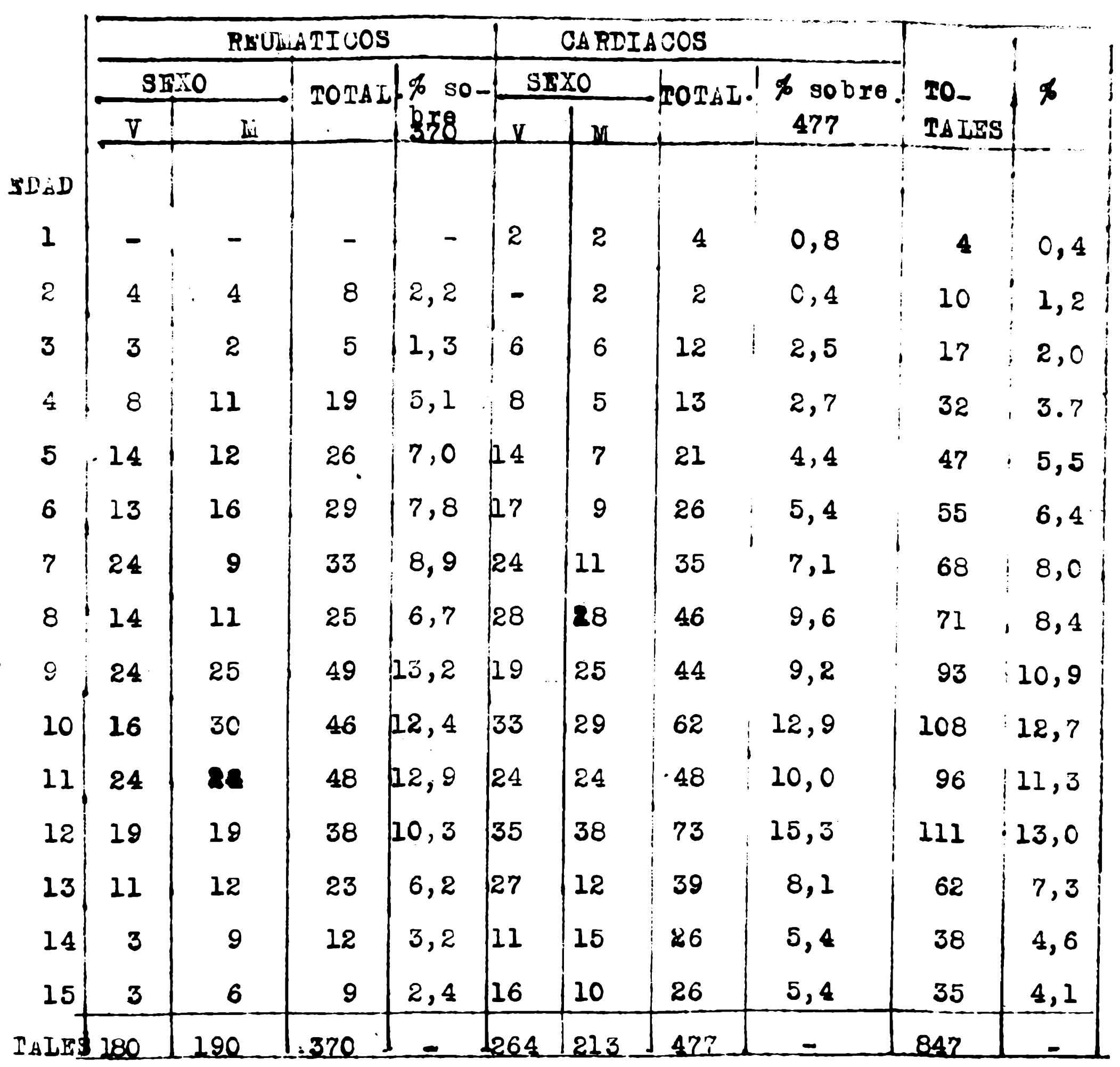

No obstante no observarse en este encuesta cesos dentro del priwer año de le vida con tiebre reumética, cabo menclonar qu hey ouservacioner on la literatura liédica mundiol de coloo de fiobre reuubtioa que se produjoron iaste en ni nos do pocos wores (Feill, Pocock y Schaffer, Ruchfas, otc.)

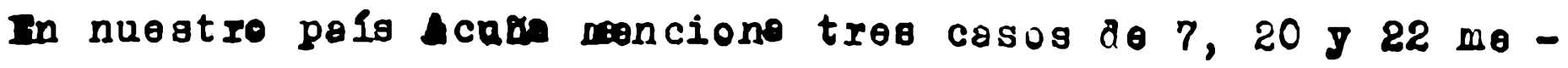


ses y croo con lostr berten1 y Smith Bungue quo las formas de fjebre reumbtica anter de los cinco años son monos rares de lo ve so aopte comunliente, $\theta$ insisten subre $\theta 1$ carácter atipico do la onfermeded cuando so presenta a $\theta$ os odod.

In el cuadro siguiente se pueden colporar los ni î́os con Fnformodad do Boulliaud, con o sin carálopatía, por grupos de ededes $y$ de sexos con sus porcentajes corres. pondientes, que fueron atendidos en el año 1938 (16 Hospitalea) $y$ en el año 1942 (Il Hospitalog) de la lapital Foderal. In estos atos estadísticos de los Dreo. liacera, Ruchelli y Costa Bertani, vemos que los porcentajes en los distintos grupos de edades se repiten con gran similisua. Asq el mayor porcentaj de niăos reumáticos con o sin cordiopetios corrospona a las odader comprondidea entro los 10 y 12 a tor de odad con el 38 \% on el a gom 1938 y cas s1 el 37 to on 1948. Intro las edades de 7 a 9 atos 11080 on 1938 al 30,5 \& $\mathrm{g}$ on 1948 al 27,3 \% . In los otros 8ra pos de odad los porcentajea concuerdan ertrechamente on ambos porlodos

\begin{tabular}{|c|c|c|c|c|c|c|c|}
\hline \multirow{3}{*}{$=D \& 1$} & \multicolumn{3}{|c|}{$s=x 0$} & \multirow{2}{*}{\multicolumn{2}{|c|}{ TOSAI I }} & \multirow{2}{*}{\multicolumn{2}{|c|}{ 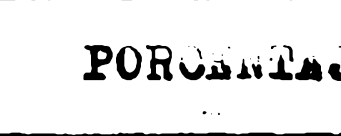 }} \\
\hline & \multicolumn{2}{|c|}{ Voron } & lujox & & & & \\
\hline & 1938 & 1948 & 19381948 & 1938 & 1848 & 1938 & 1848 \\
\hline $\begin{array}{l}3: 500 \\
6: \\
80 \\
150\end{array}$ & $\begin{array}{r}17 \\
81 \\
147 \\
213 \\
84\end{array}$ & $\begin{array}{r}15 \\
74 \\
133 \\
151 \\
71\end{array}$ & $\begin{array}{rr}11 & 16 \\
71 & 60 \\
162 & 99 \\
282 & 168 \\
78 & 61\end{array}$ & $\begin{array}{r}88 \\
158 \\
339 \\
156 \\
256\end{array}$ & $\begin{array}{l}31 \\
134 \\
238 \\
315 \\
156\end{array}$ & $\begin{array}{r}8,5 \\
13,6 \\
30,5 \\
38 ; 0 \\
14,0\end{array}$ & $\begin{array}{r}3,6 \\
15,8 \\
87,3 \\
2,8 \\
26,8\end{array}$ \\
\hline
\end{tabular}




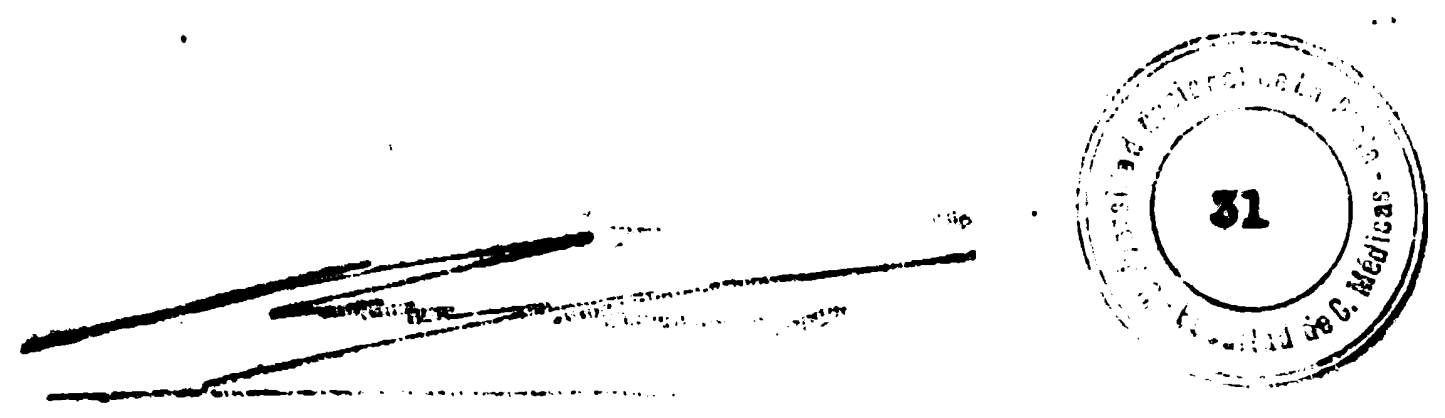

\section{MODNT TrOMA}

In eI III Congreso Internacional de Reumatismo do Paris de 1932, comunica Care y Coombo, que de acuerdo a sus estudios estadsticos llerados abbre 2.000 casod de enfermodadès orgánicà del corazón poála afirmar que el reumatismo caralaco era une enfermedad de primer orden entre las causas de muerte entre los hombros y que aproximedamente el $50 \%$ de los casọ, provienen de procesos infecciosos, entre los cualos puode imputarse 10 gran mayorla al roumatismo. Por otra parto Pierro Woil, Glover y otros en ese mismo Congreso, sostionen que más de las dos terceras partes de los roumotismos gue serán mortales más tarâ remontan a la edad de 5 a 15 años. In Sud América os bioruluio quien wás se ocupa del reumetismo infantil, y observanas al correr de muchos años 18 onorm proyocción social que encerraba osta onformada cristalizt su noblos antiolos con la creación de la Pollclínia Caraiologia Infantil on 1933.

Intre nogotros, Macera y Cogta bertani dan un 22 de mortaliad por fiebre roumbtica o sus complicaciono

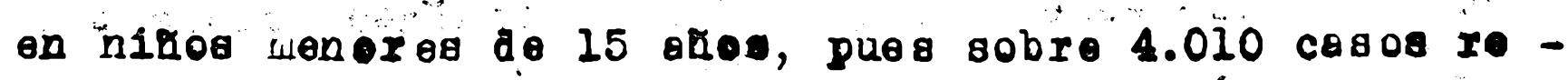

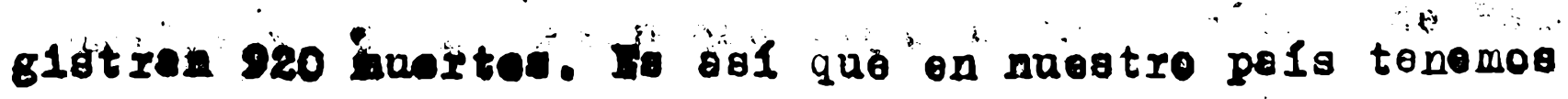

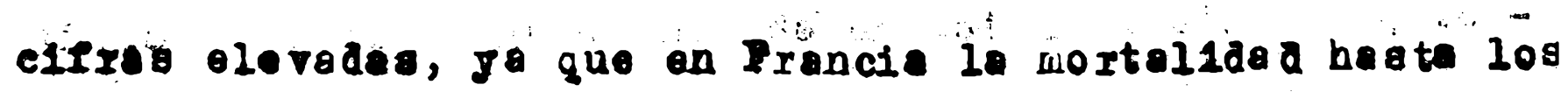

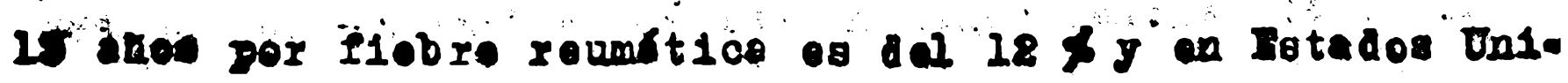

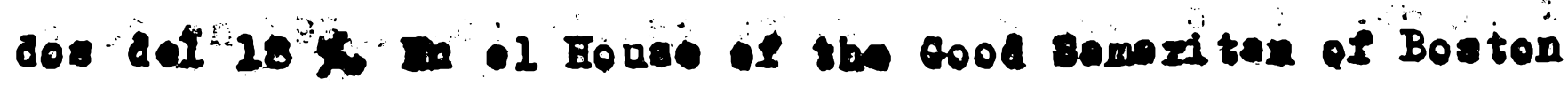




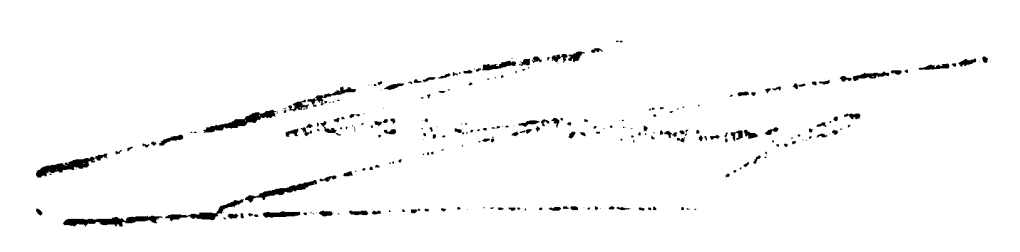

los Dres. Sland $y$ Jonerd declaran que haste 1938 han tron tado unos l 500 nilos y adolesconter con reumetismo de los cuale fallecieron 306, valo aecix poco más dol 20 s. Costa Bortanl aice que do lo revisión de lo ostadistica puolicada por el De,artamento Nacional de Higieno on el Anuario Demográfico corresponaiento al a do 1935, la mor-

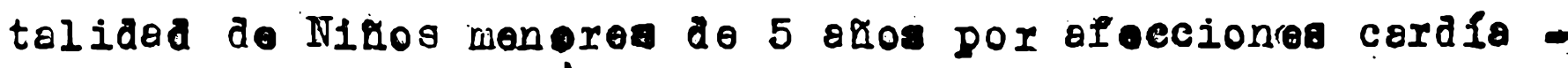
ces que se registra og la siguientes

Reumetismo aticular agudo ...... de 1 a 5 años ..13 caso Porica aitis aguda .............. 7 díag a 2 ". 5 " Tndocarditis crón1ce

(incluso afoccionea valvulares.. " 1 mes a 5 "..20 lijocarditia agudas ............... n 0 a 5 anos ..62 " Hiocaraitio crónica y aegenera ciones miocáraicas............. 1 ... 18 meses... 2 n Infermedader funcionales del corazon" 7 aĺa a 5 añogl4" Otras enfermededes del corazón.sta.

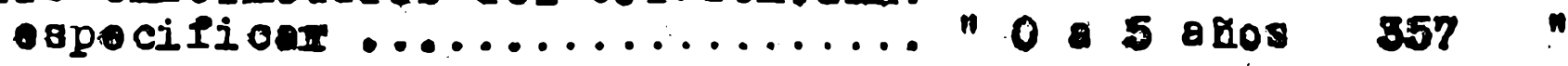
Indocerditis eguda............... 7 ales a 5 años 5 n

81 deducimos ol $90 \%$ de las cirres consignader de acuerco lo universalmente aceptode, com correoponaiento

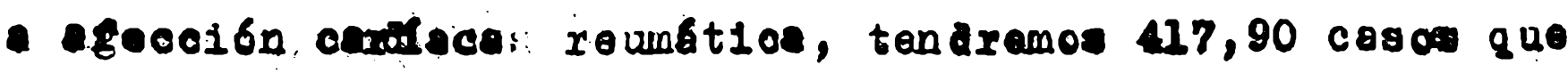
anmador los 13 casoi pe sigaran on el rótulo de Reana t1smo articular agudo, nos de an totol do 430 dofunolo nor porformoded roumbtice on nilos monoras do cinco

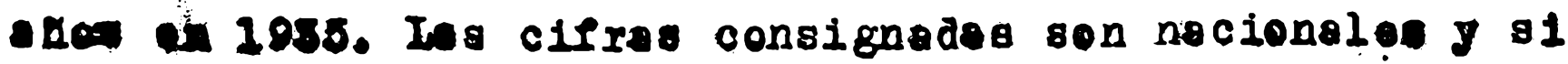
blen os meaton oeopter que puede hober errox on lo oprom 

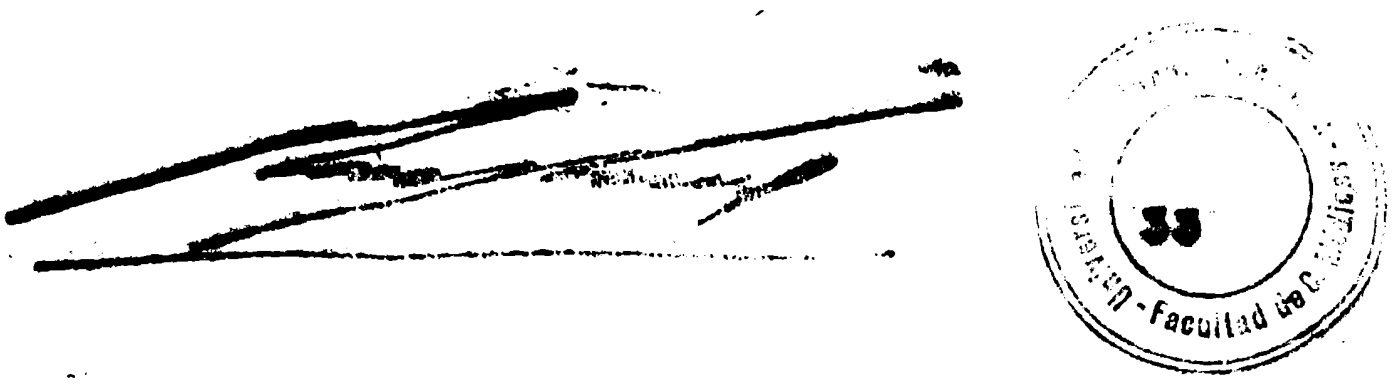

cieción dol motivo del fallocimionto del nixo, no luo.

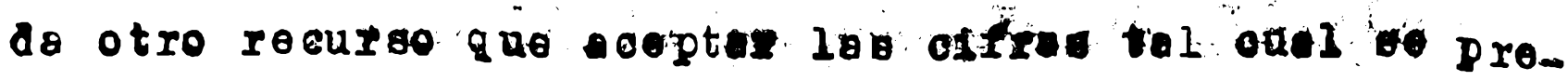
sentan y sacar do ollas el concopto fundamontal do la

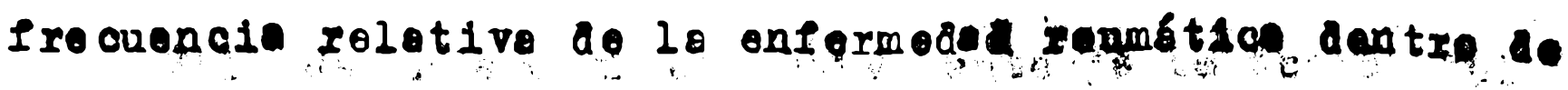

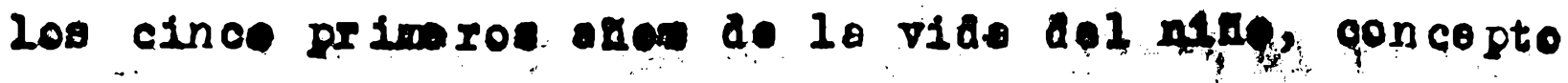
boste hace poce nogedo por Inveatigadored tan vereadoe. comon Norgnia. 

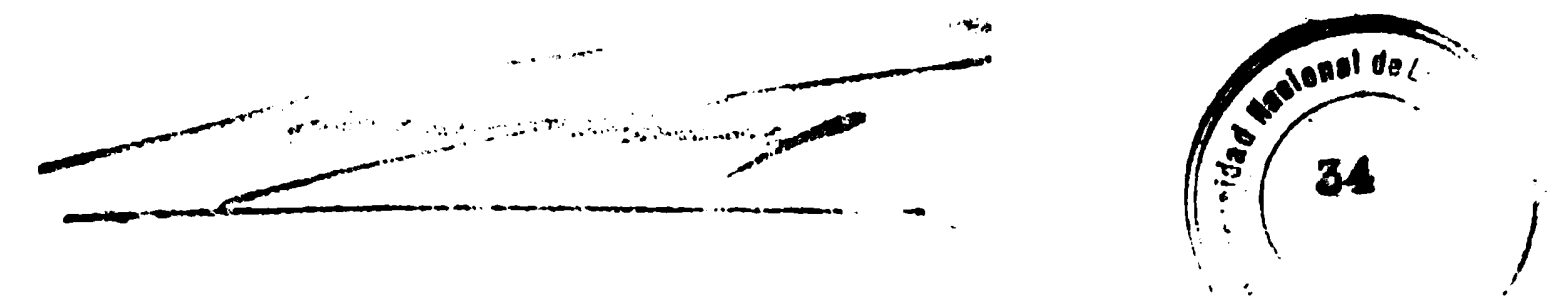

PROFITAXIS DE IAS CARDIOPATIAS RPUNATICAS

II 10 dopende cesi exclusivanente de lo accion del médico, yo que ostá vinculade airectamente al tratemionto $y$ va airiglda ovitex on lo posiblo las reciaives de 1. enfermedad, teniona como bases fundamentalea la cli noterapia y la quimioterapia.

\section{Clinoterapia. -}

Sin duda al guna la clinoterapia os el tratacionto de mayor eficecio pora prevenir o disuinuir los localizccionea corafacas que determina ol Roumatismo do Bonillaud. Il. reposo comploto y prolongado en cama, ha oido adoptado por todas las clinicas roumatologicas dol muna. J entro nosotroo goz de la mismo acoptación por sua rom galtados holagăenos. Ias investigaciones dé Band y Backett Jopp (1939), gobre 1.000 ninos rounticticos seguidos durante un perlode de 19 anos, pone de xelievél le bondad de estie netolis.

In 60 is de 100 onfermos on bocho ollnoterapio

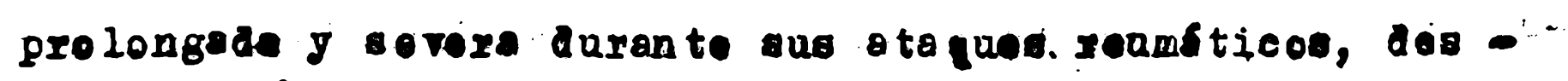
pue de 20 anoo do observación, lloven uno vida normal,

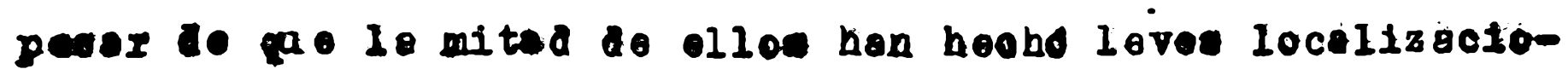

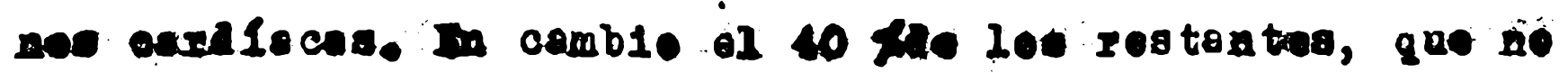

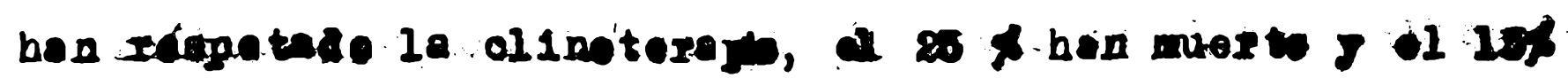

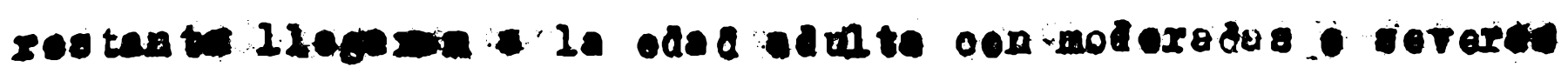
lad oner caralace y oimilex actividad flater. Il tiompo 

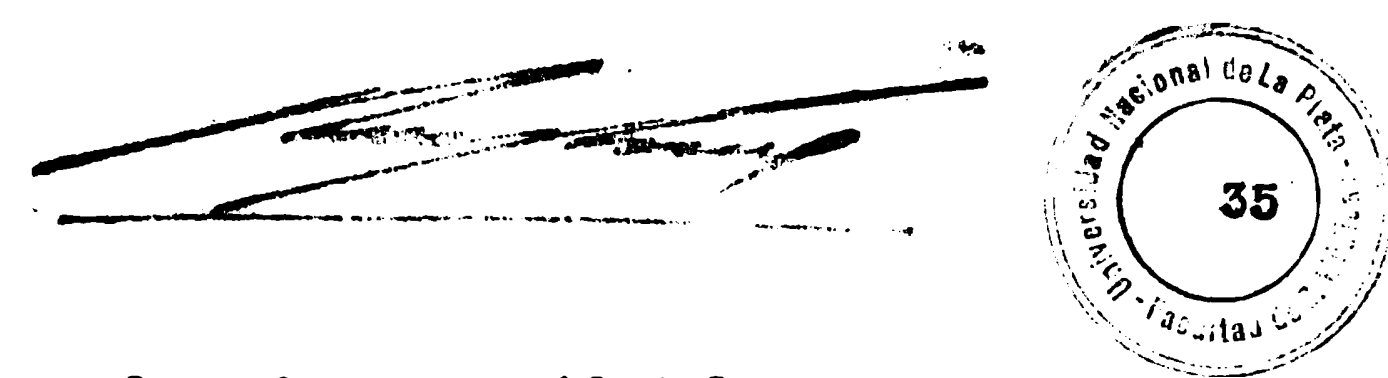

visa do acuerdo a lo intensida del reumatismo y presencia o no de localizacionos cardícos do 2 a 6 wo se8. Ademís de log síntomas de orden general coulo ser fiobro, adelgazamionto, palidez, taulcaraia, otc. que incican actividad del virus reumático y que son elomontos de juicio pera prolonger o ne el reposo en coma go controla la clinoterapio por lo orstrosodimontación, pruobo de le que no dobo proscindirso on al tratamion to racional do ostos enfermos. Cuando está muy aumentade la clinoterapia os de regla en forma absoluta. Guando en el curso del reumatismo apergce una ceraitis se debo ser más exigento - ún con la clineterapia. Iuego la movilización sorá hocha en lorma progresiva, por etapas, con ejercicios graduados d. marche, ote. Ios resultados obtenidos con osta disciplipa son altamente faporablea, desde que las estadisticas revelon que los ninos que las, cumplen estrictemente hacen un 50 menos de caraiopatía que los que no la cumplen cono ho nonciopado.

\section{Animinterenje.}

Dordo qua os to onformodad so lo consi=

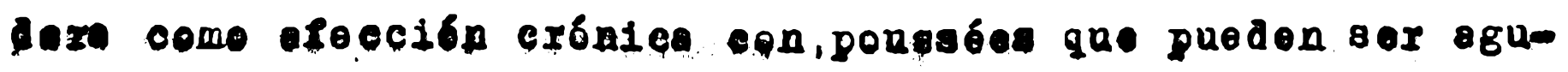

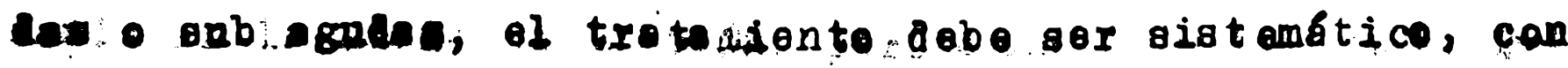

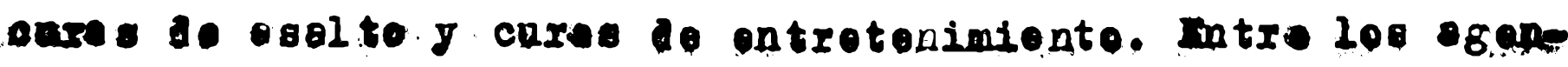

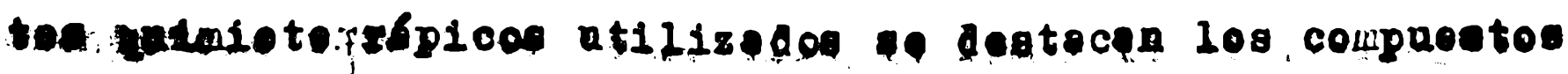

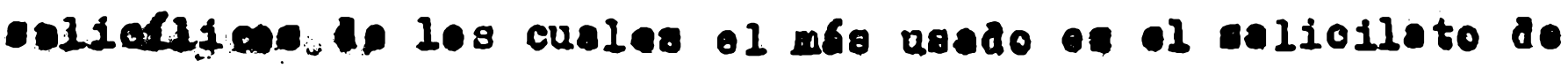

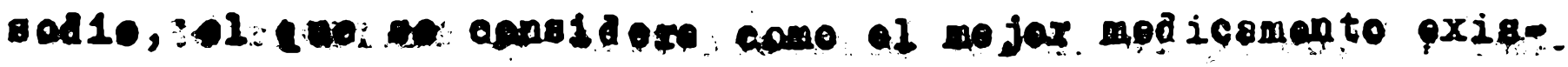




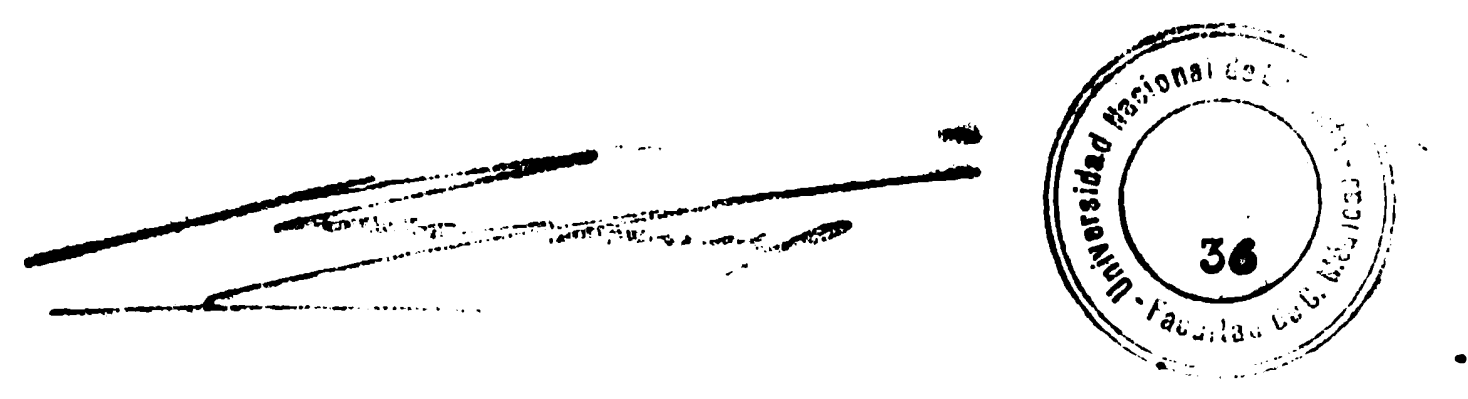

te.

Lo acción col salicilato do solo es rápida y oficaz activa on ocasiones de diagnósticos dudosos, como piadra de toqua (en la denominada prueba salicilada) dofiniondo siturciones a veces difíciles. La aroga debo ser pura. Ia dosificación y el ritmo de suministro bien precisade; os inocua para el organismo siempro qua so le asocio alcalinos (oarbonto de sodio a óxido de magnesio) doble de dosi para el primero, J mita del sefundo con relación a la dosir de salicilato de sodio J siempre que se cuento con buen rix6n.

Il tratolento "Standara" os el siguiente: desinfoccirn del rinofaringe con gotas gomenalos y tópicos de azul de motilono al 3 o dos vecos diariss, durante 20 dias; roposo Ilgarose on cama, salicilato do sodio 1 gramo por ax- do orad jor dia distribuldos en intervalos de 3 ho ras (ara J nocho); iny ección de 1 gramo do salicila to do sodio intrauugcalar por día. Si la clínica nos revela un proceso grave, en lugar do una injocoión do 1 gramo hare. nos doe, con intervalos de 12 horas. Fete desid par via orel - intramacular, la mantonomos duranto 10 días despa6e de of te plaze continuaramos el tratomiento por vio orei con la mism medicación, paro deacendiendo progrealivamento de 1 gramo de salicilo to de sodio cado 8 afa j haciendecoon intervalo do 10 ala un gramo intramusculer 2 a las iqguiaca.

se vigilare lo exitrocedimentacion, el puiso, la tóm 


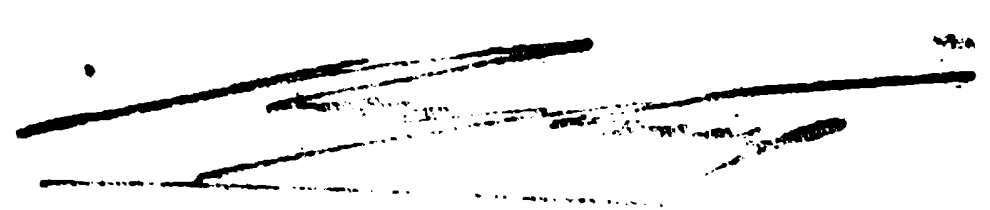

poratura, funcionawionto ronal, ol regimen alotético opropiado y ol estado cardíco por la clínica le eloctrocor.diografia y la telerradiograpla. Fsto durante semanis hasta que lo wejorio del onformito permito aisminuir la do sio hasta un gramo do salicilato por día duranto los áltimos jcho dís. Sista cura la continuarb on ou dowicilio, vigilando desdo el dispensario, que ge lo administro 3 fro wos aiarios duronte 10 dlos consecutivos en cado mes, vigilando le eritrosedimentación cad 30 días y su estado cardíaco dos vecei por mes.

Fata técnica en caso à preântar caráópatia dúra alredodor do 2 año o más tiompo. cago de intolerancio al salicilato, se ha utilizado con buen éxito la ingulimoterapia a la ảosio do 10 unidador 2 vocos al dí, asociada al auero glucosada, al Glucolín o Dextropar. Como morĩionte del salicilato cuajo oste no actúa, se utilize con roacitado favorable la protoinoterapia (loche) esociade, If odicilate on formo do enteroclisis, on considere que dobo practicara on los cesor de roumatiomo agudo intenoo, atilizanăo lo solución isotónica al 23,20 bo on dogio de un gramo por azo do oda J pat dia, durente, doo o trea alas. pare continan luego al suminigtro del oelifasleto por via -rel. In el nigo la aplicación do oete matode tiono ono in-

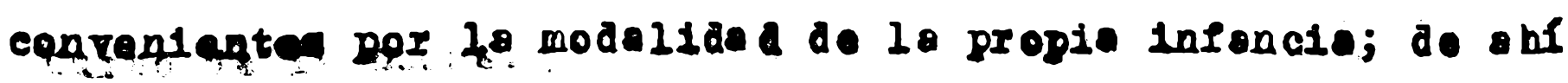

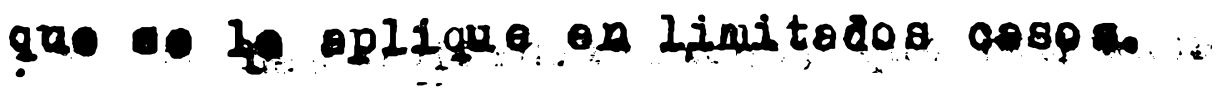

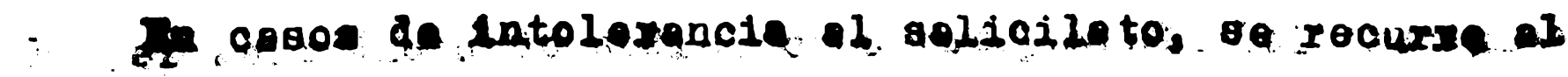

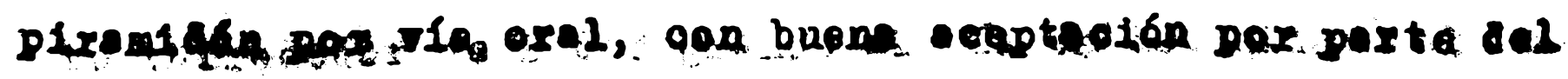




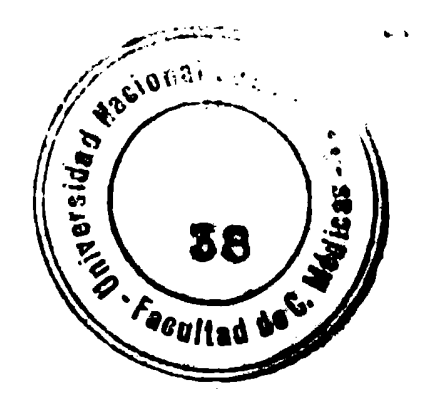

enfermo $f$ - la dosi do hasto dos gramor par alo.

In goneral, las artralgios, la Piobro, otc.; noooden con 18 rapider que se obtione con el gelicilato de solio, do ahi el universel ontasiarmo por osta aroga, que so consicara por el momento como lo móa eficar. Il pirani aón, por otra parte expone al enfermo la egranulocitosis.

In ol adulto, aceptan la casi totalidad do los avo tores, como dosig meäi do 1 a 14 gramos en 1 as 24 boras distribuía cada 3 hora, dia y nocho por vía oral

In la practica so suolo reforzar la dosis con infococione ondovenosas, en la cantida de 1 a 2 gramos. Autores de la jererquia de Ruiz lioreno, aconsejan no utilizar con excesiva Irecuencia egta última vía por la esclerosto que en las venas determina el salicilato, además do crearlo innecosario, ya que sostiono que bien a aministrado el salicilato de sodio no da reacciones de intolerancia. Contrariamente a lo que oqurre on el nifo, on ol adulto, 10 onteroclisis con la solución isotónica do selicilato de oodio al 23,20 foo, os ao aplicacion sumomente fácll, al.

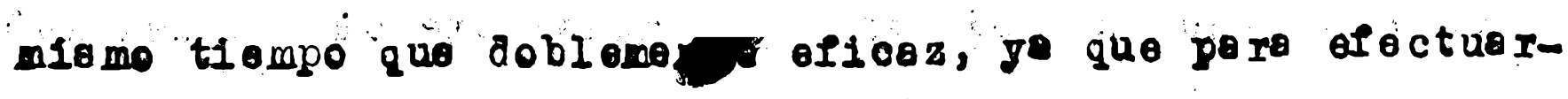
10, neceseriomente el paciente dob guardar reposo aboola-

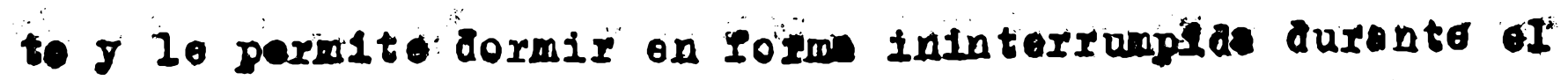
ourat to Is nocho.

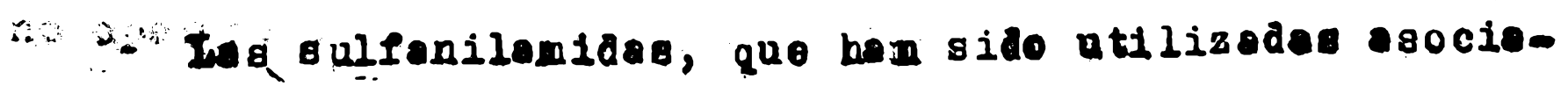

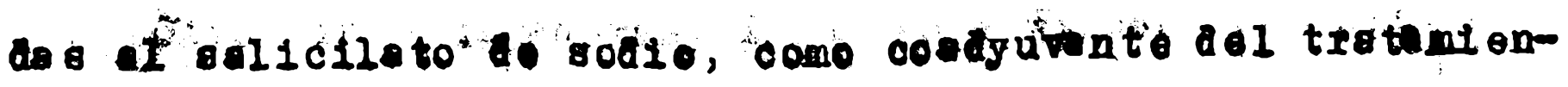

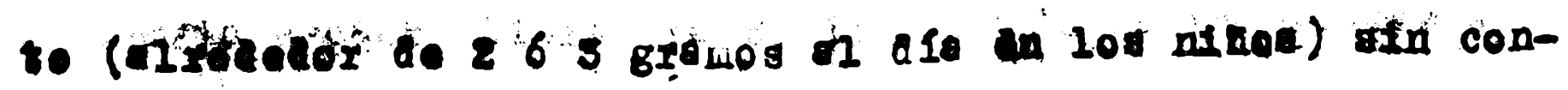



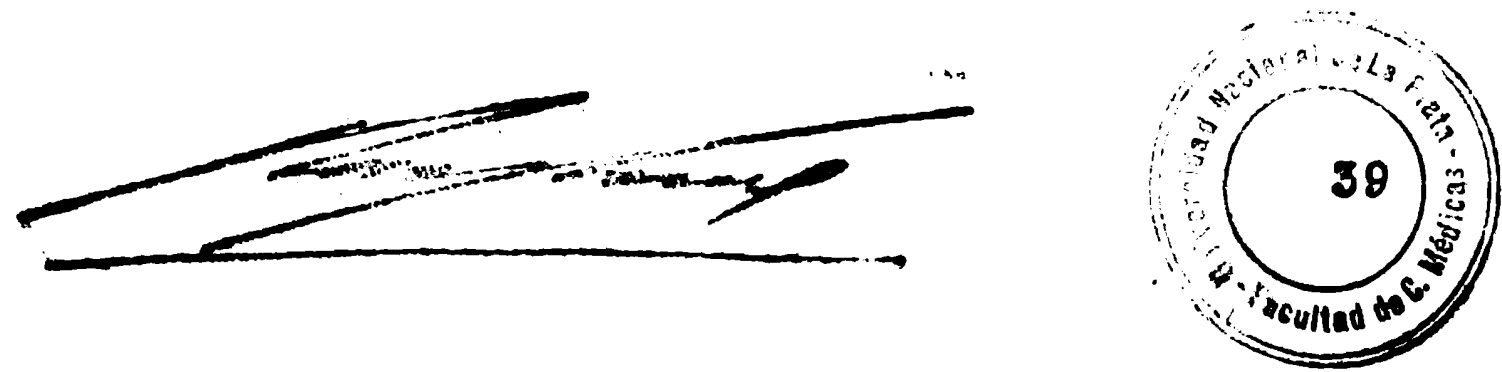

seguir boneficios ostonsiblea han sido aiandonodos.

\section{Infocciones focelos.-}

II concop to de la participación do. los focos sépticos, on espocial los amigalinor y faríngeos tieno amplie acoptación en Clínica Roum tológice aosdo beco muchos años atrás. Istuajos exporimontelos do diá yer y las investigeciones de Devio y Curxman, Folbora, eto., J entre nosotros las de Castex y 80 escuele están acor :des on le intervención de estos focos séptioos on lo othopatogenia de esta enfermodad.

Para Loe, Moe g Worms, de acuerdo a sue Invostigacipnes, nilos oporados do oug arigdalos despué do sp pramax taque de Fiobre Reamstice, roducen sus reciäivas a más àl 90 \%; on cambio 108 nitros reumbticos operadog terdamente oolo oo bonofician on un 20 \% Foiser invertige lo oblación a las anjgalas y vegotecioner adenoideas sobro la frecuencio al reunetiomo.

Sotablece que en 20,000 nix́os operedor, la erecuencio ael renmetismo era monor an un terclo, on relación a los niloos no operado que fueron 28.000; al mismo tiempo obserm io que 100 operadoe que hicieron poeteriormente reunetiomo, - cusaron un 50 s menos caraiogetiog que en los rounbticos ne operedor.

Otros Invertigadores, Ingerman $\mathrm{y}$.4280n, oneuentran

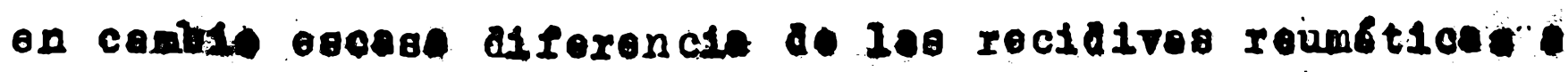

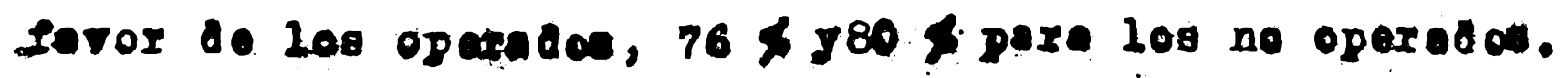




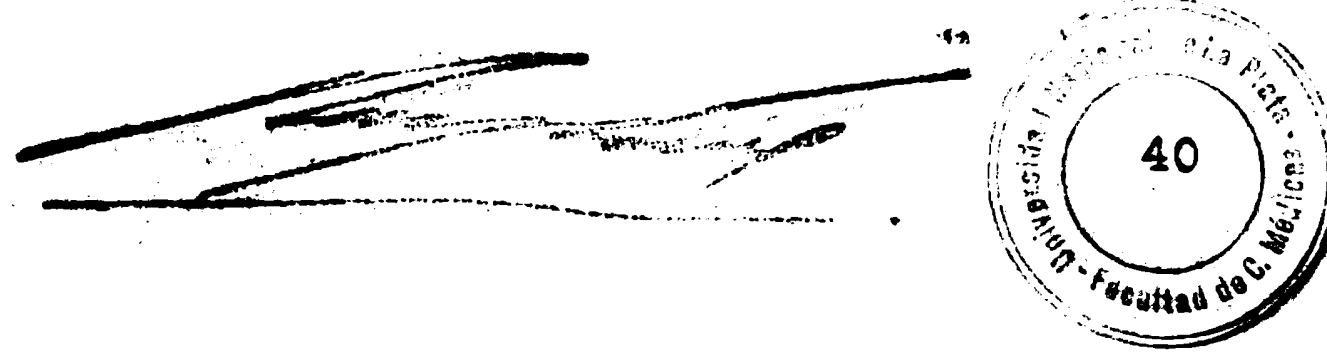

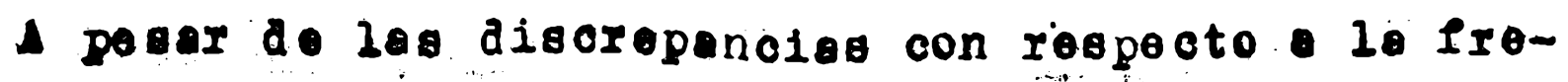
cuencia do las rocidivas roumbtica, goghn so opero o no, ia tenancia general os ocoptar que so dobo extirpar todo

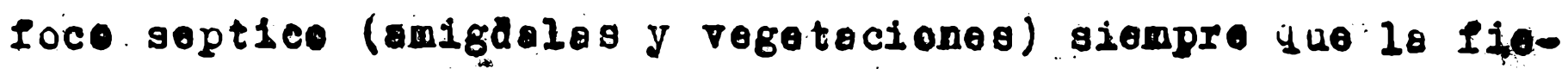
bro roumatice no so oncuentra on ativided clinice $y$ humorol, valo docir, con oritroseấimontación normel: 

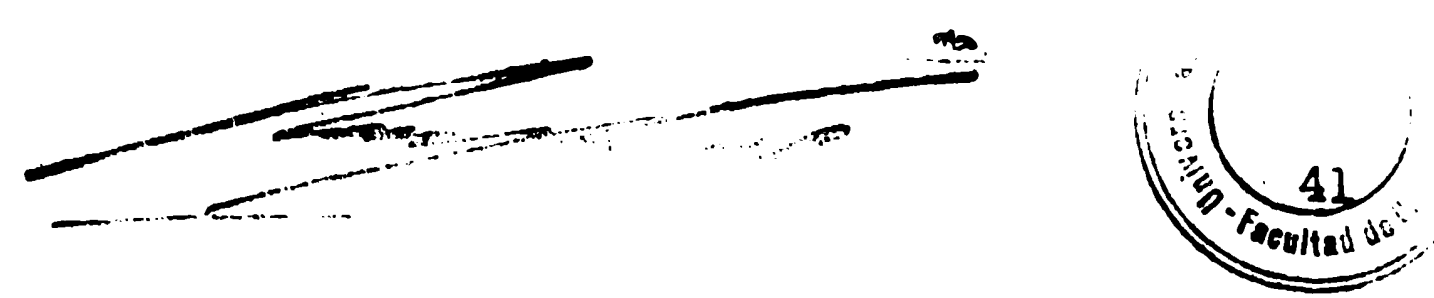

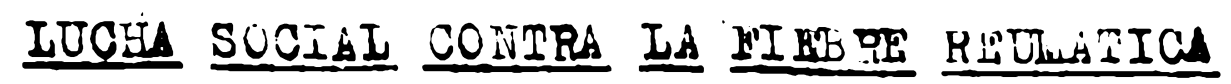

\section{intecedentes histöricos.-}

Is a pertir do principios de oste siflo que en Inglaterra y ristados uniros la proocupo aión ze los investieadores oncuentru oco on log orenis Los estateles, crećnaose una serie de instituciones destinudés a prestar umparo y cuidados al carríaco.

In Fstados Unicios, en 191z, os fundada le priciera clínice cardíce para adultos en la ciucad do Nuova Yor: y li a riberas para nifios en 1915. In Inglaterra, a par tir de los riscios arios, se han he cho progresos notablos c pensas de su ox janización nacional. Fn Francia, ol almo de la woderne organizáción de le lucha cintra las carâiopatías fú Vaquaz. Es tanbién en gren parte, gracias a su entusiasmo y dedicación a estos probleves cue se han orcanizado en otras jartes del luando y en nuestro pels, sefín veromos Lás adelonte disponserios, nospitaIo: a Institutos. In 1929 fundó en Parls n'laide uax Cardiagues" la que he realizado uno obre importante dentro do su finalidad espocffica.

Takibión por esa época el profosor liau fuña "L'esio ciation Amicalo des Caraiaques" que ba lescruila?o una

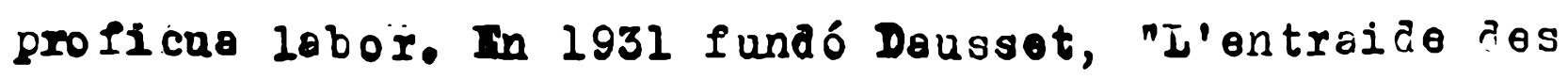

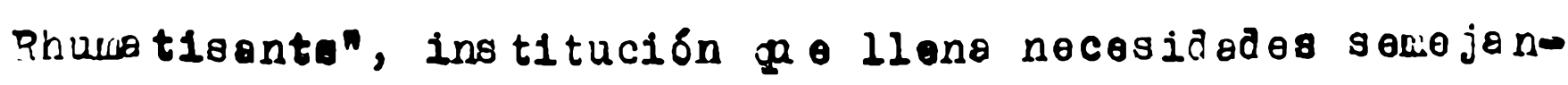
tog a los onteriores. In 20 Ropúulice Argentina los Dres. Liscere y Costo Borteni habilitan en Agosto de 1932 un con- 

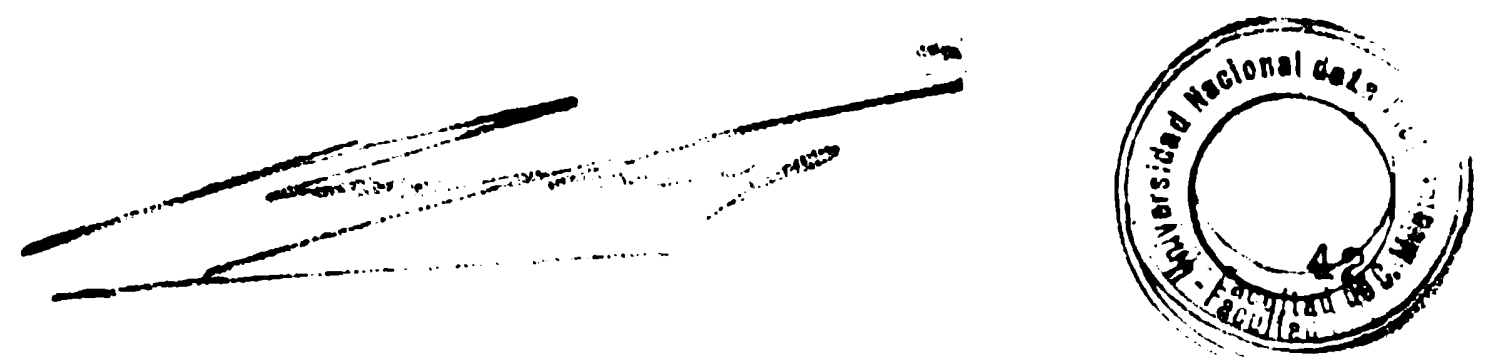

sultorio do Rouratologla y vardiologio que furciorie degia egr fecha.

\section{ORGANI'ACION DE LA LUUEA BN RL EXTKAIUURO}

Io lucha ontirrouricitice on Inglate rra cuenta en su organizución con los casos de convalo concia y las oscuelas pare nirus reuiláticos y cerdiocos que junto con los coistros de diagnóstico y tratamiento de la Cruz Roja Británica, dew en sa tonicos cowo modelo

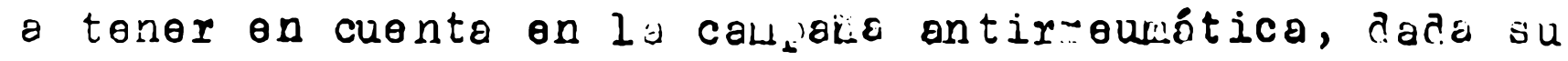
perfecta organización. In los suburbios de Ionares, funcionan los Huspitalos de Cershalton y de Fost Ticknow, yo ost an regervados a los niros reumaticos, contendo 400 camas el prírero y 80 el sogundo. Cuando salen de los hos: tales generales aquellog que tienen lesiones cerálacas principelmente, son sometidos a un reposo prolongado en condicioner excepcionalmente Lavorabler de clima, erea cion, soleamiento $\mathrm{j}$ alimentacion. 1 emás ge ban tomado to- 

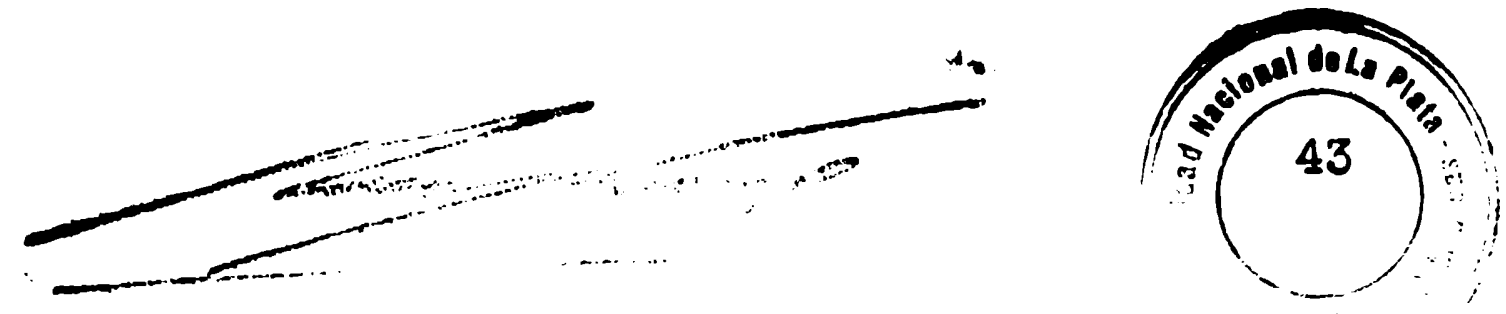

das las disposicionos para iue puodan pasar cuatro, seis mesos o más, pudiendo all1 mismo continuar sus egtudios. Toalía al abajaonar eitog esta lecilientos, se les dace jeir alounas gei..enas en una cagu ie convaleciontes a orilles del war y hecen una últilie ostedia de ocho a quince

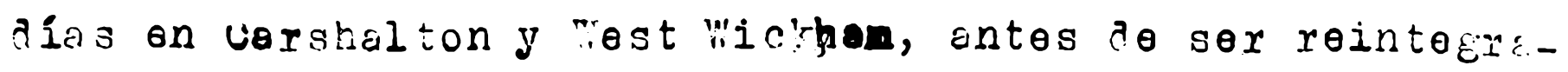
$\Rightarrow \partial: \xi$ sus hocares. Degpués son vi ils dos turante largo tien o luediante visitas regulareg on su casa o en los consilturios hospitalorios. Las condiciones de habitación is los nifios hospitalizados sont oujeto de encuostas particulares y en lo posible los defectos que se congtatan son reliediadus. A su salida de los haspitales especiales los nî́os son dirigidos a las escuelag que tiás le conviene en relación a sug posibilidades. Is unicad de comando y una cooraineción perfecta, asefuran el rendiwiento es ieredo.

In Fot ados Unidog, condo fueron fundados por price ro vez oxisten casas तo consalocencia similarea dostińn dose une coma de convolecientes de rematisuo corílaco para cada 100. v0 habituntes de las grandes ciudades.

In cuanto a los escuelar especiales para nirios reuLéticos or ae haoor notar que es on Ingloterra, y ristacos Unidos a ona exigten, teniondo entro sus ceracterloticas

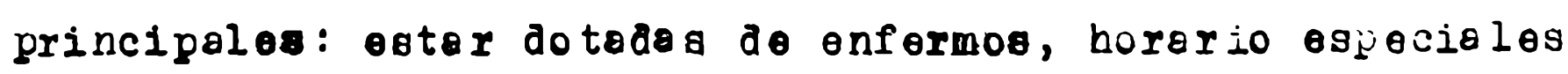

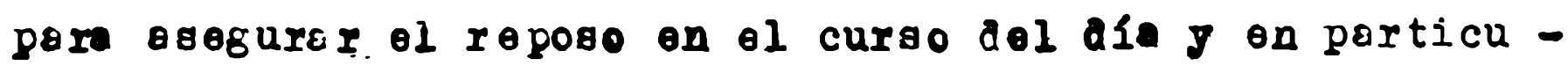
lar despues de 188 comider, supresión de las escoleras, etc

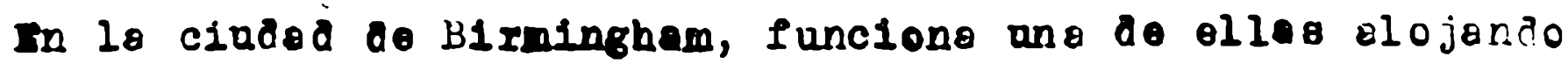



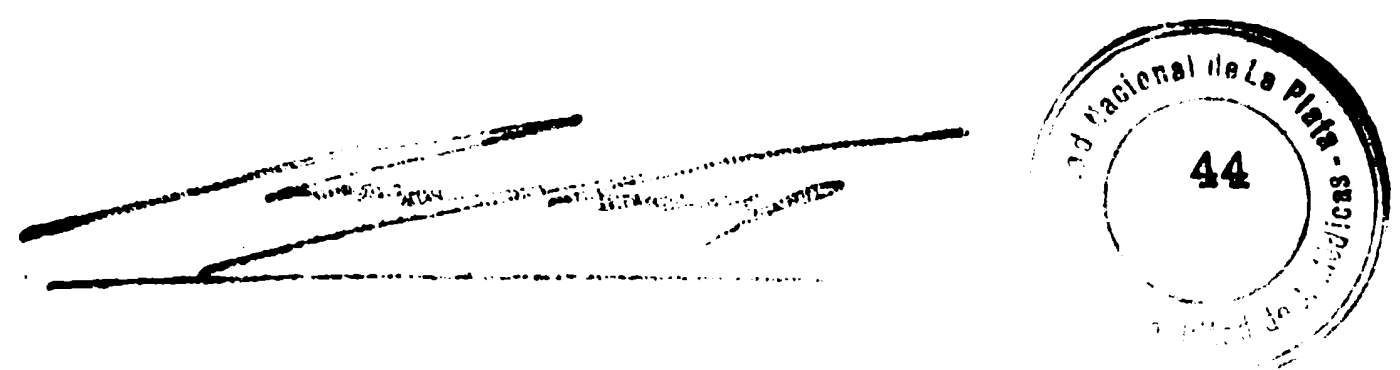

90 alumnos reperticos en cuetro divisiones de acuerdo

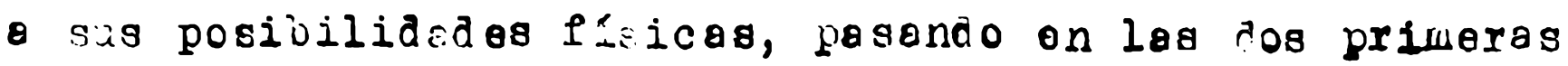
casi todo el dio obro reposeras, pera ir luego $\varepsilon$ les siguientes a vedici que su estado mejora. se destine ur buestro por cada 25 nirios, habiand 4 zo norag do curso IOS soliont.

in inilo desco 1909, data une ley de Prevención do las varaiopetías, Luoorculosid y sifilio por esta hay se giigo a todos los vonoficiarios de las lajas re Provi-

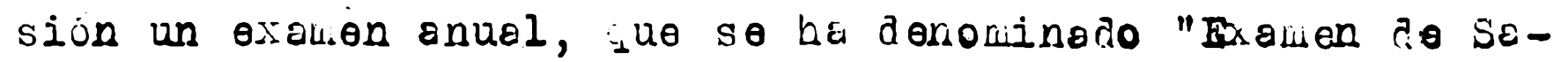
luan que consta ce une revisión sowera tenciente a ros star las sfecciones enumeradas. Los casos pusitivis peis un rupo de jéaicos ejecialistes para su tratawiorto.ji el incividuo estuviese seno, quedan consignados sus enteco dentos on una ficha ospeciel que so archiva naste el proxwo exalion anuel.

Los enfermos aparte de las medièas terapéuticas Jzan de un "Subsidio reposo" en clime apropiodo si se creyere necesario o bien en su doraicilio. Fl "subsiaio rososo" significa la mintonción col galario íntegro curcute el tielupo conveniente. Todas estas medidas son estuciadas y a aptados por la Comisión de holicina Preventiva, coll puesta de un Presidente, Secretario $\mathbf{g}$ tres wécicos: un caraibloco, un tisiólogo y un sifilólogo que juzgen en su: respectivas espocialidadea. Fquipos asl, se hallan instalk dos on la principalos ciudados dol pals. Para ol wodio rurel e日 cuente con equipos wotorizados provistos desde Bagog $X$ a laboratorio, que bacen el "examon do salua". 

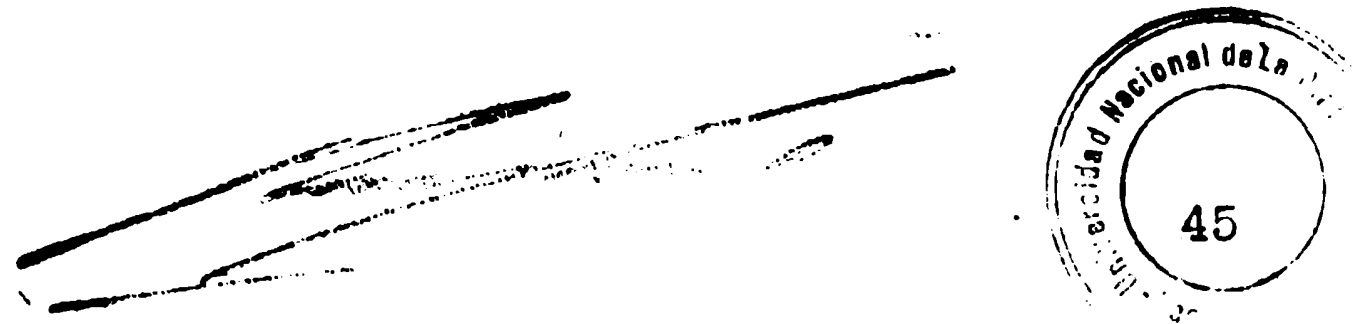

In lo concerniente a Cardioloela, el"eyou de salud" cou:rande: o) oxalion físico y gotore higtorio clínice, in cl kio detoruineción de la tensión orterial; b) rariosco -

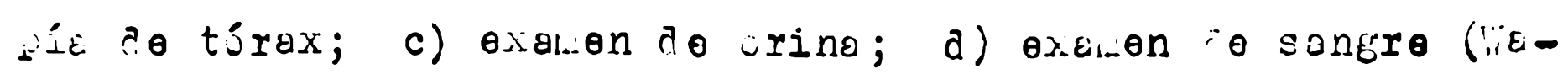
siorwenn $\mathrm{y}$ Than). Cuelquier al teración sospechose ze afec ción coríocirculaturia, aeterina el envio del paciente

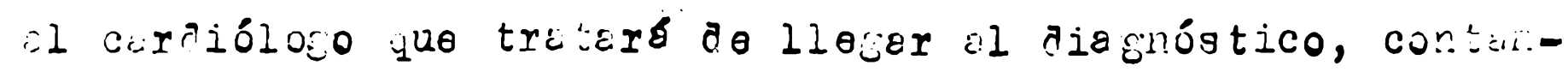

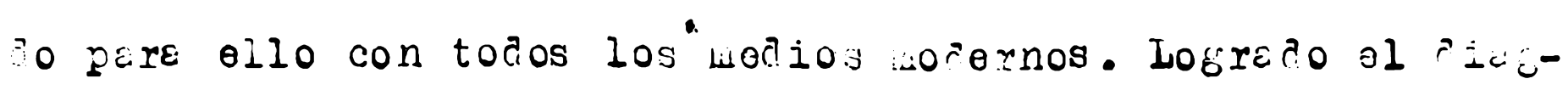

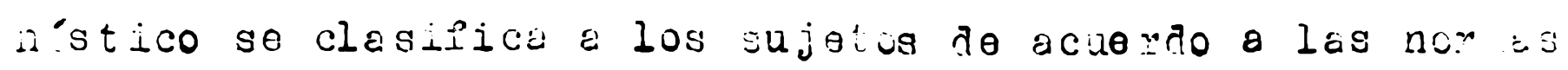
$\therefore$ li duerican rieart association: 1) faformos corriocir -

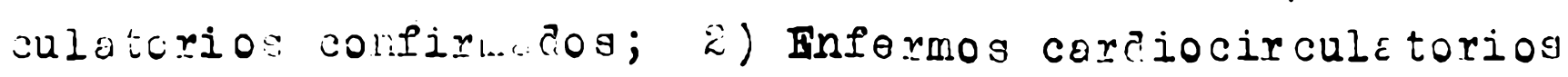

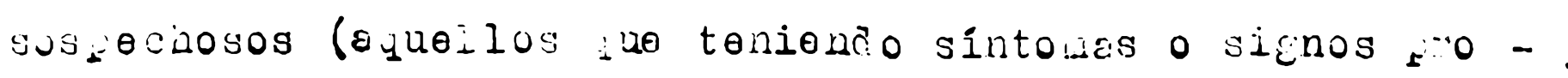

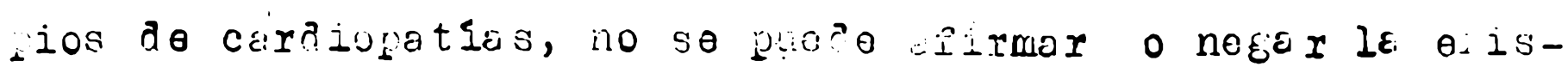
tencia do una caraiopatía aeterkinada). Después ea un je ríco de observación se los de de elte o se lo incluyo on el crupo anterior 3) Finferwos prodispues tos (aguellos iue no toniendo ningún síntoma do afocción caraiovascular icece-

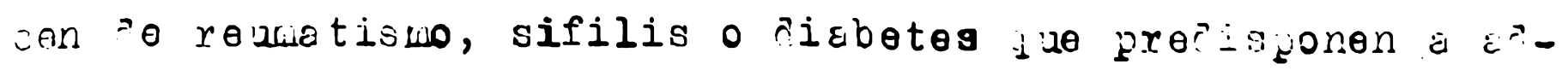
dirirlaj.

Ios enfermos del grupo 1, son aividiaos en: a) a.uollos the a pegar de su enferneda pueden deserrollar on buonas conaicionea su travajo; b) los quo ofoctúan su treivio con jequeras linita.ioner; c) los ue trabajan con grindos limitacioner; a) los jue estón imposibilitados çe realizar cuslquier trebajo por sencillo que rea.

In ostos cuatro sub grupos, la Lej do liod cina Froventive oo oplica plenawente. Ios enfermos gozen तel subsicio 

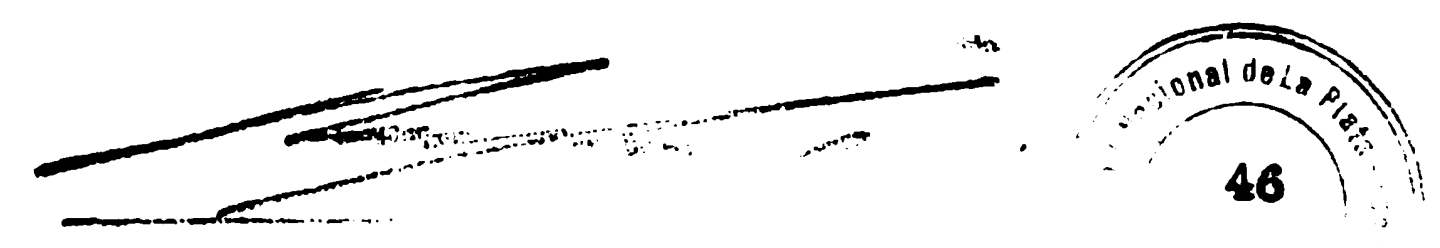

reposo" durante un tiezpo prirenctal en su boser o en 1. unes de las "casas de reposo" con ine se cuente a $t$ l. Pin. Si se efectúr on el dolicilio del enferio, el wéđico prescribe un tratemiento y le indica alo y rora pare seruir su evolucion, mientras una visitadora especialisada controlo la correcto roalización do lag proscripciones ordanades duranto las visitas peribaicas a douiciIio.

Si el enformo p.isenta alcuna exavodad os hospitolingão o traslado a les"casas de reposo" dirigiea por un carcióloro y dotade de todo 10 necesario para tratar es $t E S$ afeccioner.

Le duración de le hospitelizs ción en estas casas es verieble de acuerâo el caso, despús de lo cual se le reinterre al trabejo si este es compatiile con sil cojuciतed funcional. In el caso de no serlo, oowo sucede con tanto frecuencia, el Servicio socinl es el oncargado io bus cerle otro lio se halle te acuerdo con las postbilicades तูel enfermo.

In el Policlínico Varaiológico del Valperaiso, se nan organizado centros do Roadaptación do Caralacos clinicalente recuperador, a quienos go las enselio una ocapación sencillo ju no decante major esfuerzo.

Iog individaos recuperados viren permenentemente bajo viglancia mólico para ovitar on lo posible las Irocuentes agravecioner. Ios 1rrecuperablos, al ser doclaredos tan 108, no puodon gozer del beneficio de esto Iaj, dobiendo 

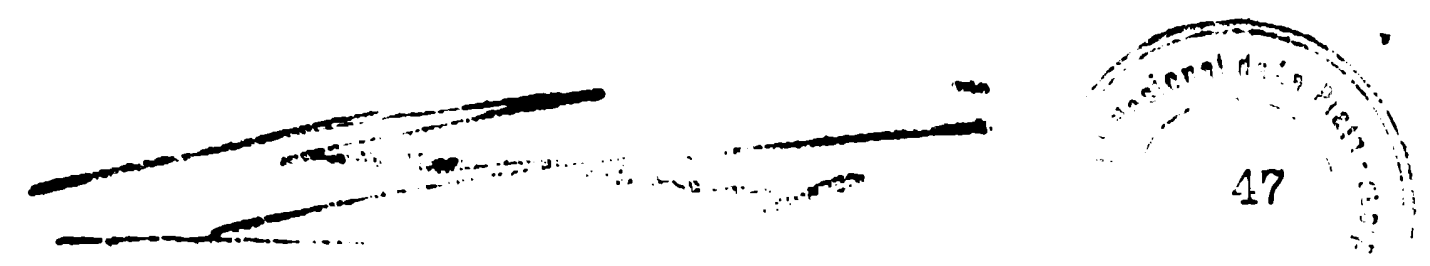

Ecozergo a la disposicioner provistag para estas oven tuglidedor. La venteja de ostos servicios eg lo unifor-ifid de orocnie ción en todo el pals, tanto adwinistraiive colo cientificalento; el criterio diafnóstico y te-

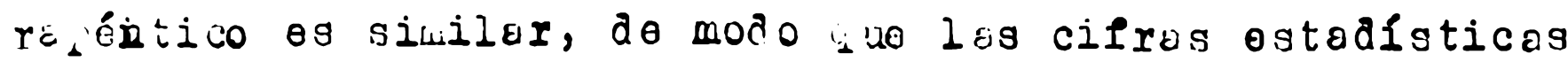
son co: pemciles antre si, con lo cue es posible establecer I6 íversicad de frecuencio de egtas afoccionos on las $\therefore$ stintas rojionos iel pels. il colonter detaliadaünto ic Loy Uilena de Provención do lus vardiopatias, he pra-

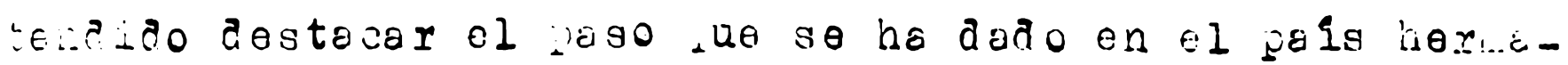
no iccia une trojor solución del proulewa que las enfer -

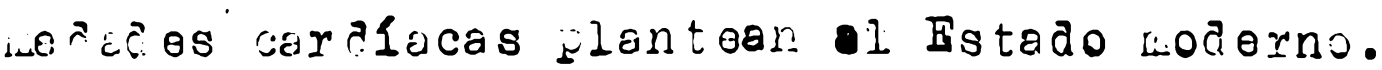

In el Uruguay, la lacia contra las carictopatias red-

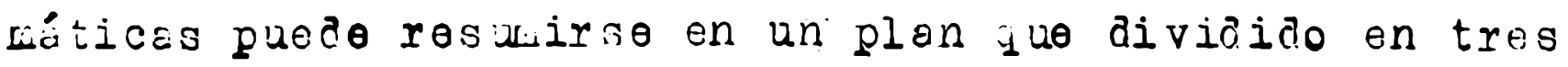
ertes contepla los as actos carainales żel problelua wé àico social ize làs wist..as involucran.

La primera parte jue titularemos de Bnselianza P.pular cowpende: 1) Distribución profusa re cartillas ?o projacanda; 2) Conferencias yue se propalan por radiotelefonta en forka de ciclos; 3) Publicaciones perió àcas en la prensa; 4) Conferencias en lugarea públicos; 5) Colocación je letreros $\boldsymbol{y}$ marales. Io segunda parte tonominada de Colaboración oficial, comprende: 1) Obtención

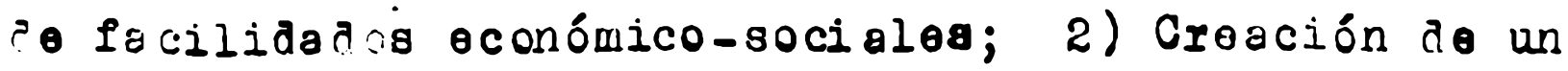
Centro Antirroulético caraiológico infantil; 3) Craación de sala para nlios con caraiopatlas reuwáticar; 4) dmplia. ción y porfoccionamionto de la Policlinica Cardiológlca (local,personel, útiler, etc.). 


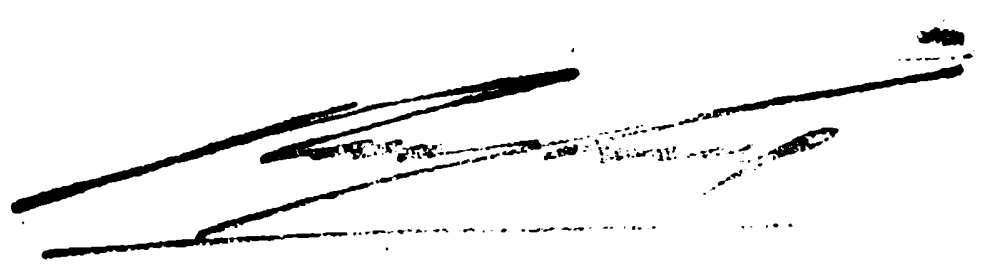

48

Wo tercera parto ael plan titulodo: Insedanza lídica, propugnar 1) Dirección especial del estudio de la In formeda de boutllaua, en la racultad de irodicina; 2) Cursos especiales los ostudientes de liedicina, odontologlo farmacia, obstotricia, nurses, visitadoras, y enferwes; 3) liantener la atención de los méricos distribajendoles 100 datos clínicos estadisticos de interés, sobre la knferme dad do Bouillaua. 

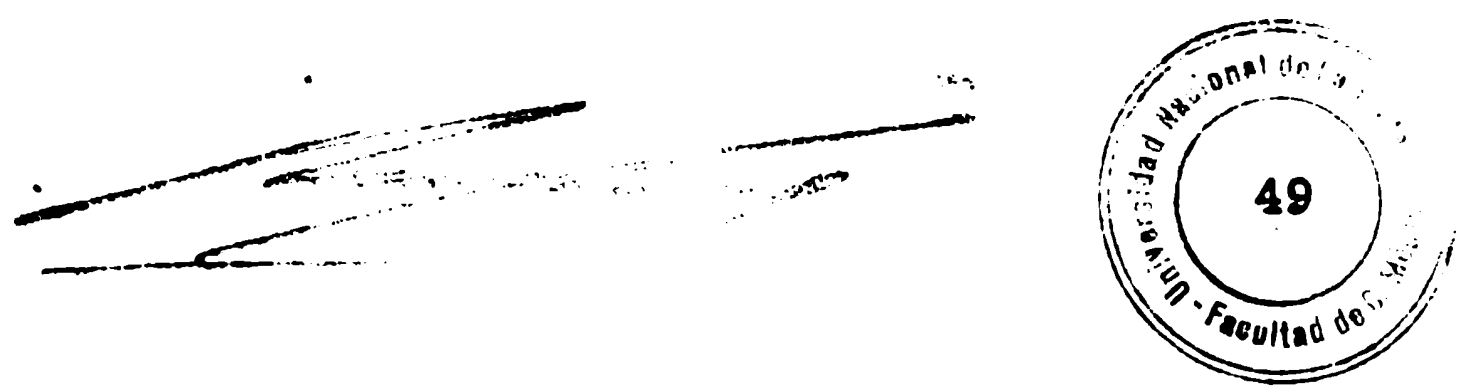

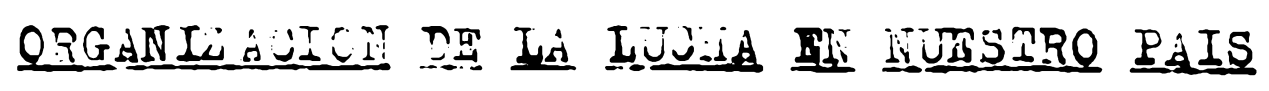

La lucha wedico-social contra la fiebre reumética - las cardiopatías por ella determinadas he tenido on la Repáblica Arentine entusiastas y compotentes propuisores. Ios Dres. José M. kacera y Guido Costa Lertani, habil-turon en Agosto de 1932 un coisultorio de Peunatología $\mathrm{y}$ Cerdioloria que funciona dosta entences. Iuego en abril de 1934 el sexior loste Bertani presentó un proyecto socre Profilaxis del Reuliat ismo que fué aceptado, propicianco el bteneo ze dicho consultorio la realización तe Jornaras Liédicos Reumáticas que se realizaron en 1935. Fueron confeccionados adeliés, cartillas con consejos, cono asi tenbién se difundieron pülicaciones sobre la importancia del rasmatismo en el niño, couo la del Dr. Rodolfo Rey sumay. A continuación fú creada la liga entirrejuatica. Y cesi simultáneanente, es creado por la Iey 12.30c0 el lentro Antirroumbtico de la ra ulted de wodic ine de Buenos aires. Il projecto de ley Lué presentado on 1935 por los Dres. Jos6 Arco, y rauráo Brauden y promulgado on sotiombre de 1936; esté on f́uncionawien to desde maxo de 1937, sionço dir ifido por el Dr. Anfbal Rulz lioreno.

Il proferor Dx. Rafael Eullrich os el iniciador y propulsor do ia "Ayuda ol Caralaco" organización yu con 108 mlitiples dispensarios que dispone comalmante presta uno importante y ofica ayuda on la lucho contro las car- 

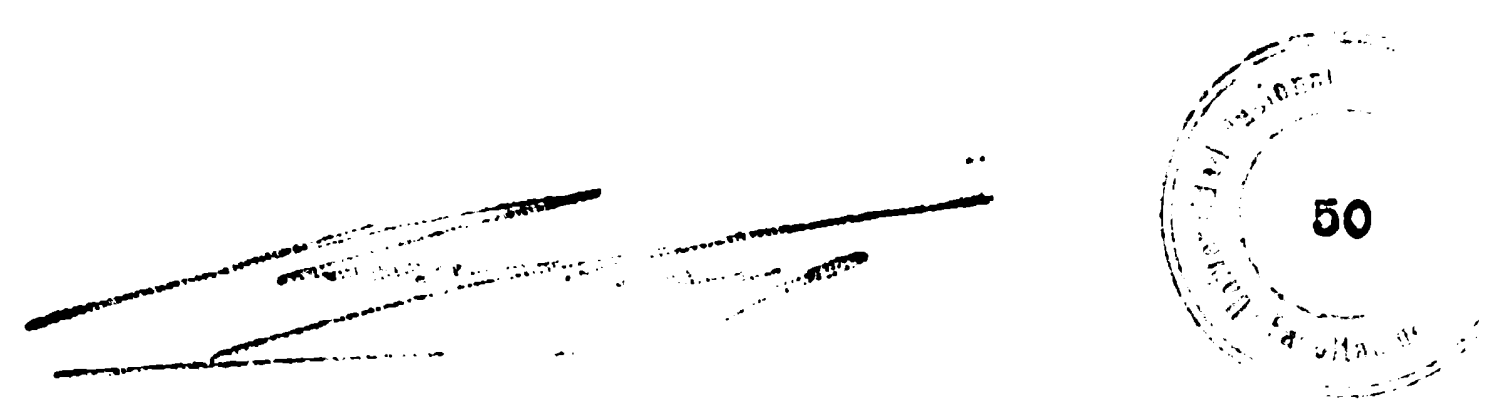

diopetios. Ir lucha so completa on le ciudad do bugnos a iroa con congultorios do jouratismo y de cardiolosia anexos a las séles de ulínica Médice on cagt todos log Hospitalos municipalos y privados.

Ia organización de Ajuda al varalaco, en el litoral irgentino, oficiolizada por la facultad do liodicino तel Iitoral meáiante ol Dispensario que iunciona en la cáterra de Clínica véaica ael profesor staffieri bajo la lizrección del Dr. Iuis bionzárez Sabathié, llova curpliáa unc i.portante y fecuna labor.

Io misko cabo decir del consultorio de Infermeda des Reuréticas y jarááacas que funciona desđe 1939 en 10 cáter ra de línica Pediátrica y Puericultura del Profesor J. R. Recalde cuestas.

Por lo que llevamos dicho; vemos que entre nosotros la actualización del problema médico social de la liebre reinbtica, reconoce una antigüedad muy limitada. In el lapso de unos pocos anos so han hecho pues grandes progresos lo que es justicia destacarlo. Conenzando por combatir la ignorancie del público respecto a la gravedad del reuratismo poliarticular agudo, apercibiendo a los parres de lo invalidoz que significa una localización caríraca de la enferrodad reuútica, educándolos sobre la ituportancia de reconocer los pequeloos olntomar: aolores articuleres ligoror que on detorminada ocasiones acusan sus bijos g - los pe no 80 les atribuye ningune trascendencio, doloroo mascalorea, anginos fobriles, otc. So ba tomado on 


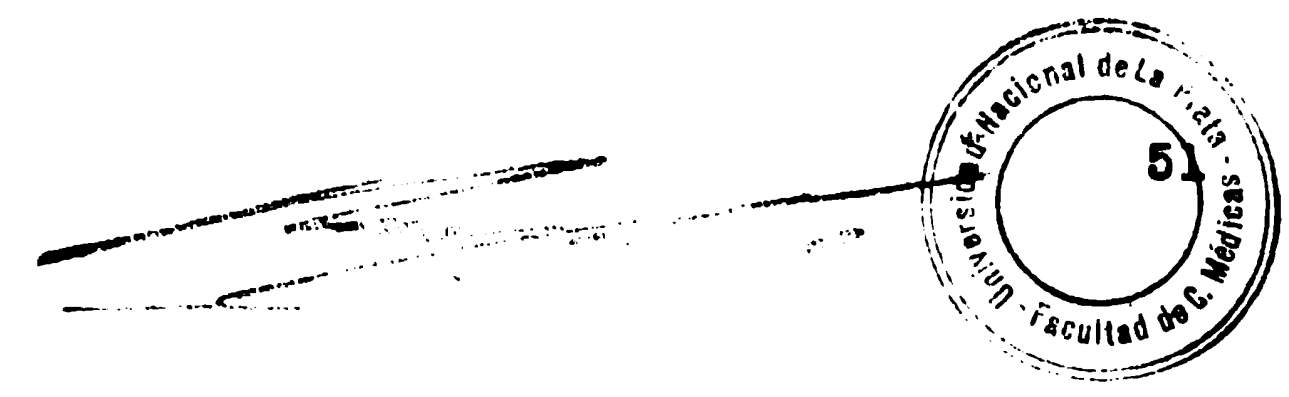

cuente definitivamento, la lificultad que entrana uno observación prolija y un tratamionto adocuado do ostos onIer!os en los consultorios externos de hospitales ceneralos, siempre muy concurríos y con esceso personal para su asistencia. De la consiaración de estos proilecras en tode su profunaiaa y extensión; frocuencia ael reumatisno con sus localizaciones cardíacas proporcionando gran número de ničos lisiacos; ignorancia del pueblo de la trascenảencia do los pegu oños síntomas y la irsposibiliảa de jetener el mal $\boldsymbol{y}$ combatir eficazwente sug efoctos degristrosos en los servicios de clínica coneral, ha surgido en nues ro peis, ese magnefico boviciento de protección y oú

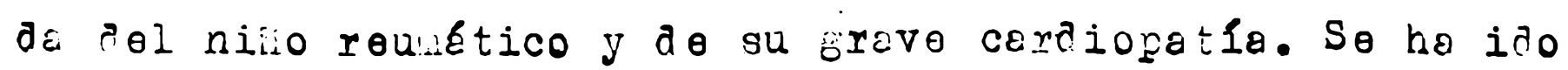
rocofiendo la expriencia y los edelantos de los palsos que rarchan a la cabeza de las conquistas kédico-suciales J en la weaida de nuesiras posibilidados, so las va incur- oranco a nuestro merio. Se contewpla lé lucha en todos los frentes y crean centros y aispensariog a cuyos consultorios concurren tan golo reunáticos y cardiovasalaros. Desdo el punto de vista de la profilaxis, so ilustro al público Lodiante conferencias radiales, como las qua euspiciedas jor la Sección "Infermodados Socialean, fueron propaladas on la ciuiad de la Plato de abril a junio de 1946; se dan conIerencias on tiblioteces, clubes do barrios suburbanos; so fublican articülos en los perióticos, affichos muralos, foIletor, otc. insistiena sobre: a) graveda a le enferciesea reumética; b) Importancia de consiltar por los más poquexos 

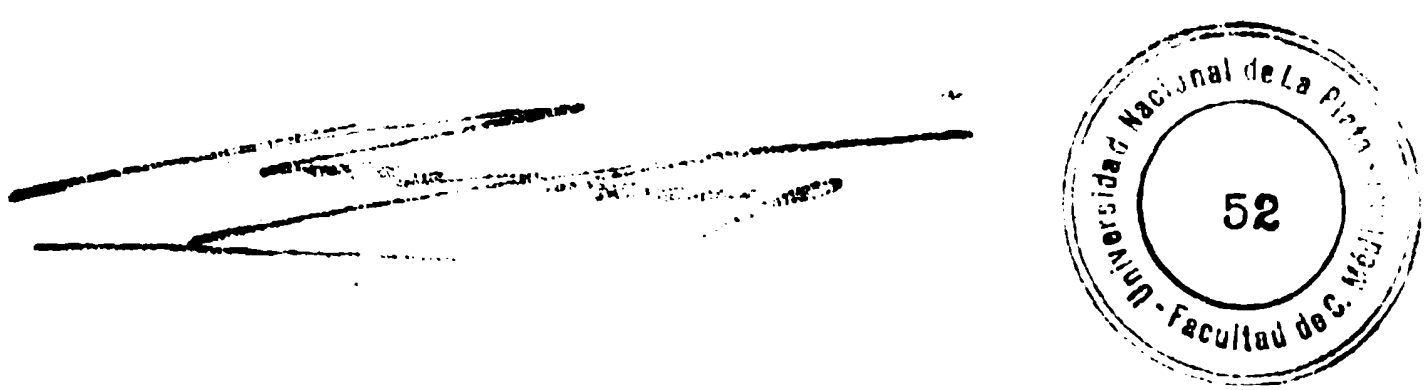

sirtomas; c) vrabar la importancia de hacer correctaciento el tretaniento duranto todo ol tiempo que el weaico consiAere preciso para alejar la posibilidad de 10, locelisación ceríca; d) arvortir que son caugag preaisponentes: el Prío, los luegaros húmedos en que vive el niño, lo vivion(i: entihigiénica, pobre on luz, alre y sol, los focos sépticos de anigalas y dientes, otc.

La vigilancia de los onferwos de reumetismo solo se juote hacer con provecho en clínicas dispuestes a ese rin, $\therefore$ cuenten con personal ospecializaco. A estos centros cuncurrirán los nínos que presentan cualauier manifestación Colorose sespechade de reurietisto, que han sido vistos on

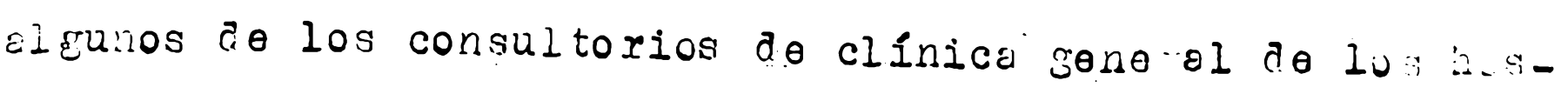

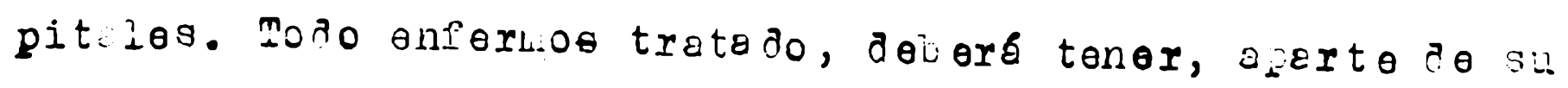
bistoria clínica, su Picha cariolócica comploto, por lo gue rosulta indispenseble conter en cara centro de lucina - Dispensario con un electrocaraiórrafo $y$ un aparato de Rayos X. Adewás co. tarái con laioratorio anexo para íajserwacan, Khan y eritrosedinentación.

BI amermato por otra parte, sorá instruido para iue aprenda a reconocer y valorar las poqueras manifostaciones de la enferliecad reullatica is a cuidar sus fuerzas y enorgias para no walograrlas en inútil y polisrosa actividad, asl como a considerar el reposo como la medicaciún saborana de la elibonón' caralaca.

12 lado de esta obra méaida, está la social, que el Centro Lntirreumatico realiza, $J \sin 1 a$ cuel agnello os tó destinada al eracaso. Sabido os la importancia de la vibi- 

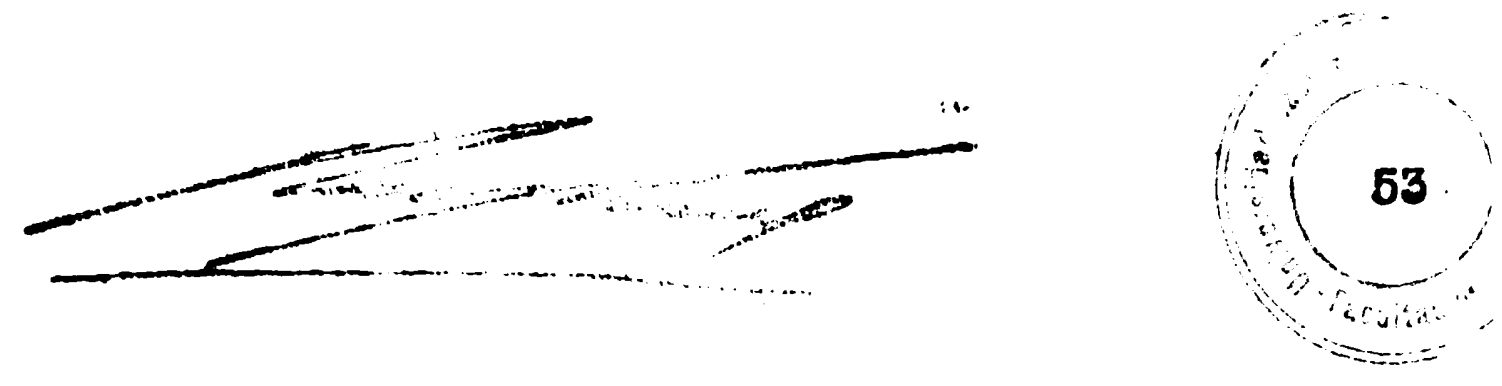

lencia del cumplimiejto do los prescripcionos wédicas s.éc el éxito terapéutico, on enfermos como estos on que las inaicaciones respecto a la vial, reposo. y alinentación deben ser cmmpliáa con rigurosidad por an tioso abitualwente way largo. Bs la Visitadora quion deto irestar una colaboración moral de la najor importancia. La reacción de los enfermos y familiares, cuando se diagnostice una enferiredad carcíaca, que la wa oría consjera incurable $y$ de la major Eravedad, es un aspecto que debo ser tenido en cuenta. Ia Viaitadore Social que aeie conocer en sus lineamientos cenerales la especialiada en quo actúa, con espíritu psicológico será la encargada de orienter al enfermo, de darle conforilada ospiritual y confianza en el tratamiento: instruirá a los fawiliares soire Io conveniencia a e cooperar en el. culpliento exacto del wisno; hará cumplir las prescripcionos nédicas, no co:-.o una imposición ael maico, cowo wuchos enformos sienten, sino como una necosidad incividual, corio realuente es. Debe recordar poriócicaliente la necosicada de consultar al Lédico, de continuar lag directivas so aladas y evitar Ia péràde de confianza y la desworalización. Trataré de procisar las circunstancias socialer y oconómicas do le failio del enfermo, as como las condiciones hiøiénicas de sa uliridad, areación, hu. odad, otc., de la vivionda. Fo en este forna como se prolonge la acción del médico basta ol hogar del paciente controlondo ol curso de 18 enfermeda y creana vinculos afoctivos que facilitan y 

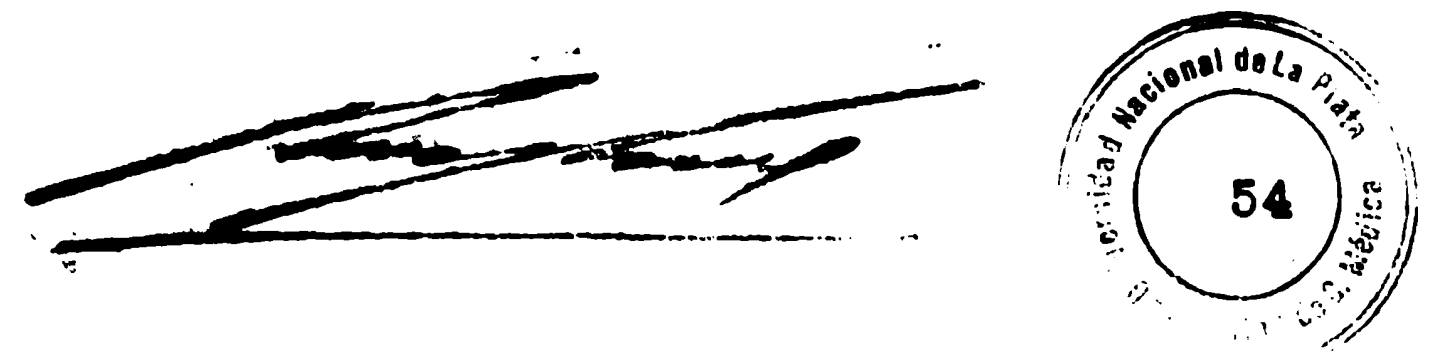

y hecon nos crato j elicaz lo realización de lo obra.

Ir Ajuda social os la que tiono por objeto faciliter a los de conaición oconúmica doplorabla: placas raiio-

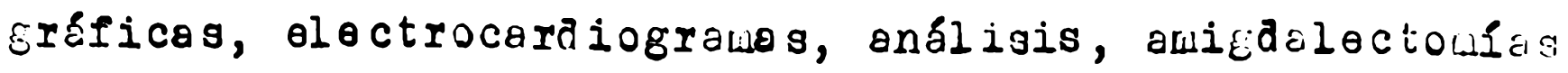
- o. tracciones dentarias gratuitas, así como los medicaLientos neceserios para una correcta y eficaz terapéutica. For intermedio de la ayuda Social so curiple pues, con una terea de profundo contenido humeniterio.

Pero para el éxito de le lucho contra la enfercieda reumetica dadó la complejicad del problema, de sus tíliLlos facos, fué necosario en la provinciá de Euenos bires Ia estructuración de un plan integral de lucho. Ie elaioración ael wismo fué confuada al Dr. Rawón Tau, Jef $\theta$ तe Io Sección "Tnferwadader Socialea" pox el lirector de :igiene de lá Provincia de buenos Airea de aquel entonces, Dr. Hrancisco Ro. D'oviaio. Hl plan coliprendo la lucina on el terreno curativo, preventivo y en el social habiancoso seruido para sus linearientos las inaicaciones de los ProI esore日 Dres. Hafael Bullrich j Aníbal Kuĺz Lioreno.

raté dividido en canco parter y usca la unifurwided de organizacion on todo el territorio del primer es índo argent1no, tanto desdo ol punto de vista cientifico cowo aduinistrativo, 10 que apertede una ma or oficacia on la acción. emprenaida, orutiré que las cieras ostacistices que ae oitengen resulten comparables entre si j que de ellas surja la denoidad y Irecuencia de las enferlioda reumetice en la provincia. 

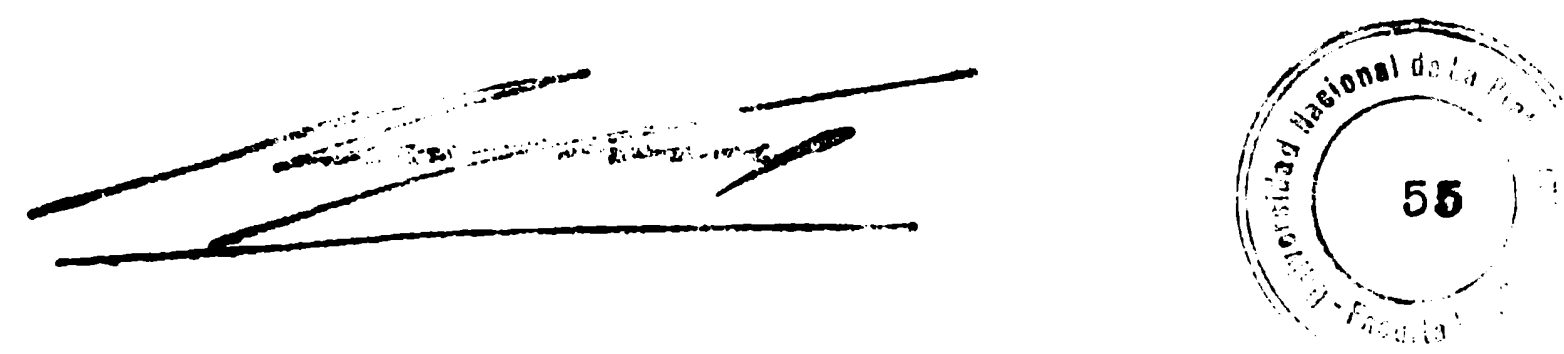

In la primera perte propugne que la airección de la lucho sea ejercida por la méxima autoricad sonitaria de lo Provincio, cetusluento, el winigterio io Salua Páblice quion podré delograrla para su conancción en el Jefe de la Sección "Enformedader Sociales".

Ia seguna parte encara la formacion à un"Consejo de luchan", Liedida harto justificoda j necosaria para eviter interferenciar y superposiciones. Puos si fien, antos Dirección General de Higiene, hoj linisterio de Salua Píbica, tiene el cometiáo de la defensa de la salud de lo potiación on todos los órdenes, hay que recordar que ha: reparticiones on el oräen provincial jue por contar con sus respectizos cuexpos méaicos y gozar de gutonocía aảLinistrativa, es indispensable agruparlos en la Lucha s.ntirroumática para coor inar los esfuerzos. A los representantes de dichas reperticiones se ha agrecado uno de le l'acultad de kíaicino de la Plata, con ol fin de vinculsr -190nsejo तe Iuchan con nuestra més alta case à ostudio. In ritive instancia, estarla compuesto asi: por el jefo तe la Sección "menfermedados Socialea", ol delegado de la Pacultad de Modicino, el delegado do Dirección bonoral do

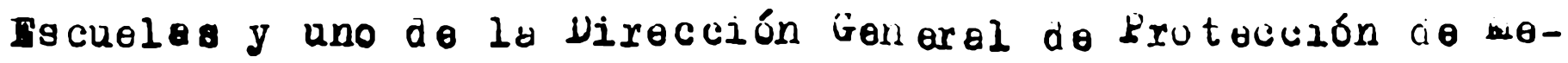
nores. Fate vonsejo de lucho "tiono como objeto coorainar 18 - ccion ; aunar los egfuerzos on las regpectivar jurisdiceloner de cada delegado.

In tercere perte esté diriglae - lograr un mejor conocimiento de lo Hebre Roumética por los médioos j por 


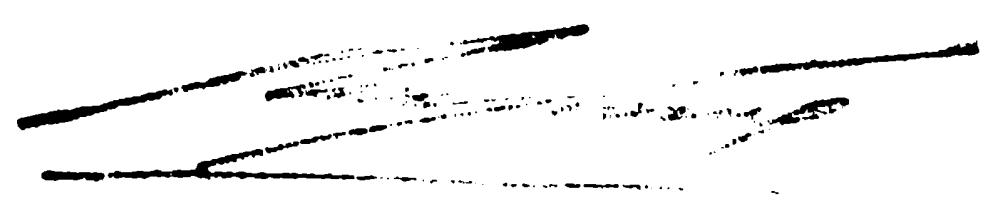

56

Sus colvioradores inwedítos pare una wás oficez tarea : a conjunto. So la ha iitulado de "Faucación Senitaria" - pretende lograr: a) Para los wéaicos, que en la r'acultéd se roalicon cursos teórico-práticos para graduados, - los zuo estarian obligados a concurrir los bécicos juo se J̈odicaran a la Iucho antirreunático y Cardiovaocular, los que serian de actueilización j perfeccionamiento. pars los que estuvieran ya en funciones corriendo el \$itacio con los gastos de pasaje y viáticos.

b) Para los estudiantes: solicitar a las autorisanos De la Facultac de ledi cina la intens ficación del estario al Revuatismo de las Enformedados Jardiovasculares desje el punto de vista wédico Social.

c) Para las Visitadoras de Víúiene y asistentes jociolos: Propiciar ante las Tscuolas de Visitadoras io la eqterra de İfieno de la Facultad de bodicina, ante el cuerpo Fédico Facoler y ante la Fscula do bsistentes jocialer y otras afines, la inclusión de la espocialida rejato-carijovascular entró las alumas que siguen estos cursos.

a) Para log farnacóticos: 1legar hasto los faruacóticos, idóneos, etc., tratenao de ilustrarlos pare ju sepan encaminar a los enfermos que llegaron a ellos an tren de consulta, al móaico o a la Institución que aplicer la sin taráana ol tratainionto neceserio.

e) Pera log enfermeros: Preparación del personel de enfermeros, 1nclujende bolillas do Profilaxio Antirreumáti 


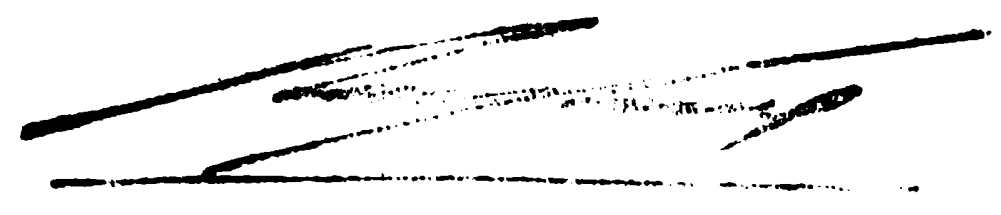

ca jo las Fnfermodador Cardiovaculares on log procritias del curso que pera desempoíargo como tol as dejon se guir.

1) Para el páblico: trator de llegar en toda forke a las as populares para informarlos por lo nenos co los zrincipiog básicos del la lucha Antirreduética. PEra este fin se dejerán atilizar periódicos, volantes, radiotofonía, cine, escuelas, afichos, conferencias, etc.

Ia cuarta parte a el plan comprente las "Orgeniza ciones Senitariag", encontráncose enu erados aquí los recursos que la técni za tioderna ofreco para ser puestos al servicio de la lucha Antirreumática. Intre ellos, un Contro entirreunático, Dispenserios, casas de conerecencio ¿Asilos o Pabellones para crónicos.

5 Centro Antirreumático a instalarso on la Cepitol de la Provincia abarcoría la parte de experinentición - La perte Asistencial. Deber estar dotado de:

-) Consultoríos atendidos por especielistas

b) Salos oxclusivas para roumb́ticos cordiovesculares.

c) Pono g electrocardiografla.

a) Gabinot do Rajos $X$

o) Lo bortorio

P) Sección Deperimenteción

8) Mdenoteropia

i) Sección fisioteropio 

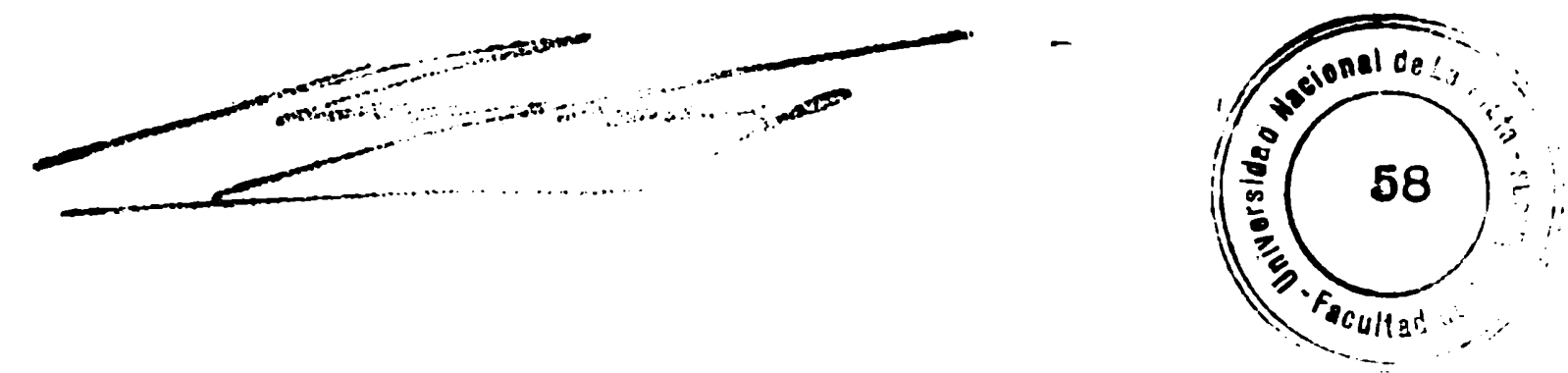

i) Servicio Sociel, a base de Visitadoras de IIigiene.

1) Sección para la terapáatica por el trabajo y la reoduceción.

In cuanto a los Dispensarios, se तistribuirén for l. Provincia de acuerdo a le densira de le poilación $y$ $\varepsilon$ la corilinad yortalidac rousética y carediovascular. Se procurare por otra parte que en ceca hospital y on todos los Servicios de Pedietría, haya anexo un Disponsario die lucha ancirreúática. Incudaledente, el ideel

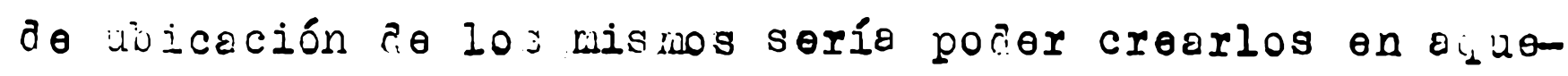
llos luceres donce la rorbilicad y wortalidad fueran més elovadas por fiebre reujútica y enfermededes caraiovasculares, pero ello no será posible hasta tanto se cianto con cifras estadistices de vercadero rigorismo científico al par gue habría que subrepasar la dificultad do que mucios de los Hospitales diseminados on el territorio rovincial, pertenecen a los Marioiplos; sale decir no dojonáan de la Acministración Provincial, aparta por suzuosto de aquellos que pertenecon a Insituciones prizides.

In la ciudad de ta Pla ta so cuenta con tres Nigsonsarios Antirreunáticos. contra las Enforludades Carciovasculares, siendo ellos: el del Hospital Policlfnico que runciona on horas de la wañana, el de la Asistencia pública que lo boce en hores de la tarde y el del Hospital de lilnos. Asicilamo existen otros Dispensarios del mismo tipo 

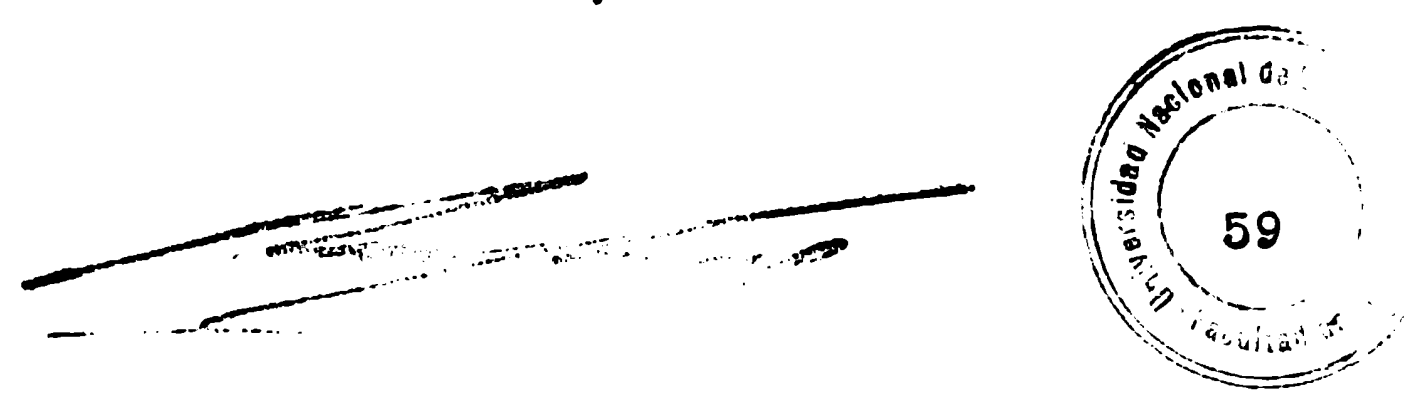

on ol Instituto "Iuis Gliemer" do Hoodo on ol Hospital Foliclínico de Bahia Blance, on el Hospital Regionala io Junin $y$ en ol Hogpital Runicipal de Chivilcoj. Fncontréncoso proi ectodos yo la creación de otros gimilares en las localidad es de Ź́rate, General Villejes y Jobos. Uade uno de ellos cuente por lo renos con un médico jefe une Visitadora je Iifieno y une enferisala, cowo personel tócirico indispensable. Y en cuanto a elementog: un electrocaraiógrafo, un aparato de Rayos $X$, arcilivos तe rad cograflis, electrocariorraras o listorias Clinicas, instruLentel para realizar el examen completo de los enfermos, ¿sí como wericawentor para los pobres.

Fl horario de funcionamion to de los uismog será citecuado para la majorío del público; de preforencia tros voces por semana y en forma gratuita para los pobres, pu dióndose establecer un aráncel para los que puedan pácar. De resprende la conveniencia de jue los Dispenserios cuonten para sus asistidos con Laboratorios, Rayos y Fisiotoraria, asl como el mantenor estrocho contacto con los servicios de Clínica y Cirugía, Fopocialidador, Podiatría, Co:totricia, Tisiologla, Diaboté $\mathrm{J}$ de Infor gre. Atenderán adembs del pbblico que concurre esponténeaLente, los enfermos enviados por los wedicos, los escolérog enviadoe por las Visitedoras, los obreros que surjen de la pesquisas sis tembticas que las camparas de Faca-ción sanitarie popalar propiciarán en fbrricas tailleres; los owploados de la Administracion y los aspiranter a t1- 


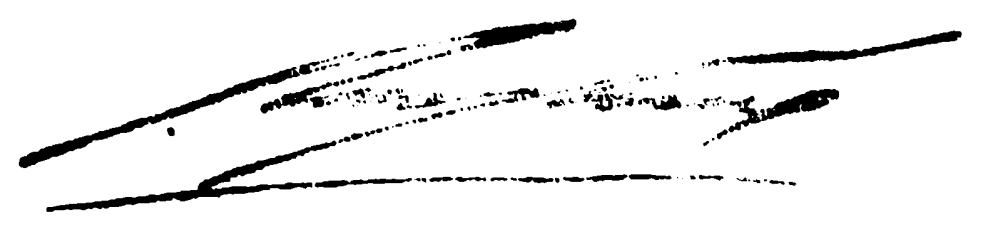

tulares; los aspixantes a juhilacionos o jensiones por infer recad reunifice o coraiovascular.

De las"Oagas ie Convalocencia", alróruo so propi cia su creación en furme selisejante a las ue ho moncionato funcionan en Inglotorra, Hotados Unidos, etc., con el objeto do internar a paciontes que acaban de suerir 10 ifer $\operatorname{coda}$ a reumática.

sn ciénto los Asilos o por lo menos Pabollones paro crónicos se nec sitan con $\theta 1$ fin de internar a pacientes de rejuieren ser evecua ioos de los sexvicios hospitalerios comunes a por falta de capacidad, ya por exigir larços lapsos de reposo. Sería ideal que contaran con una sección de Laborterapia y Reeducación.

Tn la quinte $\mathrm{y}$ últime parte de este plan de lucho

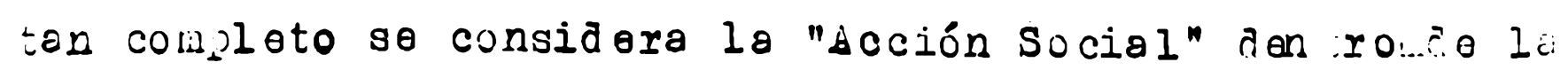
sual consirera cowo principales horizonites: a) coubatir les heivtacionos húnedas y fría; b) Propiciar el sezuro contra el Keimatismo; c) Propiciar la aisminución del cos to de vida y buenos salarios para los obreros. Vigilancia especial de las profos oner mag fatiganter. d) inspecciones periódicas a los locales de trabajo para eliwinar los am bienter húmedos, eríos o ventosos, que pueden farorecor 18 eclosión तel reunetismo. e) Propiciar alrededor de loo Dis-

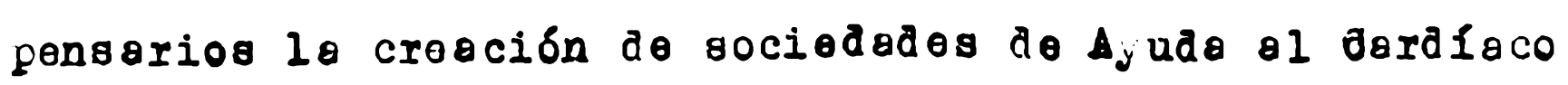
g al Koumático, al ostilo de la lapital rederal y do las ¿que funcionon on el extranjero, o los efoctos do prostar tutela moterial y moral a los enfermog que por su dolencia se ven obligados a hacer abondono de sug tareas. I) Propi- 


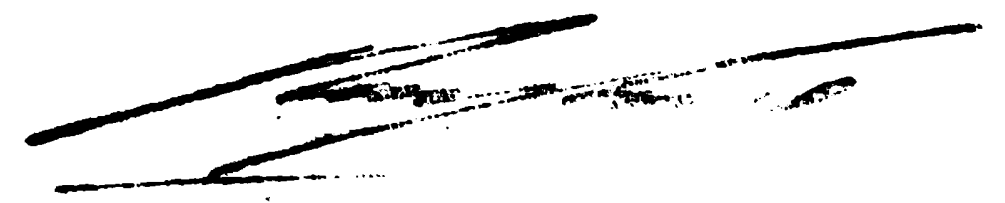

clar anto los Poderos Públicos, tanto provincial os como Municipoled y ento 1oe Institucionos Privade que los corgor sedentarios sean otorgedos de preforencie a persones con cerdiopatfos, con disminución do ou capacida flaica - que podrín ser inaicados por el centro e 108 Diepeñearios Antirrouméticos.

Con lo enumeración J comentario del Plan ae Iucho Antírrenmética de la Provincia de suenos dires doy por terminado el estadio que sobre lo Jucha médico-sociel contra los caxaiopotia Roumbticas ho realizado como modesto trabajo de Tesis, haciendo votos para que en breve plaso nuestro petrie so encuentre a la cobeza de los paísea que maxcan rumbos on el terreno de las conquigtas médicosocialos. 

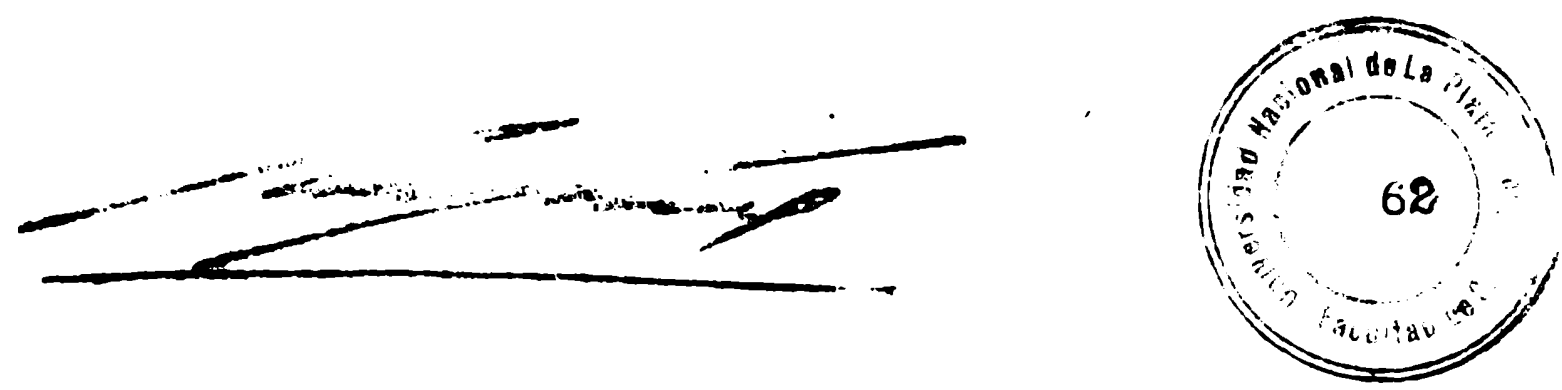

\section{YOTCLDSIONBS}

1) La liebre reumética mereco ser declareda enfermecad social, por la gran cantidod de enfermos que ello reistra sobre tudo on la sefunda infancia jadoloscencio, los zue por sa localización curalaca lleva a ser elenentos inútiles a si mismos y a la saci $\theta$ äaci.

2) Io fiebre reumátice ocupa el cuarto lugar entre les caluas ì ceráiopatías, con el 12,7 ol 14,25\%, gegún las estedisticas arontinas.

3) Gran parte de las personos que son incajeces fisicalente por lesiones cará́aces, reconocen la rilobro Reumática como causa do su afocción.

4) Io jiebre peumatica es tanto más curablo cuento wás precoz sea el diagnóstico y el tratawioâto.

5) Todo caráaco con antecedentes fauiliarés reubáticos o reiter adamente anginosor, debe hacer sospecher Fiebre Kovinática, aún en el caso que sus síntowar articulares ba. à posado inadvertidos.

6) Todo enfermo de Fiebre Rounét1co, debo oer considerado contagioso para log que conviven con 6l, por 10 que ovitera los contactos innecoserios $\mathrm{J}$ directos $\mathrm{J}$ las convivencies estrechos.

7) Por el desconocimianto que tiene el público de - esta enferweda, oo necesario insistir con la propasande periodifica y rodiotel ofónica, cinematografioe, offi cher, conferenoies en escueles, bibliotecas, etc. 


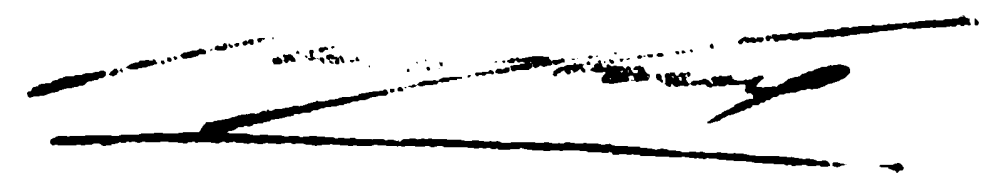

8) Is necosario iue en la racultad te Ĺedicine so intensifique ol estudio del Kounatismo y de las In-

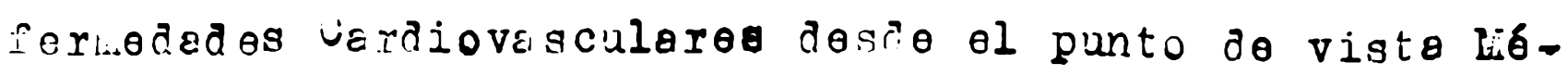
ico-Social.

8) Is necosario que los colaboradores inlioriatos

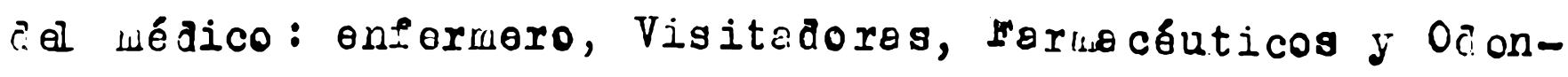
toloros, conozcan mejor la fiebre Reustática, pera obsener Lejoras resultado en la Iuche conjunta emprendia contre este onferredod.

10) Por la probada necusidad î los Disjonsarios ते Lucho Antirreumática y contra les knfermedades Caraiovascilares, debo propiciarso se anexe uno de ellos a cada Eospital del pais.

1I) Cac a Dispensario deve ser dotado de pors nol especielizado y de todos los roclirsos worernos a a dignéstico y de trataniento.

1z) Debe propiciarso le creación to Casas de Convélecencia y de Egcuelas para nifros he uáticos y con losiones cará́acas, sevejantes a los ilue funcionan an Ingleterre y Datedos Unidos.

13) Dobe propiciarse la creación de Asilos o Pabo Ilones para crónicos del Aaparato Caraiovascular, los que deicerán ostar dotados ḋe Servicios de Laborterapia y Reraucacion.

14) Solicitar a las Autoridadea Nacionalor, Provincialea y Hunicipaler, esl cono a las Instituciones privadas ju los caralocos qu solo pueden realizar esfuerzos fícicos infnitor, sean oupleados de preforencia on los carjos goaentarios. 


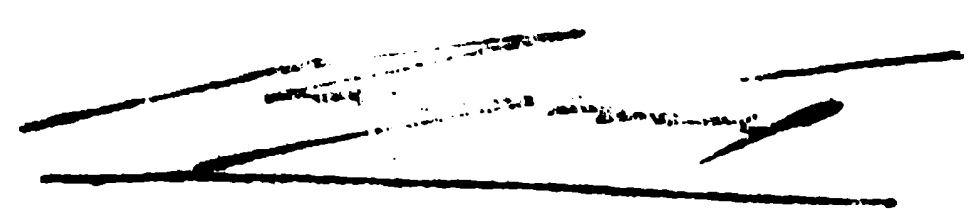

\section{BIBIIOGRAEIA}

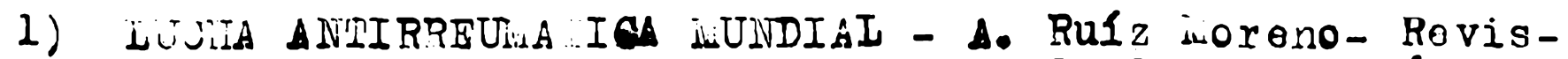
ta Argentina de Roumatolocía

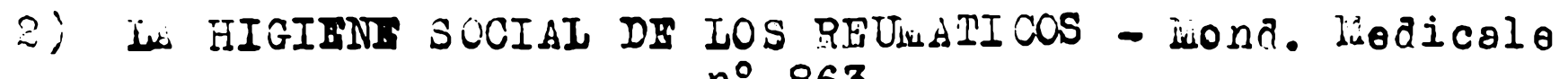
$n \approx 863$

3) vOLO IVITÁR REUIDIVAs RBUkistaAs - Cáteảra y Clínica nㅇ 56

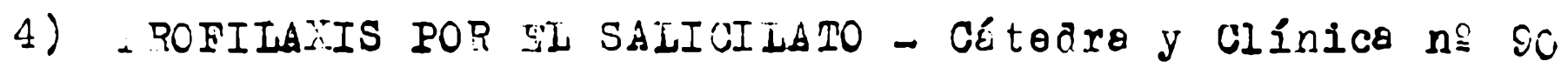

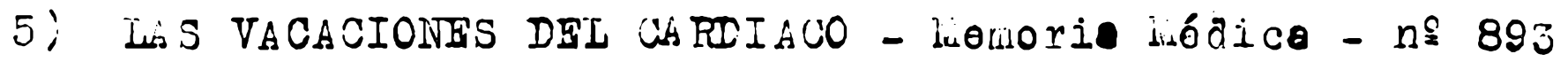

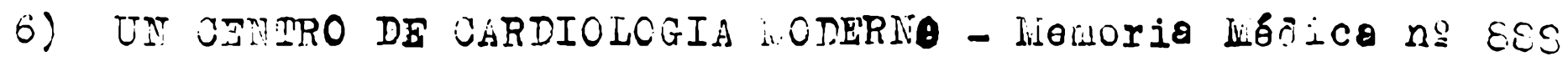

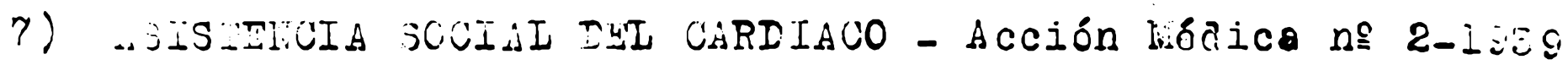

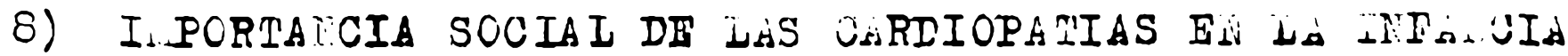
Semana Liodica - 1941

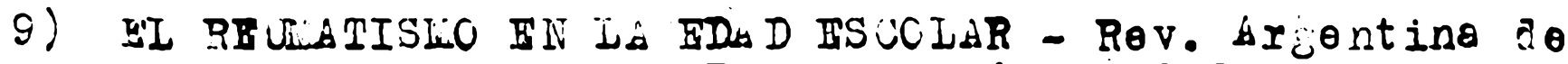
Roulatoiogia - 1938

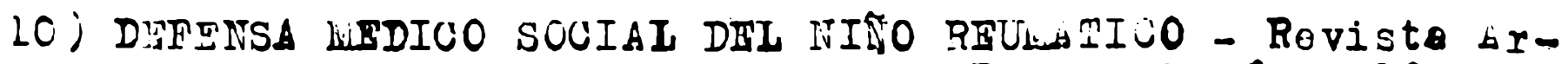
gentina de Reuriatolocila - 1937

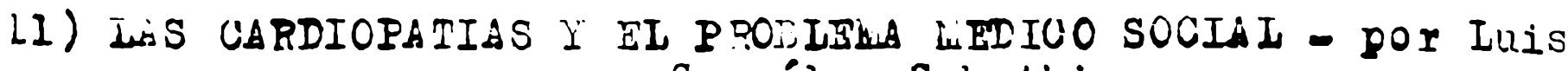
Gonzélez Sabathio

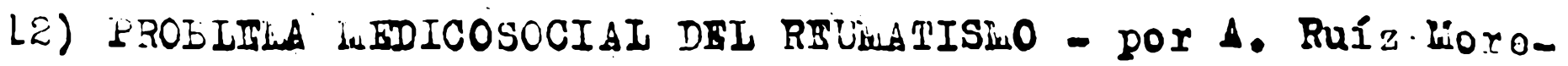
no.

L3) PIAN DF IUCHA ALIIRRIUU LICA Y CARDIOVASCUIAR DT IA PROVINCIA DI BUENOS AIRTS - Analer de la facultad de wor. d. La Plata a 10 13 


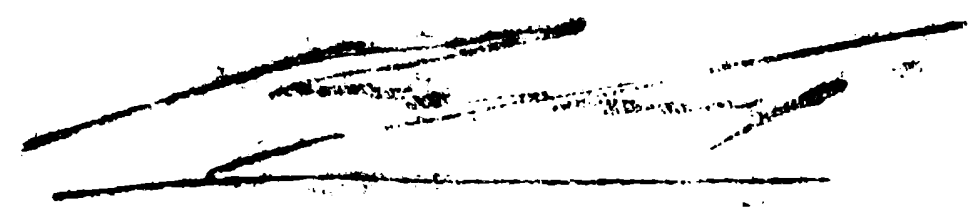

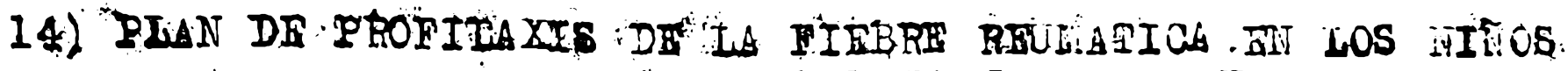
Actag del 59 Jongr so Tacional de, liealicine.

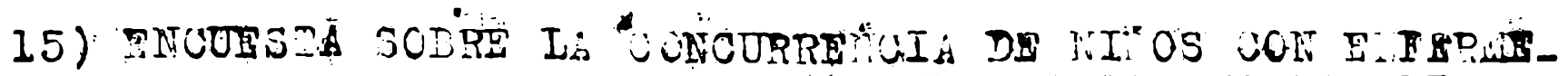

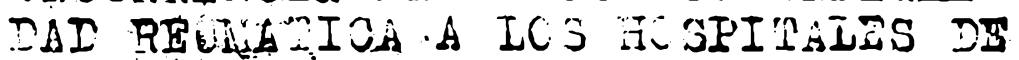

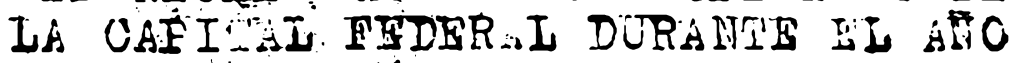
1942 - Día liécíco no 1 ia 1946.

16) HORALIDD IIFANII PAR FIERT REULATIOA TN LA RHEUBIICA IRUITINA on 1934 - Rovisto. Argentina do Reusetologio on $1837^{\circ}$

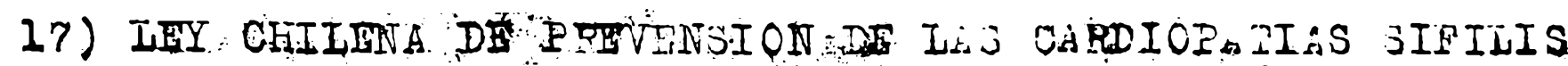

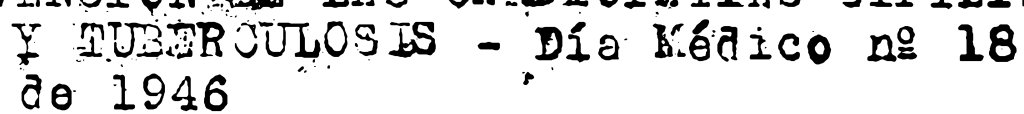

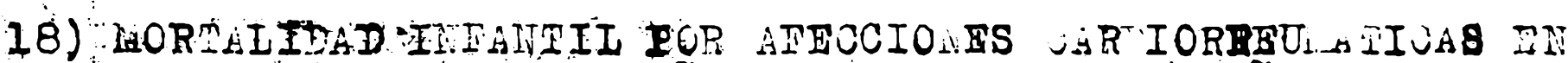

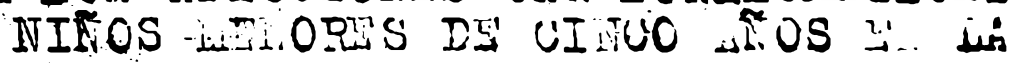
RBPUBII Arg. à Reuratología.- Agos to de iass

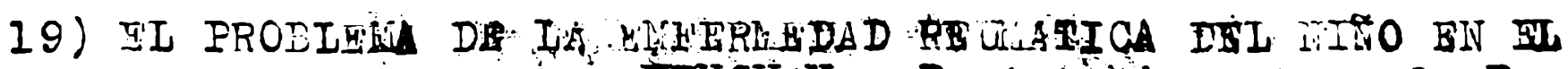
URUGUAY - Roviste Argont ina do Rautolofia - Viavo.1.939

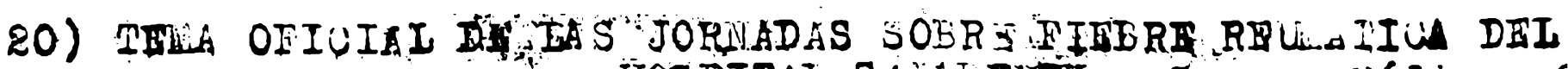
HOSPITAL SALALERT - Sollano liédica Af 15. a 0.1936 .

\%

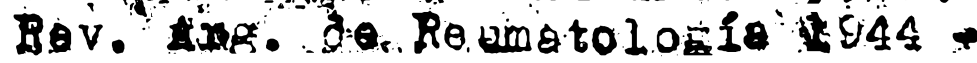

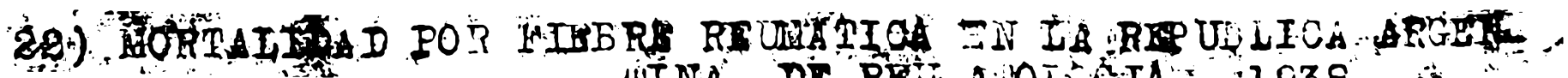

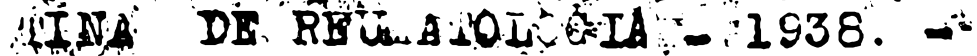

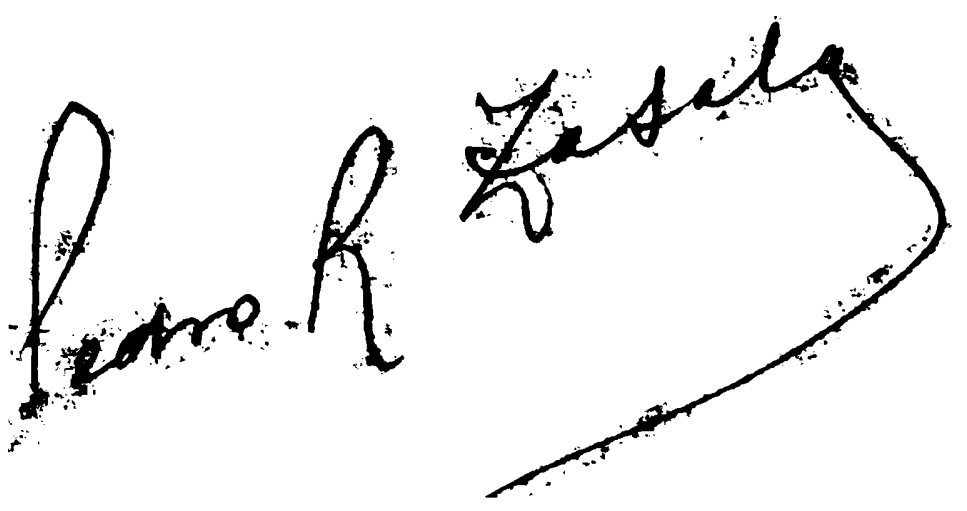

